NOMADIC LEARNERS: AN INVESTIGATION OF PERCEIVED AFFORDANCES ACROSS FORMAL AND INFORMAL LEARNING ENVIRONMENTS

\author{
A Dissertation presented to the Faculty \\ of the Graduate School at the \\ University of Missouri-Columbia
}

In Partial Fulfillment of the

Requirements for the Degree

Doctor of Philosophy

by

AMY M. FRISZ-CONLON

Dr. Laura Cole and Dr. Benyamin Schwarz, Dissertation Committee Chairpersons

MAY 2021 
(C) Copyright by Amy Frisz-Conlon 2021

All Rights Reserved 
The undersigned, appointed by the dean of the Graduate School, have examined the dissertation entitled

\section{NOMADIC LEARNERS: AN INVESTIGATION OF PERCEIVED AFFORDANCES ACROSS FORMAL AND INFORMAL LEARNING ENVIRONMENTS}

presented by Amy M. Frisz-Conlon, a candidate for the degree of doctor of philosophy, and hereby certify that, in their opinion, it is worthy of acceptance.

Dr. Benyamin Schwarz, Co-Chairperson

Dr. Laura Cole, Co-Chairperson

Dr. Robert Walsh

Dr. Joi Moore 


\section{Dedication}

These years of work, tears, and enthusiasm are delivered at the feet of every woman in my family who, despite brilliance, was not able to achieve the education, degrees, and recognition they deserved. This work is also for my paternal grandfather, Herman Joseph Frisz, who survived multiple battles. I dedicate my work to my parents, who have sacrificed, supported, and encouraged me. For my two young daughters who arrived during this dissertation journey and together carve a profound path of light, joy, and laughter through my existence. For my daughters, I am trying to hold a lamp to light your feet through this very uncertain world. You are my whole life. 


\section{Acknowledgments}

I would like to thank my co-advisors, Dr. Schwarz and Dr. Cole, who have guided me through this dissertation process. Dr. Schwarz, thank you for seeing my potential and for inviting me to the architectural studies program. I am so grateful for your unrelenting enthusiasm and patience. Dr. Cole, thank you for your brazen energy, infectious optimism, and future vision. I would like to thank Dr. Joi Moore for being an example of embodied grit and intelligence. Dr. Walsh, thank you for your creative mindset and welcoming, calm support. I would like to thank my professional teaching colleagues for supporting my research and making my data collection a reality. I am appreciative of the young learners who dedicated selfless hours to this research project so that others may have a better future. My academic colleagues who have supported me over the years encircle the globe, and I like to think that we, with outstretched arms, can continue to collaboratively instigate change. I am grateful to each one of you for imparting your light, wisdom, and hope. 


\section{Table of Contents}

Acknowledgments .................................................................................................................... ii

List of Illustrations...................................................................................................................... ix

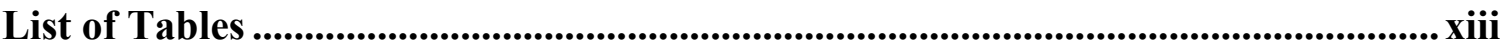

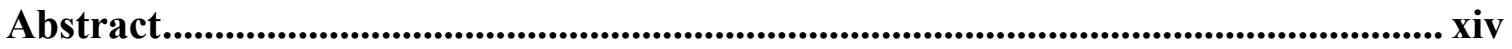

Chapter 1: Introduction .............................................................................................................. 1

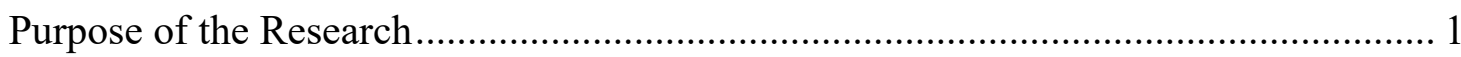

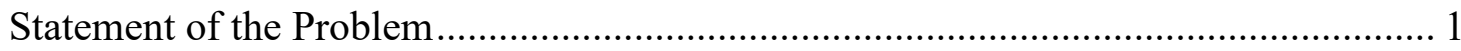

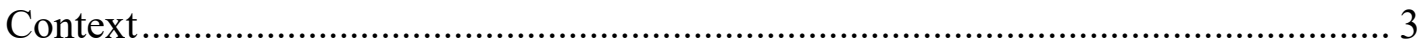

Assumptions of the Researcher.............................................................................. 3

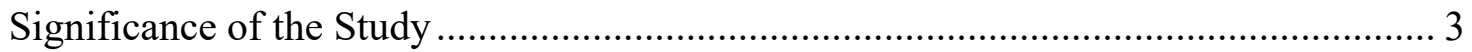

Roadmap of the Dissertation Chapters .................................................................... 4

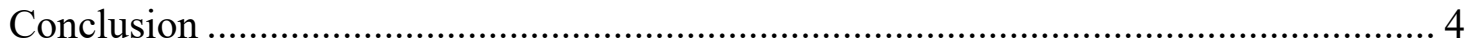

Chapter 2: Literature Review............................................................................................ 5

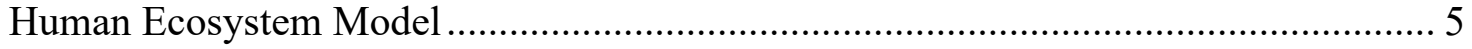

Formal and Informal Learning ........................................................................... 5

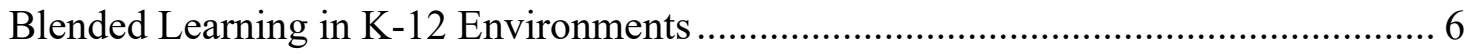

Blended Learning Models.............................................................................. 9

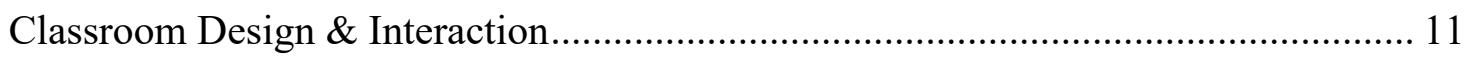

Cognitive Effects of the Physical Learning Environment …..................................... 12

Physiological Effects of the Physical Learning Environment .................................. 13

Affective Effects of the Physical Learning Environment.......................................... 14

Motivation, Cognitive Load and the Learning Environment.................................... 15 
Interactions Between the Physical Environment and the Task ............................. 15

Interactions Between the Physical Environment and the Learner .......................... 17

Interactions Between the Physical Environment, the Task, and the Learner............ 17

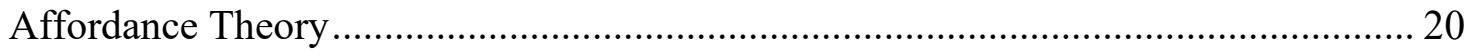

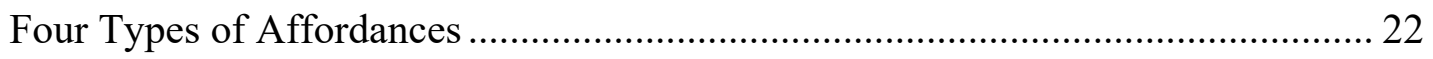

Perceptions of Self-Regulated Learning ............................................................... 25

Metacognition \& Self-Regulated Learning ..................................................... 25

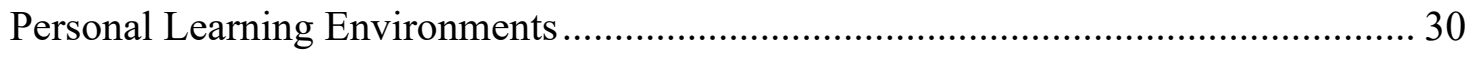

Conceptual Framework ............................................................................... 31

Chapter 3: Methodology............................................................................................................. 34

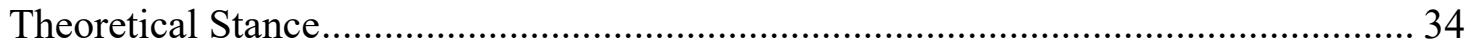

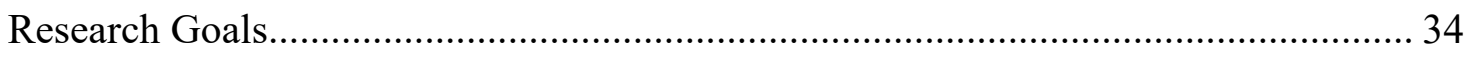

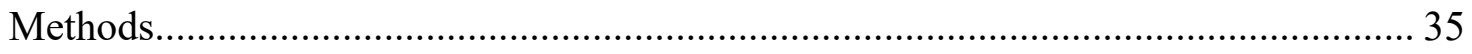

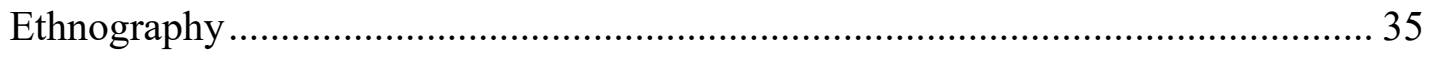

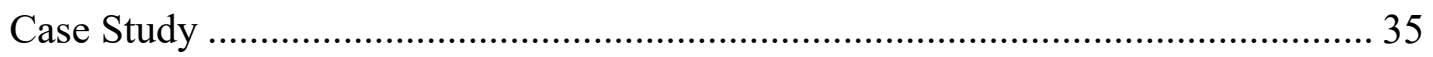

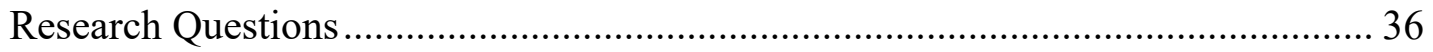

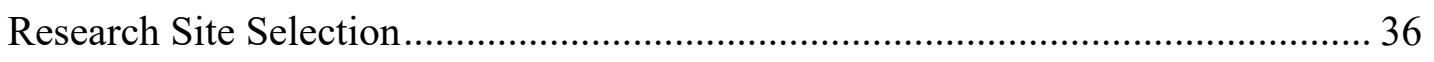

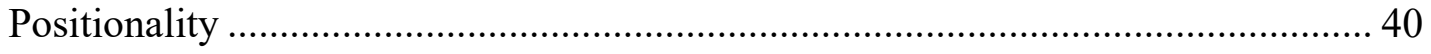

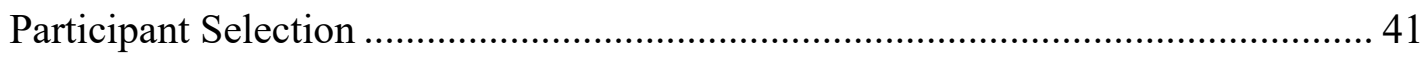

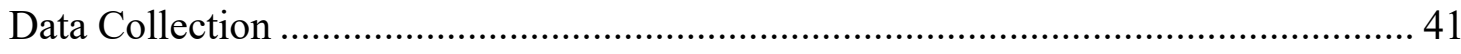

Phase 1 (March - April 2018) .................................................................. 42

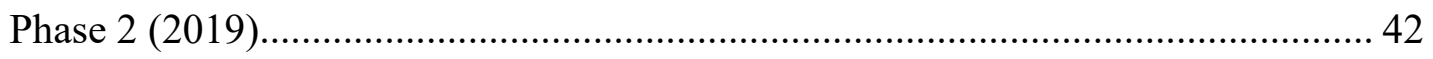

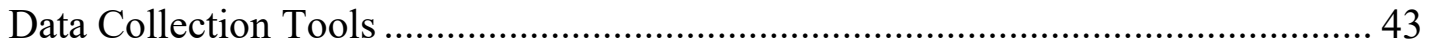




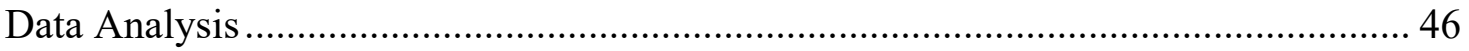

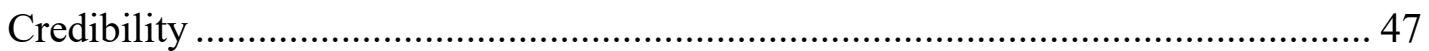

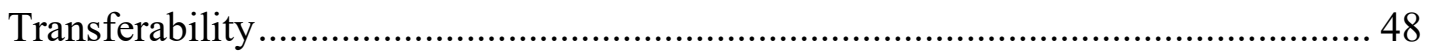

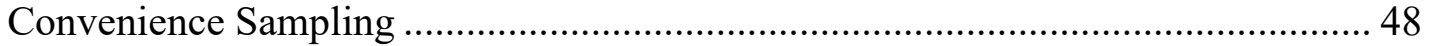

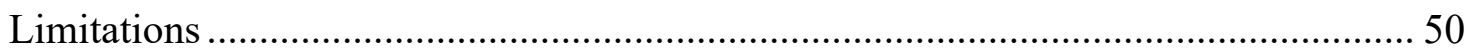

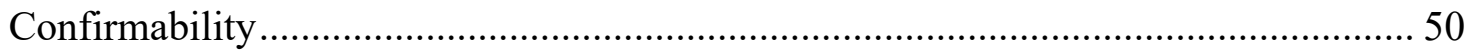

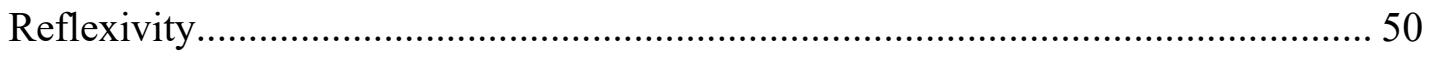

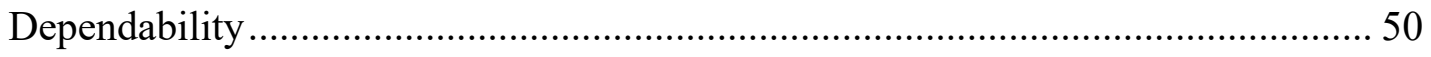

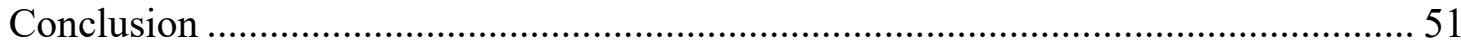

Chapter 4: Findings ............................................................................................ 52

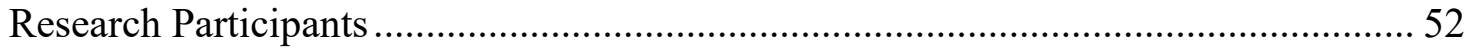

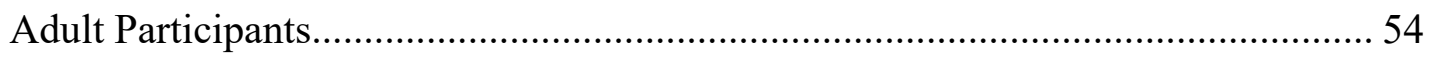

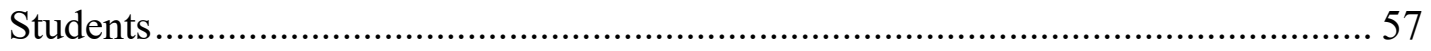

Physical Classroom Descriptions................................................................................ 59

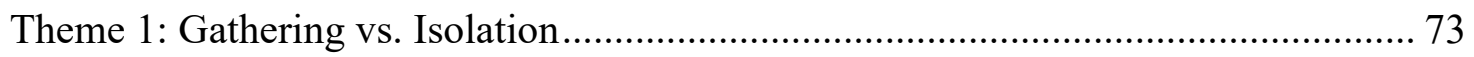

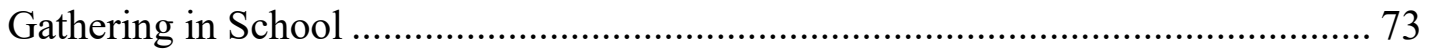

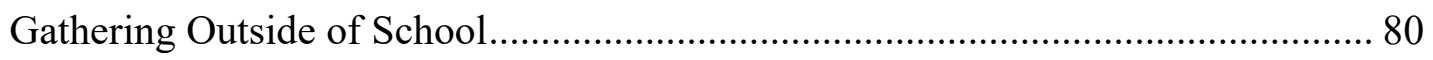

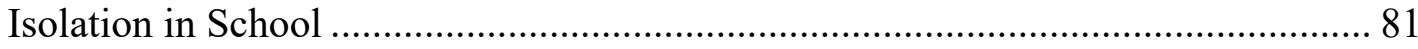

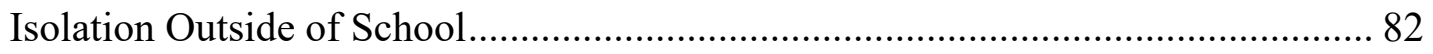

Conclusion of Gathering and Isolation ................................................................ 83

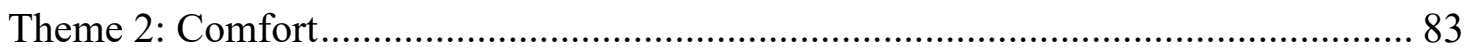

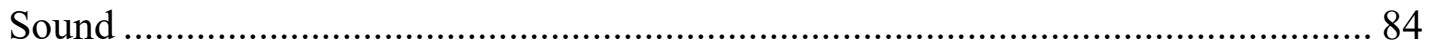

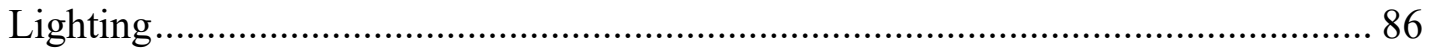




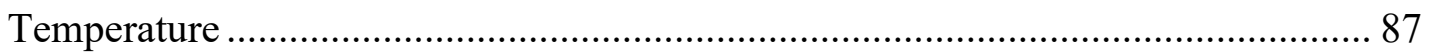

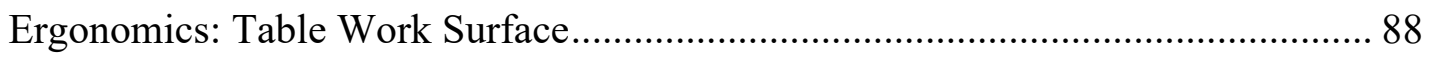

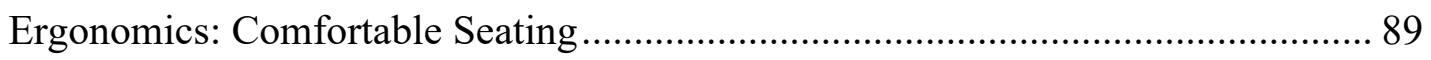

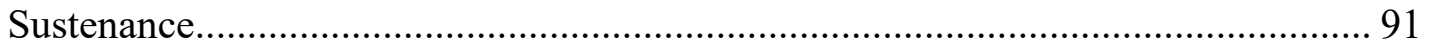

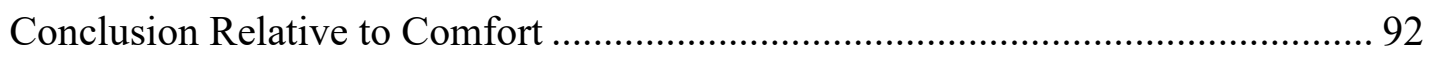

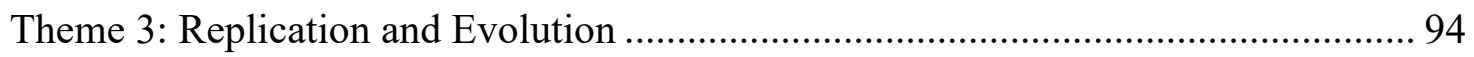

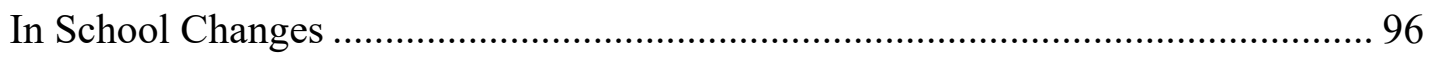

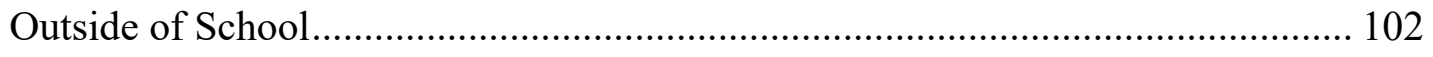

Awareness of Parent Panopticon ........................................................................ 104

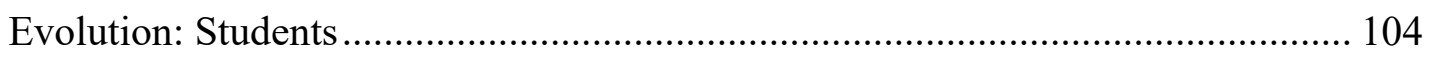

Conclusion to Evolution Theme ……………………........................................... 105

Additional Figures Related to Theme 3 ............................................................ 105

Theme 4: Perceptions of Self-Regulated Learning and Spatial Preference: Spaces to

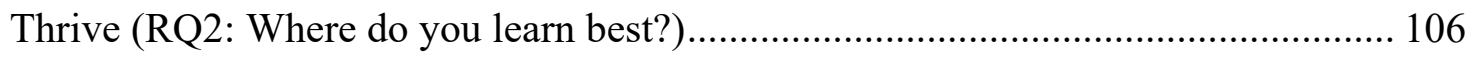

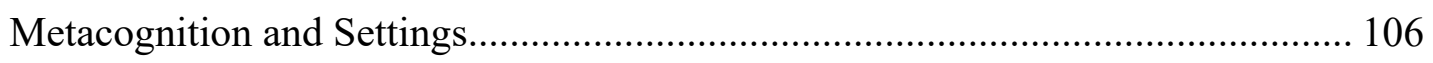

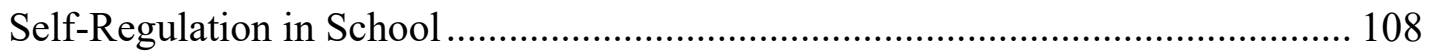

Self-Regulated Learning Outside of School ......................................................... 113

Parent Panopticon: Avoidance and Desire.............................................................. 115

Conclusion to Self-Regulated Learning .............................................................. 116

Additional Figures Related to Theme 4 ........................................................... 116

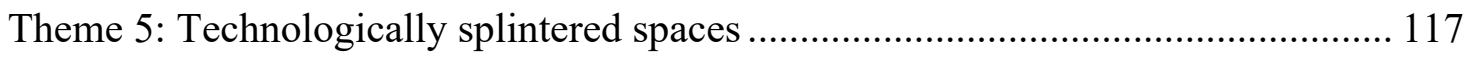

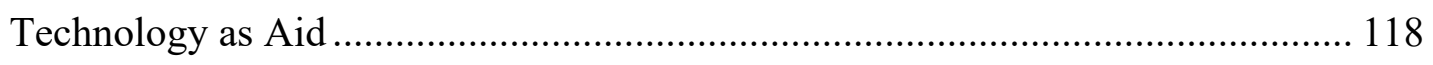

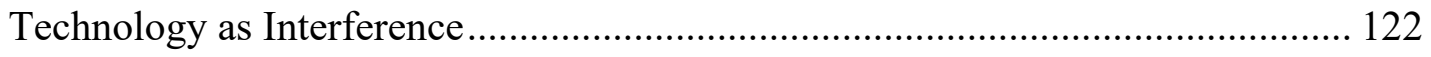




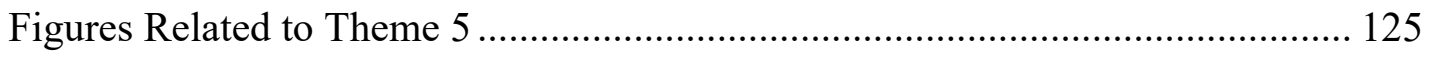

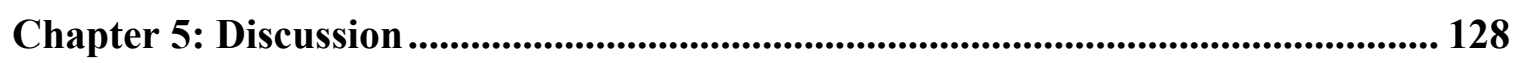

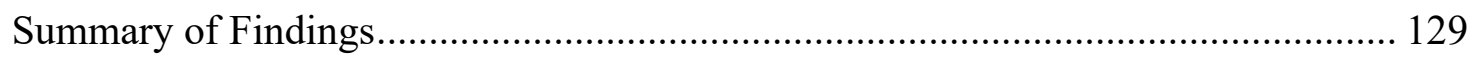

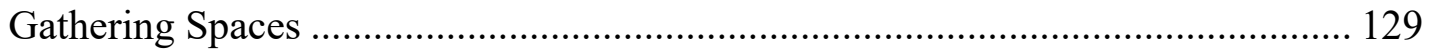

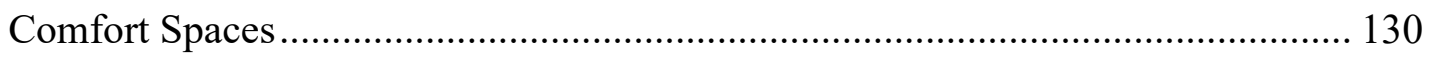

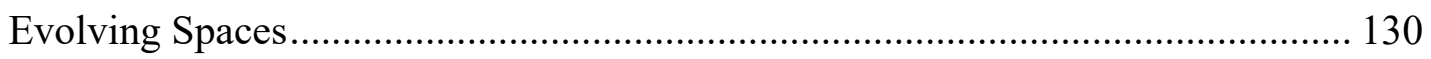

Self-regulated Learning: Finding Spaces to Learn ................................................ 131

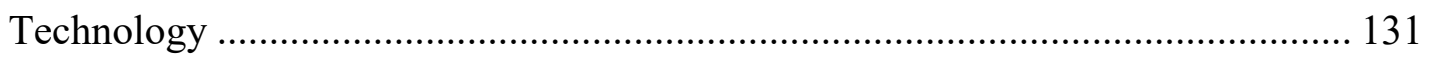

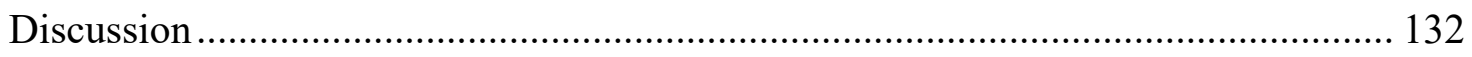

Operationalization of Affordance Theory.......................................................... 132

Conclusions About the Research Questions ............................................................. 134

Conclusion 1: Having choice: Students have spatial preferences for specific learning

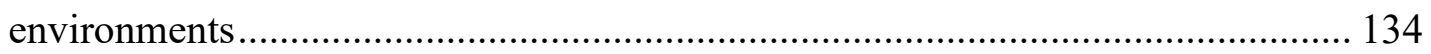

Conclusion 2: Having variation: Students seek a variety of learning environments to impact self-regulated learning......................................................................... 135

Conclusion 3: Technology helps and hinders ................................................... 135

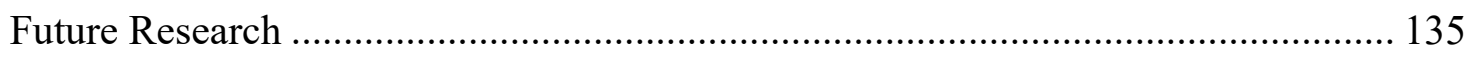

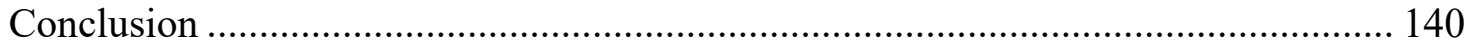

APPENDIX 1. Introduction Letter to Teachers................................................................ 143

APPENDIX 2. Introduction Letter to Students ................................................................ 145

APPENDIX 3. Introduction Letter to Parents .............................................................. 147

APPENDIX 4. Consent Document - Teachers................................................................. 149

APPENDIX 5. Consent Document - Students 18 and Older ........................................ 153 
APPENDIX 6. Child Assent Document

APPENDIX 7. Consent Document - Parents

APPENDIX 8. Photo Release Form for Subjects Not in the Study, But Who Will

Have Their Photo Taken . 165

APPENDIX 9. Student Photo Release Form ............................................................ 167

APPENDIX 10. Photovoice Instructions........................................................... 168

APPENDIX 11. Teacher Interview Questions................................................................ 169

APPENDIX 12. Student Interview Questions .................................................... 170

APPENDIX 13. Schedule of Data Collection......................................................... 171

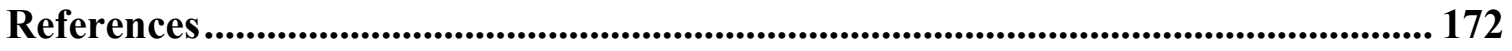

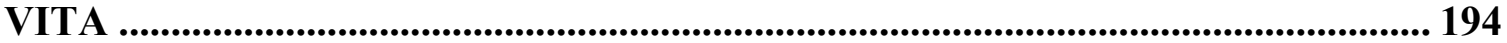




\section{List of Illustrations}

Figure

Page

Figure 2.1: Blended Learning Models .........................................................................10

Figure 3.1: Aerial view of Catamount High ....................................................................39

Figure 3.2: Catamount High School main building floor plan ..........................................39

Figure 3.3: View of the commons from the second-floor balcony ....................................40

Figure 3.4: View of exterior space between modular building and main brick classroom

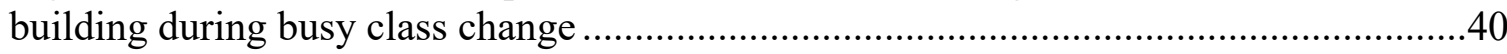

Figure 3.5: Hallway observations in the collaborative locker bays during SMART lunch

Figure 4.1: Mr. Brunsen and his chorus students …………..........................................60

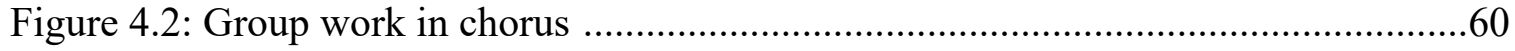

Figure 4.3: Chorus students singing from the classroom periphery ..................................61

Figure 4.4: Collaborative learning in chorus ..................................................................61

Figure 4.5: Chorus class using the acoustic affordances of a stairwell ..............................61

Figure 4.6: Students collaborate in Ms. White's English classroom ..................................62

Figure 4.7: Students collaborate in the locker bay for Ms. White's English class ...........62

Figure 4.8: Students collaborate in Ms. White's yearbook class ........................................62

Figure 4.9: Ms. Bold working in her math classroom .....................................................63

Figure 4.10: Ms. Bold's Math classroom.....................................................................64

Figure 4.11: Ms. Crouven's AP Physics Lab................................................................64

Figure 4.12: Ms. Crouven's AP Physics Lab...............................................................65

Figure 4.13: Ms. Crouven's AP Physics Lab ……………………………................65

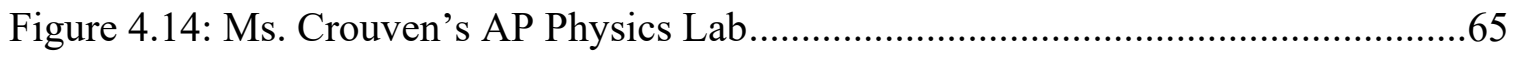

Figure 4.15: Mr. Curran's game design classroom ………...............................................66

Figure 4.16: Mr. Curran's game design classroom........................................................66 


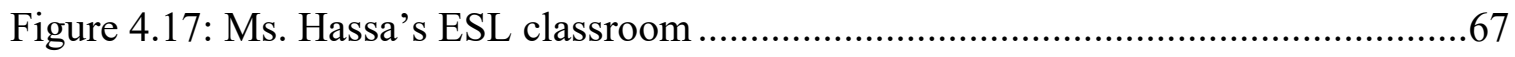

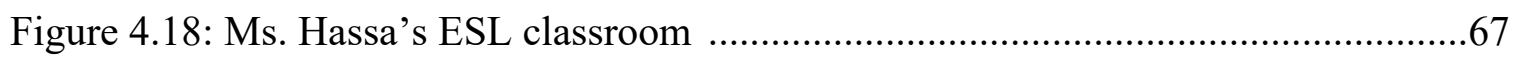

Figure 4.19: Ms. Sandy's Special Education classroom ............................................68

Figure 4.20: Ms. Sandy’s Special Education classroom ..........................................68

Figure 4.21: Ms. Sandy’s Special Education classroom..........................................69

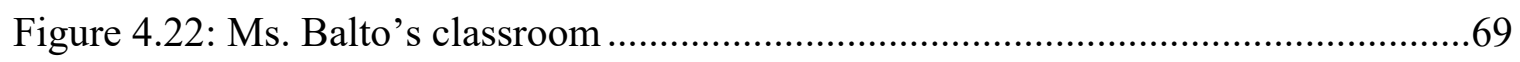

Figure 4.23: Ms. Balto's Spanish class uses the commons..........................................70

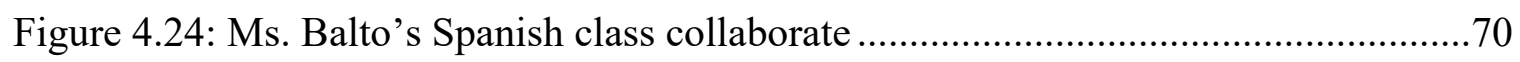

Figure 4.25: Ms. Balto's Spanish class uses the commons for sound assessments ...........70

Figure 4.26: Ms. Balto’s Spanish class uses the media center..................................... 71

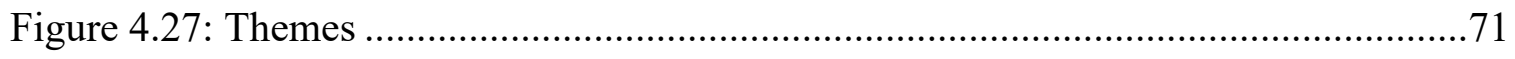

Figure 4.28: Table of Data - Students ............................................................... 72

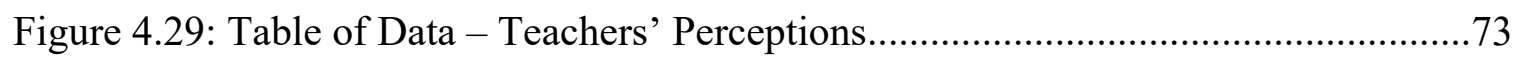

Figure 4.30: Collaboration in class according to Tya ............................................ 74

Figure 4.31: AP Computer Science table groups ...................................................... 77

Figure 4.32: Priya and friends playing a collaborative review game in their classroom

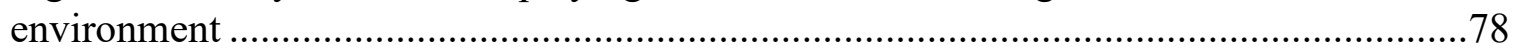

Figure 4.33. Collaboration in a Fine Arts classroom ................................................. 79

Figure 4.34: Students working collaboratively in an autism classroom ........................79

Figure 4.35: Studying in the kitchen at home to be by family members ........................81

Figure 4.36: Adi studying with friends at a local library .......................................... 81

Figure 4.37: McKenzie studies in the library during lunch to stay focused .....................82

Figure 4.38: Student individual desks in a classroom.............................................. 82

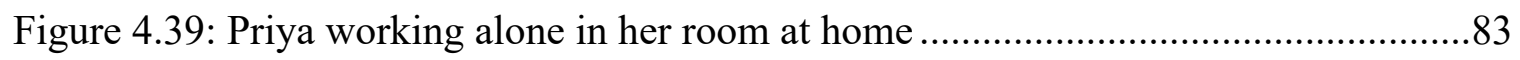

Figure 4.40: Ambient sounds in Spanish class, in between loud math and silent English

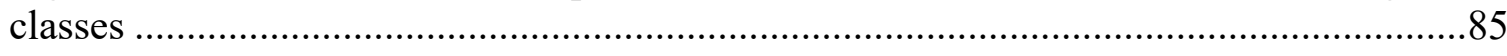




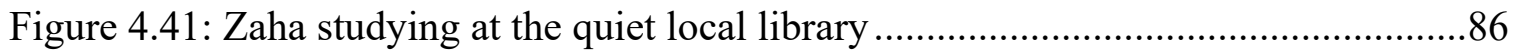

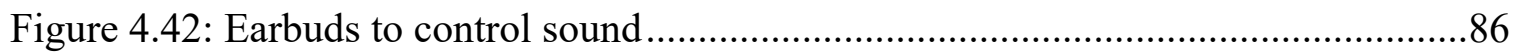

Figure 4.43: Classroom with fluorescent lights off, allowing for only natural and incandescent light

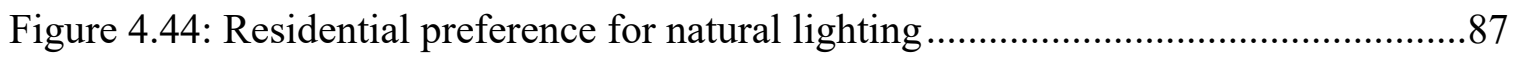

Figure 4.45: Student avoidance of personal spaces that are too cold ............................8

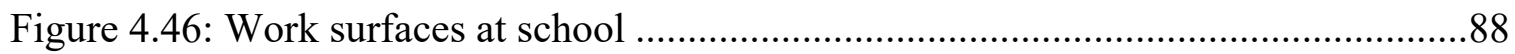

Figure 4.47: Work surfaces at home: Zaha's workspace in her dining room ..................90

Figure 4.48: McKenzie working at her dining table ................................................. 90

Figure 4.49: Comfortable seating at school ...................................................... 91

Figure 4.50: Some students sought comfortable seating at home when doing schoolwork

Figure 4.51: McKenzie studying on the sofa at home when completing easier work ......92

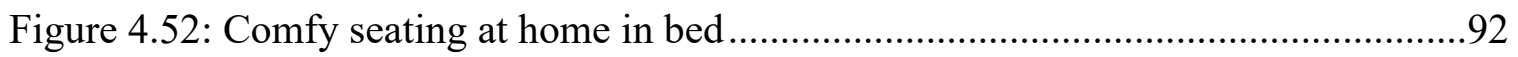

Figure 4.53: Priya liked to work in the kitchen near her mom and food .......................93

Figure 4.54: Aerial view of Knight High, Wave County prototype for Catamount High .96

Figure 4.55: Aerial view of Catamount High 2006 prior to modular additions ...............96

Figure 4.56: Aerial view of Catamount High after modular additions ...........................97

Figure 4.57: Rapid redevelopment surrounding Catamount High................................97

Figure 4.58: Classroom configuration evolution 2018 to 2019 ...................................99

Figure 4.59: Students using the gallery collaborative format learning method ..............100

Figure 4.60: Students use the locker bay spaces as refuge from a crowded math classroom .100

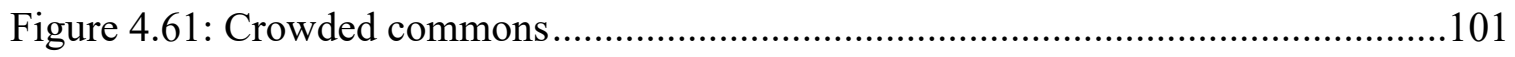

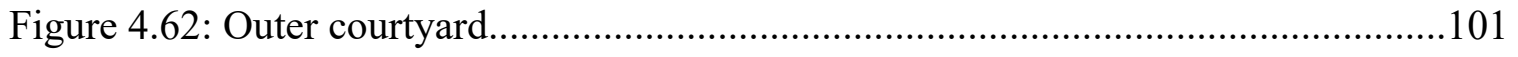

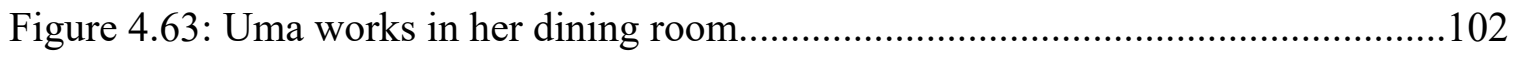


Figure 4.64: Photo of a bedroom home study environment........................................103

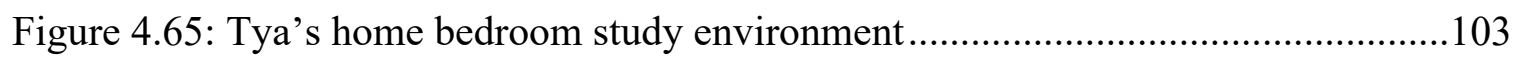

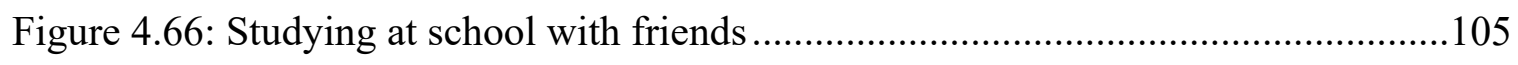

Figure 4.67: Uma's view while studying at the media center after school....................105

Figure 4.68: Incentivizing the class through the placement of goal banners..................106

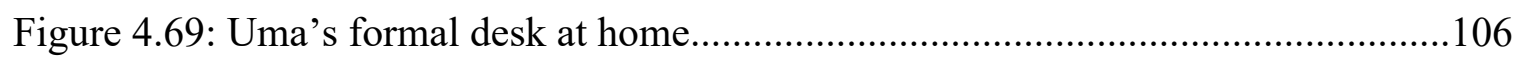

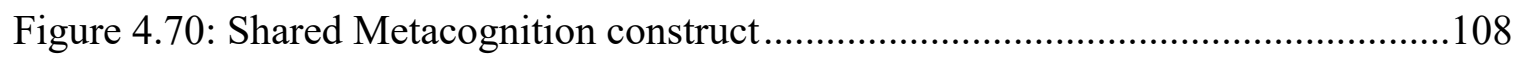

Figure 4.71: Priya's view of getting organized and working in the locker bay alone .....109

Figure 4.72: Getting work done on the comfy sofa before family members get home ...116

Figure 4.73: Phone proximity and notebooks to get the learning done ........................116

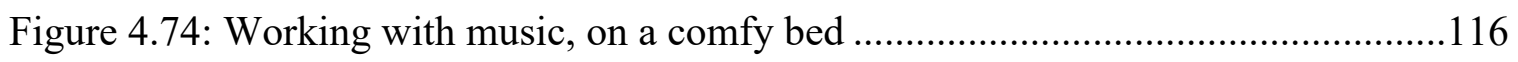

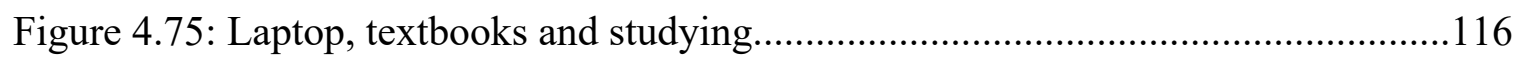

Figure 4.76: Writing the content out on the board to review before an exam in the same

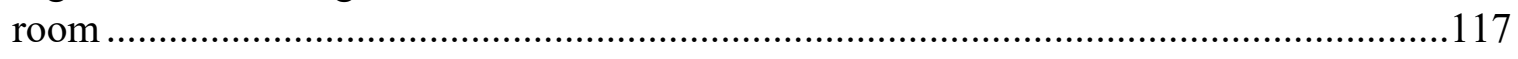

Figure 4.77: Spanish teacher color coding terms on the board for better cognition ........117

Figure 4.78: McKenzie doing work in her homeroom at 7am before the start of the school

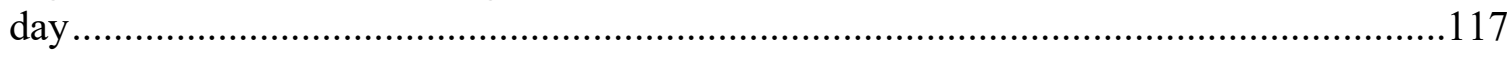

Figure 4.79: Teacher's use of both the white board and new led tv screens for instruction

Figure 4.80: Classroom projectors, retractable screens and white boards .....................126

Figure 4.81: Student using technology alone in an autism classroom ...........................126

Figure 4.82: Students taking notes from the large led screen and the white board .........126

Figure 4.83: Collaborative hallway gallery activity QR codes..................................127 


\section{List of Tables}

Table $\quad$ Page

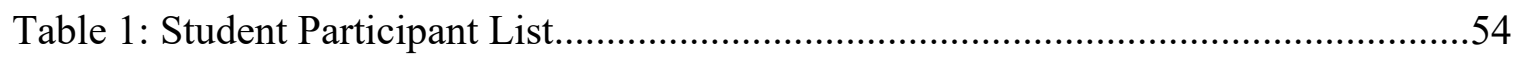

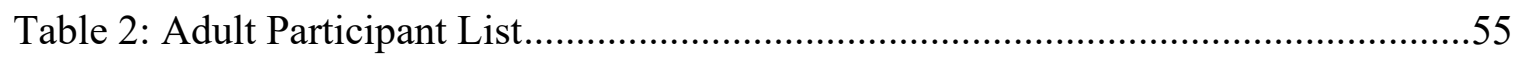

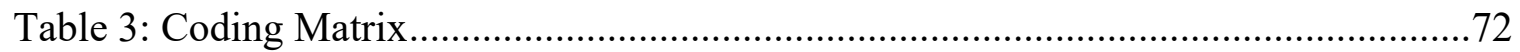




\title{
NOMADIC LEARNERS: AN INVESTIGATION OF PERCEIVED AFFORDANCES ACROSS FORMAL AND INFORMAL LEARNING ENVIRONMENTS
}

\author{
Amy M. Frisz-Conlon
}

Dr. Laura Cole and Dr. Benyamin Schwarz, Dissertation Committee Co-Chairpersons

\begin{abstract}
Learning environments play a critical role in learning outcomes. This ethnographic case study investigates adolescent students' use of formal and informal learning environments and their self-regulated learning and technology use in these spaces. The researcher has been immersed at this public high school research site as a school faculty member for over eight years. Data in the form of observations, interviews, cognitive maps, and photovoice blogs were collected from sixteen students and teachers over one year between 2018 and 2019. This research was collected in a technology corridor of the American southeast growing at an extremely rapid pace. Many new schools are being constructed to keep up with the severe population growth.

The conceptual framework involves spatial preference and technology use related to self-regulated learning. Affordance theory buttresses the investigation. Research questions were What are students' spatial preferences in informal and formal learning environments? What are students' self-perceptions of learning in formal and informal learning environments? What are students' use of technology in informal and formal learning environments?
\end{abstract}

Key findings offer a deeper understanding of adolescent use of formal and informal learning environments inside and outside of school settings. The design of the school building, as well as a myriad of residential environments, were investigated. Findings include types of spaces that manifested in both formal and informal learning 
environments. These types are gathering spaces, comfort spaces, evolving spaces, spaces to thrive and technologically splintered spaces. This work's knowledge contributions include a clearer understanding of adolescent use patterns across formal and informal learning environments. The implications of this study are the development of guidelines on adolescent self-regulated learning practices and technology related to the built environment. Theoretical contributions of this work include an extension of affordance theory and a greater understanding of how adolescents perform in learning behavior settings. 


\section{Chapter 1: Introduction}

The excitement of learning relies on a series of catalysts to fuel the fire. Physical learning environments, inside and outside of school, provide a locus for this wonderful process of learning to happen. A myriad of other factors beyond physical location affect the learning process. This research will focus simply on the relationship of physical spatial preference, students' self-regulated learning, and their use of technology in these learning environments.

This research aims to understand the range of students' spatial preferences in these formal and informal learning environments. The second aspect of consideration with this research is self-regulated learning. Specifically, the study will focus on students' self-regulated learning within a range of formal and informal learning environments. This form of self-regulated learning is related to spatial preferences. The third goal of this study is to understand a range of learning technologies employed in formal and informal learning environments. Much of contemporary instruction involves face to face interaction buttressed by online affordances.

\section{Purpose of the Research}

The purpose of this research will be to understand students' spatial preferences in formal and informal learning environments, students' self-regulated learning perceptions, and the technology tools they employ in these learning environments.

\section{Statement of the Problem}

The research problem is understanding the relationship of physical learning environments, self-regulated learning and technology for adolescent learners. Research has shown that blended learning, a combination of in-person and online learning, is 
growing at a higher K-12 and higher education level. Beldarrain (2006) cited the popularity of learning online has helped foster a shift in both pedagogical and theoretical frameworks from teacher-centered to learner-centered instruction full of interaction and collaboration. Balderrain stated, "As new technologies emerge, instructional designers and educators have unique opportunities to foster interaction and collaboration among learners, thus creating a true learning community" (Balderrain, 2006, p. 140).

Following this shift from teacher-centered to learner-centered approaches, there has been a growing amount of research on blended learning. Many learners have grown up with the Internet and know that this is a part of the learning environment. Hiemstra (2005) stated, "In essence the learning orientations of today's younger people are tied to expectations of what the Web promises...and may actually make self-directed approaches to teaching and learning the default norm" (Hiemstra, 2005, p. 7).

The effect of Internet technology is of growing interest among researchers. There is much to be studied regarding the way in which critical thinking can be fostered through blended learning environments. Critical to this goal was the establishment of a learning environment that would allow a blended learning community to move to progressively higher levels of critical thinking. There is support in the blended learning literature that critical thinking skills could be developed through the use of a range of online formats (Duphonrne \& Gunawardena, 2005; Moore \& Marra, 2005). However, other research has indicated that moving learners to higher levels of critical thinking is very difficult (Garrison et al., 2001; Kanuka \& Anderson, 1998; Meyer, 2004; Vaughn \& Garrison, 2005). The high levels of critical thinking require connecting, integrating, and applying new ideas (Garrison et al., 2001). There are a variety of explanations for why critical 
thinking was not indicated at higher levels. One reason is that the design and expectations of the educational experience did not require learners to move to higher levels (Garrison et al., 2010).

\section{Context}

This qualitative ethnographic research study provides a window into the life of Catamount High School, located at a suburban public high school in a research corridor of the North American Southwest. Adolescent and adult staff participants completed interviews and built rich photovoice journals describing their preferred learning environments inside and outside of school settings. This work helps elaborate the intersection of spatial preference, self-regulated learning and technology.

\section{Assumptions of the Researcher}

A few assumptions were made in the research study that was conducted from a collaborative constructivist perspective. Assumptions-based learning: all learners have life experiences that affect thinking, and these experiences contribute to the creation of new knowledge; learners have the potential to be responsible for and direct their own learning; and learners can acquire an ability for critical thinking.

\section{Significance of the Study}

This research envelopes a gestalt view of learning environments. Learning is not bound just to school, and this work will shed light on relationships between formal and informal learning environments. Further, this research will shed light on students' selfregulated learning perceptions in these learning spaces. This information will be valuable to key stakeholders including architects, designers, county school administrators, as well as local principals, teachers, and parents. The practical implications of this research 
include a clearer understanding of adolescent preference of physical learning environments, as impacted by self-regulated learning and technology. The theoretical contributions of the study include an extension of affordance theory and an elaboration of adolescent place dependence.

\section{Roadmap of the Dissertation Chapters}

In chapter one, we are provided a brief context of the study as well as an introduction of the three spheres of spatial preference, self-regulated learning and technology. Chapter two is a literature review featuring key contributions in the research landscape. Chapter three provides a look into the qualitative methods employed in the work. Chapter four is a report of the qualitative findings. The fifth and final chapter provides discussion of the findings relevant to the literature landscape.

\section{Conclusion}

Students will have provided artifacts related to their self-regulated learning related to each of these physical school and home learning environments. Lastly, students will have described their use of learning technologies in these formal and informal learning environments. The intention is to identify ideal learning environments that may serve as best examples in the development of educational space design guidelines for the design, architecture, and education professions. 


\section{Chapter 2: Literature Review}

This research examines the ways that blended learning can be supported across home and school environments to enhance student perceptions of their own learning. This review of the literature will examine each of these broad themes in turn to locate this work within existing literature. The human ecosystem model is one guiding framework that has influenced this work.

\section{Human Ecosystem Model}

The Human Ecosystem Model is a springboard for this research. I am using an adapted version of this model that focuses on the built environment (home and classroom affordances), virtual environment (technology affordances), behavioral environment (affordance actualization), and the human organism (affordance perceptions / perceptions of how the environment supports learning).

\section{Formal and Informal Learning}

Informal learning has been presented as "that which takes place outside the formal educational contexts; it is self-regulated, intentional and interest-based, rather than curriculum-based. It is not assessment driven and even is non-qualification driven" (Mills et al., 2014).

Khaddage and colleagues revealed the absence of a cleardefinition of informal learning (Khaddage et al., 2016). There are a few competing definitions and categorizations within the research field. Mills et al. (2014) defined informal learning in terms of outside class activities and argued that information seeking and information sharing are key components facilitating the move from formal to informal learning. Vavoula, Sharples, Scanlon, Lonsdale, and Jones (2005) defined learning based on who 
defined the goals and the processes of learning. These authors differentiated between formal and informal learning, and included a category for unintentional informal learning. Wang and Shen (2012) claimed that "informal learning occurs under selfmanagement of the learner and in ad hoc environments [...] [and] takes place accidentally, sporadically and in association with certain occasions" (Wang \& Shen, 2012, p. 563-564). Due to this, the variety and enigmatic nature of these definitions, the boundaries between formal and informal learning in education still remain unclear. This issue of definition creates difficulties, for both researchers and practitioners, to understand, employ and explain concepts in a consistent way. These difficulties concern various aspects of design of learning activities in education.

Other researchers have studied and discussed the concepts of formal and informal learning. Greenhow and Lewin (2016) examined the informal and formal learning in regard to the use of social media in education. They provided a model that theorized social media as a space for learning with a range of of formal and informal attributes. Manuti, Pastore, Scardigno, Giancaspro, and Morciano (2015) investigated formal and informal learning within a workplace context, and situated it within a broader educational framework. Cox (2013) researched how the development of information technology has influenced balance between formal and informal learning in e-learning settings (Ng \& Nicholas, 2013).

\section{Blended Learning in K-12 Environments}

The Clayton Christensen Institute defined blended learning in the K-12 environment as: A formal education program in which a student learns at least in part through online learning, with some element of student control over time, place, path 
and/or pace: at least in a supervised brick and mortar location away from home; and the modalities along each student's learning path within a course or subject are connected to provide an integrated learning experience. (Staker \& Horne, 2012).

This definition helps to set apart blended learning from technology-rich instruction, which takes place when a teacher uses technology-based enhancements, such as electronic whiteboards, broad access to Internet devices, document cameras, digital textbooks, Internet tools, and online lesson plans, but the students continue to learn in a mostly unified, monolithic way as a class. (Staker \& Horn, 2014, p. 290) The authors suggest visualizing K-12 blended learning as a matrix rather than a linear continuum: blended learning matrix and points on the matrix (Staker \& Horn, 2014, p. 291).

Blended Learning may be defined in a number of ways. There is the issue of what is blended. Oliver and Trigwell (2005) pointed out that a significant problem with blended learning is the issue of definition: "The term "blended learning" is ill-defined and inconsistently used. Whilst its popularity is increasing, its clarity is not. Under any current definition, it is either incoherent or redundant as a concept. Building a tradition of research around the term becomes an impossible project, since without a common conception of its meaning, there can be no coherent way of synthesizing the findings of the studies, let alone developing a consistent theoretical framework with which to interpret the data (Dziuban et al., 2014, p. 330).

Because this definition of blended learning is without rigid bounds, "learning variation is inherent in its underlying properties. The more fundamental research problem may not be one of definition, but rather of designing research methods that respond properly to a generalized concept" (Dziuban et al., 2014, p. 331). Further, the authors 
confirm that, "by definition, blended learning research is messy, leaving many people frustrated with our inability to develop robust cause and effect relationships through experimental research" $(2014$, p. 332). The authors state that blended learning presents many opportunities for research that incorporate modern innovations for data collection, data analysis, presentation, interpretation of results, and incorporation of findings into decisions about effective pedagogy and policy (2014, p. 333).

The implementation of blended learning is supported by the transformation in education designed for the importance of students' construction of knowledge. The learner-centered paradigm is reliant upon the social constructivist process (Vygotsky, 1978; Collins et al., 1989) that advocates for students co-constructing knowledge through communicating interpretations of concepts or ideas. Fox and Hall conducted research in regard to learning space designs in Hong Kong. Van Note Chism (2006) advocated for flexible learning spaces characterized by flexibility, comfort, sensory stimulation, technology support, electricity supply, wireless connectivity, and interest groups. Classrooms, generally, need to cater to different teaching and learning practices that support both instructivist and constructivist approaches to teaching. In order to cater for multiple practices and to maximize flexibility classrooms need to be designed to enable quick re-configuration from one activity to another during individual classes. Furniture in all classes should facilitate mobility as well as flexibility. (Fox \& Hall, 2012, p. 80) Horne's research focused on blended learning as it pertained to K-12 environments. They cite that, as blended learning is an offshoot of online learning, it offers the possibility of a broad course catalog with more customized instruction for a vast range of students. This is because blended learning bears the characteristics of a classic disruptive innovation 
that is marked by transformation from a complicated, expensive, inaccessible, centralized sector to something simple, accessible convenient, and customizable (Staker \& Horn, 2014, p. 287; Christensen, 1997). Between 2010 and 2012, researchers at the Clayton Christensen Institute collected information from 100 education experts and 80 organizations in an attempt to identify what blended learning looks like for K-12 education. Staker and Horne (2014) identified the following conclusions: Postsecondary education and K-12 sectors identify blended learning differently, namely by the fact that there is some student control over time, place, path, and/or pace, and the face-to-face component occurs in a supervised brick-and-mortar location away from home.

\section{Blended Learning Models}

The four most prevalent blended learning models in the K-12 sector are-rotation model, flex model, a la carte model, and enriched virtual model-these models represent multiple programs within a school, without the expectation that the whole school fits within a singular typology (Staker \& Horn, 2014, p. 292). Further, Dziuban, Hartman, and Mehaffy confirm that blended learning is not new: "Technology not only challenges traditional institutions, but also empowers students to take those courses from a variety of sources thereby assembling their own programs of study" (Staker \& Horn, 2014, p. 327).

Dziuban, Hartman, and Mehaffy (2014) advance the fact that blended learning has four critical values. The fact that the modality involves human intervention and technology, faculty are forced to answer the question of the unique value that individual instructors can add. The second value is that shifts focus from the faculty member to focus on students and pedagogical approaches from instructivist and constructivist methods. In traditional classrooms, faculty are at the center, while in blended learning 
course models, faculty must consider how students will work with elements and materials outside of class. A third value set out by Dziuban, Hartman, and Mehaffy, is that of faculty, by the fact that teachers are predominantly responsible for issues of encouragement, persistence, as well as responding to complexity and confusion. The fourth value is the opportunity for data collection and analysis afforded by a move to online systems (Staker \& Horn, 2014, p. 329-330).

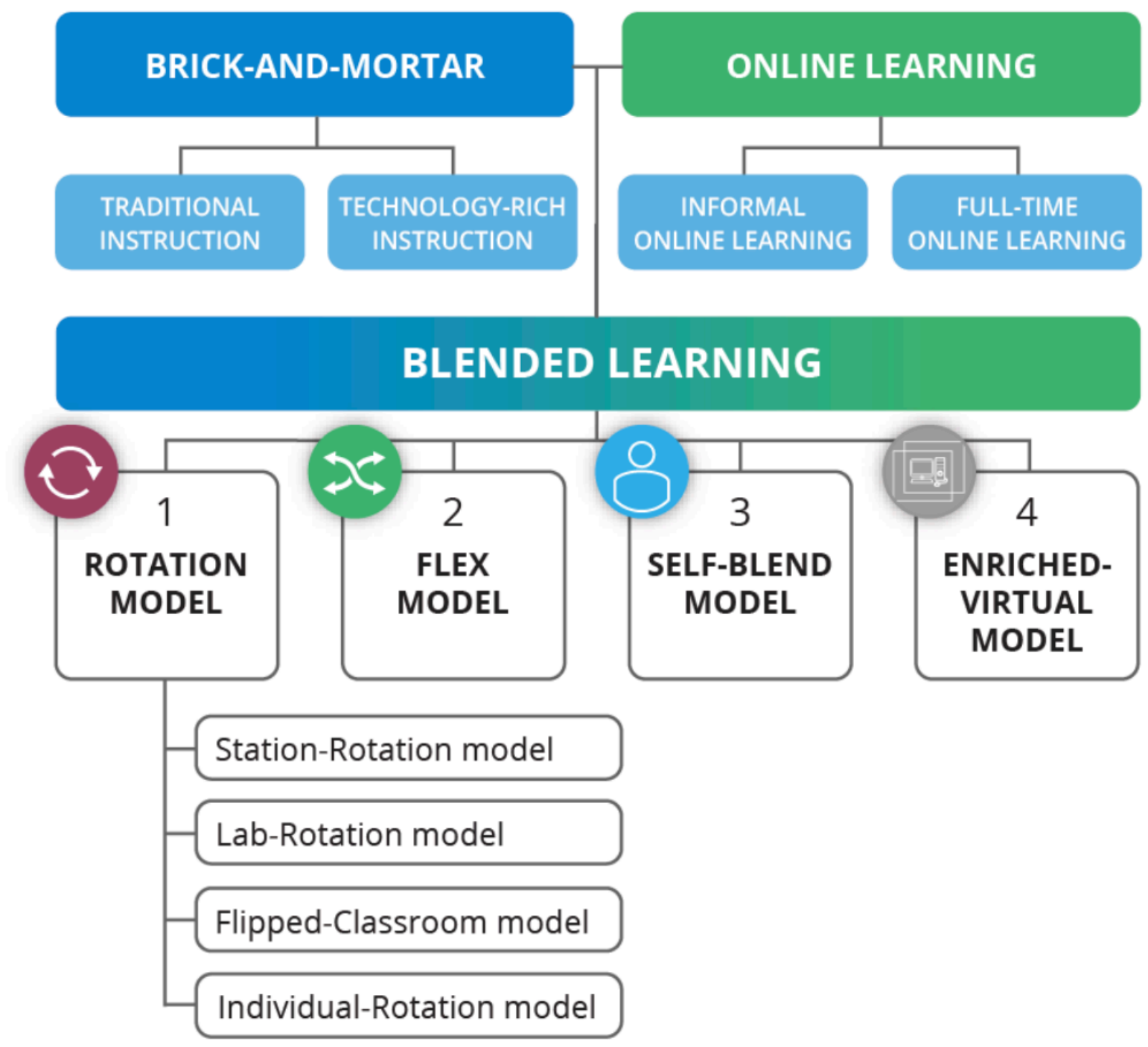

Figure 2.1: Blended Learning Models (Staker \& Horn, 2012) 


\section{Operational Definition of Blended Learning}

The case study school in the current study used a blended learning model that aligns with the Station Rotation model. For the purpose of this study, blended learning is characterized by the station rotation model. Students rotate daily on a 90-minute block schedule through their four courses, and attend lunch hour, where they connect physically or online with any one of their classes in the rotation. Outside of school, students connect with their classes online. The measuring indicator is self-reporting by students and their teachers of blended learning in multiple modalities, in school and outside of school, employing both face to face and online learning.

\section{Classroom Design \& Interaction}

A vast amount of research exists on the relationship between the physical learning environment and behavior, attitudes, and performance of both teachers and students (Evans, 2006; Jamieson et al, .2000; Mendell \& Heath, 2005; Rivlin \& Weinstein, 1984; Tanner, 2000, 2008; Weinstein, 1979). At a simplified level, the impact of the environment on cognitive processing can be demonstrated by the fact that identical objects can be perceived differently depending on the environment in which they are situated. (Choi et al., 2014) are clear to define the physical learning environment and differentiate it from environment or learning environment, because the physical learning environment encompasses both task and learner characteristics. "The physical learning environment refers to the whole range of physical properties of a place where teaching and learning takes place. These include physical characteristics of learning materials or tools (e.g., texture, color, size, shape, weight, and sound), the physical attributes of the built environment (e.g., volume, density, lighting conditions, arrangement, and thermal 
conditions), natural spaces, and the physical presence of other people. It covers sensory stimuli from the environment that can be perceived by human senses, that is, vision, hearing, smell, taste, touch, temperature, and balance" (Choi et al., 2014).

Choi, Merriënboer, and Paas identified three types of effects of the physical learning environment: cognitive effects, physiological effects, and affective effects. The researchers stated that, "It is often difficult to determine the influence of the physical learning environment on learning because of its complex multidimensional character (Higgins et al., 2005). The cognitive, physiological, and affective effects of the physical environment on learning may be closely intertwined (e.g., Evans \& Stecker, 2004)."

\section{Cognitive Effects of the Physical Learning Environment}

Studies have shown that environmental stimuli from the physical learning environment can impose a load on learners' working memory. Noise, whether visual or auditory, can be considered as a typical irrelevant environmental stimulus that takes limited working memory resources away from the learners' cognitive process. "The irrelevant speech effect (e.g., Salamé \& Baddeley, 1982, 1986) is a well-known example of this phenomenon in the auditory system, which refers to the interference from irrelevant auditory items (e.g., background speech or white noise) during immediate recall tests. Grant et al. (1998) found that retrieval success was better in the matching auditory conditions between learning and test session (silent-silent and noisy-noisy) than in the mismatching auditory conditions (silent-noisy or noisy-silent)."

\section{Performance Improves with Similar Environments}

The effect of the physical learning environment on cognition can be viewed from a context-dependent memory perspective, which refers to the finding of better memory 
performance when the (physical) learning and test environment are similar than when they differ (Smith \& Vela, 2001). An illustration of the effect of context on memory is the study of Godden and Baddeley (1980), who had deep-sea divers learn and retrieve word lists on dry land or underwater. Their results demonstrated that remembering word lists learned underwater was better when a recall test was performed under water. The same effect sustained for words learned and tested on dry land.

\section{Offsetting Negative Effects of Physical Environment}

It has been found that negative effects of physical environmental factors can impose an extraneous load on working memory should be minimized or eliminated. Although learners are able to exclude irrelevant environmental stimuli from the information processing cycle themselves by an effortful suppression process, this process imposes a load on the executive component of working memory and can better be prevented (Smith \& Jonides, 1999).”

\section{Physiological Effects of the Physical Learning Environment}

\section{The Effects of Air Quality and Temperature}

The air quality and the thermal conditions of a learning environment can affect an individual's learning performance through oxygen-related physiological mechanisms. Lan et al. (2011), found that in a warm office environment (at $30^{\circ} \mathrm{C}$ ), participants had a lower arterial oxygen saturation. The participants were less willing to exert effort than in a thermally neutral office environment (at $22^{\circ} \mathrm{C}$ )

\section{The Effects of Food}

"Another example of a direct physiological effect of the environment is related to the effects of food on the blood glucose level. Elevated blood glucose, for example 
through a glucose drink, is associated with an improvement on a number of cognitive tasks, particularly those that require effortful mental processing (e.g., Scholey et al., 2001). The positive relationship between blood glucose level, blood oxygen saturation, and cognitive performance can be explained by the brain's metabolic need to accommodate the increased need for more oxygen and glucose by task-sensitive neural mechanisms during an effortful cognitive processing" (Scholey et al., 1999; Turner \& Carroll, 1985).

\section{The Effect of Lighting}

"Several studies have shown that the color temperature of the lamps (e.g., warmwhite vs. cool-white) and the level of luminance (e.g., 300 vs. 1,500 Lx) have an impact on cognitive performance (e.g., Hygge \& Knez, 2001; Knez \& Hygge, 2002). This impact, however, may be physiological but may also be explained by affective mood changes."

\section{Affective Effects of the Physical Learning Environment}

The emotional state, mood, or motivation act as a mediator of the relationship between the physical learning environment and learning performance (e.g., Erez \& Isen, 2002; Uline \& Tschannen-Moran, 2008). Evans and Lepore (1993) provide evidence of non-auditory effects of noise on children's affect and learning performance. For example, in a noisy classroom environment, children are more likely to give up on a puzzle task than children in a quiet classroom environment (Cohen et al., 1980). Evans and Stecker (2004) also showed that noise can lead to diminished motivation, feelings of helplessness, and consequently result in lower learning outcomes." 


\section{Motivation, Cognitive Load and the Learning Environment}

Regarding a motivational perspective of cognitive load, a poor physical learning environment may influence learners' emotional states, leading to a feeling of discomfort. In turn, this might reduce learners' willingness to allocate cognitive resources to the learning task and negatively impact learning. A high-quality physical learning environment could have a positive effect on the learners' willingness to allocate cognitive resources to the learning task and therefore positively impact learning. ( Paas et al., 2005)

Paas (1992) and Paas and van Merriënboer (1994) advanced Cognitive Load Theory by introducing self-report measures of mental effort. The use of self-report measures were quickly adopted by CLT researchers around the world. The work by Paas and van Merriënboer further initiated research on the measurement of cognitive load (Brünken et al., 2003; Paas et al., 2003) This doctoral research involves self-reporting by students of their preferred physical learning environments inside and outside of a formal school setting in order to idealize their cognitive load.

\section{Interactions Between the Physical Environment and the Task}

The story of Grigori Perelman fits this perspective. This world-famous mathematician solved one of the biggest problems in mathematics known as the Poincaré conjecture. In order to solve this problem, Perelman went into the woods because, according to him, this environment facilitated creative problem solving. McCoy and Evans (2002) studied the influence of the physical learning environment on innovative thought. They hypothesized that there are certain characteristics of the physical environment that people prefer when working on a specific task. They identified several environmental characteristics that were thought to facilitate creative performance, 
including the complexity of visual details, a natural environment (per Perelman's woods), the use of natural materials, and a limited use of cool colors. Their study showed positive effects of these characteristics on the level of creative performance. In a similar study, Zhu and colleagues proposed that different types of cognitive tasks (i.e., detailed/specific tasks vs. creative tasks) could be activated by different colors (red vs. blue; Mehta and Zhu 2009), levels of noise (moderate (70 dB) vs. high (85 dB)/low (50 dB)); Mehta et al. 2012), and height of the ceiling (high vs. low; Meyers- Levy and Zhu 2007). Zhu and colleagues showed that blue color, moderate noise, and a high ceiling enhanced performance on a creative task, whereas a red color, low noise, and a low ceiling enhanced performance on a detailed/specific task. With regard to the ceiling height of the room, they found that a high ceiling stimulates freedom-related concepts and improves relational processing. By contrast, a low ceiling activates confinement-related concepts and improves item-specific processing. In their experiments, ceiling height of two of the rooms was lowered from 10 to $8 \mathrm{ft}$. With regard to the effect of colors, they conducted series of studies about the effect of different colors on different cognitive task performances. In a memory task or proofreading task, participants in the red condition performed better than in the blue condition, and it was reversed for a creative task. Zhu and colleagues explained that red and blue colors could induce learner's alternative motivations. A red color (invoking stop signs or warnings) stimulates an avoidance motivation while enhancing performance on a detail-oriented task. A blue color (invoking ocean or sky), by contrast could enhance performance on a creative task.

Regarding the level of noise, Zhu and colleagues found that increasing levels of noise fostered distraction, which induced a higher construal level, abstract processing, 
and enhanced creativity. However, more interestingly, although both moderate and high levels of noise lead to a more abstract processing as compared to a low noise level, enhanced creativity was only observed in moderate noise levels because very high levels of noise reduce the extent of information processing. Based on these findings, it can be argued that the typical classroom (i.e., a quiet or clamorous room with a relatively low ceiling) is not the most beneficial environment for creative problem solving. Creativity could be facilitated in a more desirable physical environment. The findings of Mehta et al. (2012) have actually been implemented in a web/mobile application that can add a desirable level of white noise (e.g., sounds of a café) to the environment in order to facilitate creative thinking.

\section{Interactions Between the Physical Environment and the Learner}

Consistent with the "person-environment fit account" (e.g., Nielsen \& Moos, 1978), researchers found a relationship between the preferred learning environment of a learner and his or her achievement in this environment. Learners perform higher in a preferred environment compared to a non-preferred environment (Hattie \& Watkins, 1988; Wong \& Watkins, 1996). Wong and Watkins (1996) also found that the impact of the learner-environment fit was more critical among low self-monitoring individuals than among high self-monitoring individuals. High self-monitoring individuals can more easily adapt themselves to different situations.

\section{Interactions Between the Physical Environment, the Task, and the Learner}

An example of a three-way interaction is evidenced from studies on gender- and age-related effects of indoor lighting on mood and cognitive performance (e.g., Knez \& Enmarker, 1998; Knez \& Kers, 2000). Knez and Kers (2000) found that the color 
temperature of indoor lighting differentially affected mood and cognitive performance relative to gender and age. In this study, younger adults sustained a negative mood in "warm" white lighting, while the same effect was found with "cool" white lighting for older adults. There is the assumption that the more positive a learner's mood, the more willing he/she is to invest cognitive resources, (Paas et al., 2005). Extending this, these effects could interact with task complexity, so that under warm white lighting conditions, younger adults perform better on complex tasks than under cool white lighting conditions, while for the older adults the opposite effect is expected.

In summation, Choi, Merriënboer, and Paas argued to treat the physical learning environment as a separate factor that influenced cognitive load and learning. The researchers illustrated that changes in the physical learning environment influenced the effects of instruction and its impact on cognitive load and learning. This new model opens up a new research line and could have important practical implications for the design of learning environments.

There are a plethora of additional studies relevant to the physical learning environment. The literature review conducted by Loughlin in 2011 focused on an organization of the significant research relevant to learners, practitioners, and spaces, with the three phases being design, transition, and reevaluation. A research study conducted in the same school district in which the researcher works documented the spatial organization of four small school environments and analyzed the way in which spatial relationships influenced students' behaviors and interactions. This work was conducted by Celen Pasalar and was entitled, "The Effects of Spatial Layouts on Students' Interactions in Middle Schools: Multiple Case Analysis.” 
Barrett et al.'s (2015) research detailed the relationship of learning environments and learners. The article, “The Impact of Classroom Design on Pupils' Learning: Final Results of a Holistic Multi-level Analysis," analyzed classroom design and environment behavior factors. Through the analysis of ten environmental factors and five non environmental factors, models were strongly validated. It was found that school design impacted 3,766 pupils' learning rates in the UK. This work confirms the use of the naturalness, individuality, and stimulation conceptual model as a path to organize and research the range of sensory impacts experienced by an individual within a space. The naturalness design principle accounted for $50 \%$ of the impact on learning, with individuality and stimulation accounting for $25 \%$ each. Seven key design parameters were identified that accounted for $16 \%$ of the variation in pupils' progress. These seven items are light, temperature, air quality, ownership, flexibility, complexity, and color.

The study was a HEAD (Holistic Evidence and Design) study of the impact of the design of primary schools. The overall research question was "to explore if there is any evidence for demonstrable impacts of school building design on the learning rates of pupils in primary schools." The research focused on primary schools because students spend the majority of their time in one classroom, there are available measures of the academic performance, and achievement is an important issue (Barrett et al., 2015).

There is general respect for the entity of building performance, often measured through post-occupancy evaluations (POEs) or building performance evaluations (BPEs). Often, the data is not widely available. One recent tool developed by Steelcase is the Active Learning POE. Some examples of real impacts include Ulrich's evidence of the positive healing effects of the views of nature. Further, the study by Heschong and 
Mahone found that children in classrooms with the most daylighting progressed $20 \%$ faster in math and reading. Problems were encountered when thermal comfort, air quality, acoustic measures, and daylighting were included.

Research by Barrett et al. (2015) did not build from measurable dimensions of heat, light, air, and sound quality; rather, they initiated from the notion that the effect of the built environment on users is experienced via multiple sensory inputs in particular spaces, which are resolved in the users' brains. Barrett et al. (2015) designated three dimensions, or design principles, that were used to structure the factors to be considered: Naturalness: light, sound, temperature, air quality, and links to nature; Individualization: ownership, flexibility, and connection; and Stimulation (appropriate level of): complexity and color. This research employed Zeisel's environment-behaviors factors model, which was supported by surveys of students and teachers, in addition to post-occupancy evaluations of schools. The E-B model was structured by the main three design principles - naturalness, individualization, and stimulation - and were expanded into design parameters, indicators, and factors. Barrett et al. tracked students within the same classroom. "Because pupils learn together in classrooms, we expected the pupil progress between pupils sharing the same classroom to be more correlated than pupil progress between pupil progress in different classrooms" (Barrett, 2015).

\section{Affordance Theory}

The current research examines a range of physical and blended learning environments to better understand student spatial preferences and uses of technology that ideally support learning. The theory of affordances is central to understanding the ways in which both physical and virtual environments might support learning. 
The concept of affordance originated with Gibson (1986) in ecological psychology and is understood as the interaction between an actor with the environment, defined as the surroundings of the actor itself. According to Gibson, actors are organisms perceiving and behaving in the environment. The conditions that enable this interaction include both the properties of the actor and of the environment (Gibson, 1986). Affordances are preconditions for an activity, but do not imply that the specific activity will occur (Greeno, 1994). Gibson $(1977,1986)$ intended an affordance to mean an action possibility available in the environment to an actor. An affordance is independent to the actor ability to perceive the possibility (Greeno, 1994; Hartson, 2003; McGrenere \& Ho, 2000).

Affordances can also constrain actors to perform an action. Affordances arise from object features and actor's characteristics and capabilities. In this sense, depending on the actor's characteristics, these potentials can be opportunities and constraints for action. A door, while affording the possibility to walk through for an actor whose width is smaller than the one of the aperture, also represents a constraint for an actor whose width is greater than the door size. Only a few scholars tend to consider affordances with this double nature, as both enabling and constraining the possibility to act (Volkoff \& Strong, 2013).

According to Norman (1988), affordance term refers to the perceived and actual properties of the object; primarily those basic properties that determine just how the artefact could be possibly used. Norman (1988) suggests that affordances are intrinsic and "designed-in" properties of the artefact. According to Norman (1988) the actor does not play any role in creating the affordance. In this formulation, Norman's argument 
differs from Gibson's in that he argues that affordances are not unique to the way in which the actor perceive it. Affordances do not change among different contexts of use or different actor's goals. Affordances rather that are always there to be perceived. Norman imported the term into human computer interaction (HCI) literature and the concept became popular (Hartson, 2003; McGrenere \& Ho, 2000). Relative to physical environment affordances, the word "spatial preferences" was employed. This research study involved the view of affordances relative to the physical learning environment.

An affordance is often seen as an enabler, a positive potential to perform an action. Adopting affordance theory in the information science domain produced two main consequences. First, researchers and practitioners no longer deal with just individuals as actors engaged in the relationship, but also with organizations presented as groups of people, teams and business units and consider the actors originating, perceiving, and enacting affordances with the intention to support organizational goals. In this term, the potential for coordinated action by a group of actors can be thought as an organizational affordance (Strong et al., 2014; Volkoff \& Strong, 2013; Zammuto et al., 2007). Second, affordances, which maintain all the characteristics indicated above, are considered, and often called, technology affordances, as action potentials that an organization with a particular purpose can do with a technology or Information System (Markus \& Silver, 2008; Savoli \& Barki, 2013; Seidel et al., 2013).

\section{Four Types of Affordances}

\section{Affordance Existence}

Most scholars in affordance theory literature have contributed to the landscape of affordance existence. Affordances existence is usually approached theoretically, that 
features both the definition of affordance and characteristics. Affordances can be thought of as preconditions for activity. Affordances are characteristics of whatever the actor interacts with an object that supports an activity (Greeno, 1994). Affordances, as cognitive processes (Davern et al., 2012a, 2012b) where actors perceive objects in terms of their potential for actions. Affordances can be analyzed as the relation between actors and other systems "Affordances exist whether the actor cares about them or not, whether they are perceived or not, and even whether there is perceptual information for them exists or not" (Greeno, 1994).

\section{Affordance Perception}

Affordance perception is a process of recognition (Greeno, 1994) of the affordance existence influenced by (1) the objects' features, (2) actor capabilities, (3) actor's goal, and (4) external information. The range of affordances of any object is not fully and immediately available to be perceived (Hutchby, 2001). The process of recognition of affordance can be analyzed as the relationship between a specific actor and a specific system. Considering the example of the door mentioned above, while the actor recognizes the intention to move in the other room, also considers his/her width in relation to the door's aperture. In other terms, the actor might ask to himself/herself: "Am I able to pass through that door? Does the door afford me the possibility to pass or is it an obstacle to my movement? Do I have to side to pass through the door?" Volkoff and Strong (2013) are the first to argue against affordance perception. They state that affordances, as real and generative mechanisms associated with technical artefacts for use in organizations, do not need to be perceived. In other terms, by taking into account the functional aspect of affordances, as defined by Markus and Silver (2008), they state that 
affordance exists only in relation to the actor's goal or intent. According to their point of view, they focus on the phenomena observed as actualized affordances, going back to the underlying affordances from the finished action.

\section{Affordance Actualization}

Actualization is defined as the action taken by actors as they take advantage of one or more perceived affordances through their use of technology to achieve outcomes in support of organizational goals (Strong et al., 2014). Actualization is a goal-oriented and iterative process (Leonardi, 2011, 2013; Strong et al., 2014). Recently, the interest in the actualization process has grown (Bernhard et al., 2013; Leonardi, 2013; Strong et al., 2014; Volkoff \& Strong, 2013).

\section{Affordance Effect}

Affordances have the potential to cause an event. As a generative mechanism, the actuation of an affordance produces an empirical result. In other words, actor's movement to act upon a technology becomes an entity when the actor behaves to actualize the affordance. Scholars tend to differentiate affordance actualization results in two main sets, based on actors' time perception. In the short term, the effect generated from affordance actualization is called immediate concrete outcome (Strong et al., 2014), as a specific expected outcome from the actualization and useful for realizing an ultimate organizational goal, the so-called affordance effect in the long term. An immediate concrete outcome serves as an intermediary between actualization actions and ultimate organizational goals (Strong et al., 2014). The actualization of an affordance may result in (1) enabling conditions for additional affordances, (2) development of additional information systems features, and/or (3) enabling organizational changes. Actualized 
affordances provide explanations of causality at a level that is specific to the respect of the technology and the organization (Volkoff \& Strong, 2013).

\section{Perceptions of Self-Regulated Learning}

The primary outcome of interest in the current study is the student perception about the environments in which they are successful learners, where the term "perceptions of self-regulated learning" will be used. In route to describing this outcome, however, it is useful to situate the concept within the larger context of self-regulated learning (SRL) and the broader idea of metacognition in the learning process.

\section{Metacognition \& Self-Regulated Learning}

Akyol (2013) explained that metacognition is socially situated and socially constructed in collaborative learning environments. Akyol elaborated on the fact that metacognition dimensions are self and co-regulation, individual and shared (Akyol, 2013). Critical thinking and inquiry are predicated upon an awareness and ability for learners to take responsibility and control to construct meaning and confirm knowledge. This awareness and ability has been labeled metacognition. According to Tobias and Everson (2009), metacognition is "a higher-order, executive process that monitors and coordinates other cognitive processes engaged during learning, such as recall, rehearsal, or problem solving” (p. 108). Research into metacognition over the last 30 years does suggest that learners with metacognitive awareness and ability are more successful in academic settings (Stewart et al., 2007). In summarizing this research, Young and Fry (2008) state it "appears that when metacognition is assessed through calibration of performance measures there is support for the relationship between metacognitive skills and measures of academic achievement" (p. 4). 
Conceptualization of metacognition is typically comprised of two dimensions (Flavell, 1987, Garrison, 2003; Hacker, 1998; Murphy, 2008; Paris \& Winograd, 1990; Schraw, 2001). In this view, "metacognition consists of knowledge and regulatory skills that are used to control one's cognition" (Schraw, 2001, p. 6). However, others have more recently suggested that there are three essential dimensions: knowledge of processes, cognitive, and affective states; the ability to monitor the inquiry process; and the willingness to regulate the inquiry process (Borkowski et al., 2000; Pintrich et al., 2000). As such, metacognition is intended to provide the knowledge, awareness, and strategies to critically assess the learning process. Pintrich et al. (2000) assess metacognition in three dimensions: metacognitive knowledge, metacognitive monitoring, and selfregulation.

Knowledge of cognition refers to awareness of self as a learner in a broad sense. Knowledge includes entering knowledge and motivation associated with the inquiry process, academic discipline, and expectancies (Akyol \& Garrison, 2011, p. 184). The reflective dimension of metacognition is the awareness of the thinking and learning process. This is conceptualized as the monitoring dimension of metacognition (Akyol \& Garrison, 2011, p. 184). The regulation dimension of metacognition is on the action dimension of the learning experience. It is the enactment and control of the learning process through the employment of strategies to achieve meaningful learning outcomes (Akyol \& Garrison, 2011, p. 184).

Pintrich et al. (2000) indicate that there is no perfect measure of metacognition. Tobias and Everson (2009) discuss the two principal ways used to study metacognition: observing students' performance on cognitively complex tasks and using self-report 
inventories (Akyol \& Garrison, 2011,p. 187). This research study focuses on self-report inventories of spatial preferences through photovoice.

To improve metacognition, "the essence of most practices to improve metacognitive skills is to engage students in collaborative activities such as peer assessments, collective reflection, and modeling metacognitive processes" (Choi et al., 2005; Kramarski \& Dudai, 2009; White et al., 2009; Akyol \& Garrison, 2011, p. 189). Getting students to take time to reflect, invent and investigate metacognitive processes themselves or using a metacognitive tool, such as a research journal, to promote students to plan, monitor and reflect on their work could also be applied to foster metacognitive thinking and development. (White et al., 2009; Akyol \& Garrison, 2011, p. 189).

As detailed later in the text, the photovoice blogs provided a way for teachers and students to document spatial preferences, self-regulated learning, and use of technology in formal and informal learning environments. Due to the slippery definition of metacognition, the words "perceptions of self-regulated learning" and "your thinking about your thinking" were used in the discussion of self-regulated learning with both teachers and students. There are additional explanations of self-regulated learning. "Selfregulated learning is defined as a student's ability to independently and proactively engage in self-motivating and behavioral processes that increase goal attainment" (Zimmerman, 2000). More specifically, self-regulated learning can be regarded as a skill, where students must know how to set goals, what is needed to achieve those goals, and how to actually attain these goals. Therefore, in order for students to self-regulate and direct their own behaviors, they must also be motivated or driven to attain goals (Kitsantas \& Dabbagh, 2010).” 
"Zimmerman (2000) conceptualized self-regulated learning as a three-phase cyclic model that attempts to explain why and how students achieve academically. The first phase is called the forethought phase. In this phase, prior to actually engaging in the learning task, students have a predefined set of cognitions (e.g., goal setting and planning) and self-beliefs (e.g., task interest, self-efficacy) that will impact how they will approach the task. In the second phase, the performance phase, the student begins to actually engage in the behaviors required to successfully achieve his or her goals. During the last phase of the model, the self-reflection phase, students use self-monitored outcomes to make judgments regarding their learning performance. Depending on the nature of the outcomes and the attributions students make, these self-evaluative judgments may affect future course of actions related to the first phase of the model; the forethought phase. Self-regulated learners engage in a cyclic feedback loop until they successfully achieve their goals. (Dabbagh \& Kitsantas, 2011, p. 4)"

"Self-regulated learning is defined as a student's ability to independently and proactively engage in self-motivating and behavioral processes that increase goal attainment (Zimmerman, 2000). More specifically, self-regulated learning can be regarded as a skill, where students must know how to set goals, what is needed to achieve those goals, and how to actually attain these goals. Therefore, in order for students to self-regulate and direct their own behaviors, they must also be motivated or driven to attain goals (Kitsantas \& Dabbagh, 2010). The motivational components of self-regulated learning help students persist in the face of difficult tasks and resist other sometimes more tempting options. 
Zimmerman (2000) conceptualized self-regulated learning as a three phase cyclic model that attempts to explain why and how students achieve academically. The first phase is called the forethought phase. In this phase, prior to actually engaging in the learning task, students have a predefined set of cognitions (e.g., goal setting and planning) and self-beliefs (e.g., task interest, self-efficacy) that will impact how they will approach the task. For example, a student who reports low self-efficacy beliefs in math and feels that math is not important to him/her will be less likely to excel in a mathematics course or have the persistence or effort to continue trying. In the second phase, the performance phase, the student begins to actually engage in the behaviors required to successfully achieve his or her goals. Specifically, students monitor their learning progress and use selected strategies to perform learning tasks. During the last phase of the model, the self-reflection phase, students use self-monitored outcomes to make judgments regarding their learning performance. Depending on the nature of the outcomes and the attributions students make, these self-evaluative judgments may affect future course of actions related to the first phase of the model; the forethought phase. Self-regulated learners engage in a cyclic feedback loop until they successfully achieve their goals.

The current study did not seek to objectively measure student success in SRL, but rather examined the student perceptions of self-regulated learning in a variety of learning environments. Renick and Harter (1989) conducted a study measuring self-perceptions of learning. In this project, students completed a Perceived Competence Scale for Children and subscales were revealed for scholastic competence in a regular classroom, scholastic competence in a LD or learning disabilities classroom, social acceptance, athletic 
competence and global self-worth. The difference between Renick and Harter's work and this dissertation, is that the focus is on the students' preferred use of the physical environment to help facilitate learning, rather than to focus on learning patterns and achievement devoid of environmental considerations. One of the objectives of the study is to reveal students' cognitive patterns as they learn across a spectrum of environments from school (formal) to home and elsewhere (informal). This current research at Catamount High tracks pupil learning over four different classroom spaces at school during the course of one day. In addition, students may reflect on their use of optional spaces during a lunch time. Further, this study offers a view into informal learning spaces outside of school.

\section{Personal Learning Environments}

Several studies have used Zimmerman's three phase model to support selfregulation in online and blended learning environments (Kitsantas \& Dabbagh, 2010); however very few researchers have examined the relationship between self-regulation, social presence, and personal agency which is fundamental to PLEs (Turker \& Zingel, 2008).Cho, Demei, and Laffey (2010)_examined the extent to which college student engagement in self-regulated learning behaviors contributed to perceptions of peer and instructor presence in an online learning environment where courses were delivered totally online using a learning management system. Specifically, perceptions of peer and instructor presence were conceptualized as students' ability to project oneself to others emotionally and socially and perceptions of social presence were conceptualized as students' feelings of belongingness within a community. Students completed questionnaires regarding their self-regulation and perceptions of peer and community 
presence. The results revealed that self-regulation predicted peer social presence, instructor social presence, sense of connectedness, and sense of learning (Cho, Demei, \& Laffey, 2010).

\section{Conceptual Framework}

Perceptions of self-regulated learning and environmental affordances serve as the dual guiding framework of this research work. Self-regulated learning involves learners positioning of themselves relative to their academic work. Environmental affordance theory is related to the way in which one can perceive and utilize the environment for a particular outcome. The research focused on the ways in which learners realized affordances of physical learning environments, inside and outside of school, for the purpose of maximizing learning self-regulation.

The current study found that students seemed to form a bond with settings that support their functional needs. This finding relates to the concept of place dependence, which is the person-place bonding with spaces that support human needs such as productivity.

The sense of place research has three distinct elements: place as a center of meaning, place as a locus of attachment, and place as a perception-action focus. The first element of sense of place research is place as a center of meaning, and the research strategy is inductive. We interpret how place meanings are formed individually or are collectively shared and employed. There is a hermeneutic approach, a discursive approach, a dialogical approach, and a phenomenological approach. With the hermeneutic approach, meaning is particular to the personal interpretation of context (Drethnen, 2011). With the discursive approach, place meanings are a social practice that 
can't be understood outside of interactional, cultural, and social contexts. Sense of place, here, is established through language use and everyday practice, and are rhetorically significant. The dialogical approach highlights the relationship of actions and practices (West, 2016). A phenomenological approach to sense of place emphasizes a total understanding of cognition, where actions, experiences, and intentions are drawn together spatially (Casey, 2009). Here, place meaning is individually constructed and generated through lived experience (Seamon, 2014).

The second element of sense of place research is a focus on place attachment rather than place as a meaning, as described earlier in part one. There is a top-down or deductive research strategy. Contextual information in the form of inputs (like cognitions, beliefs, attitudes, or mental representations about a place) is needed to be able to create meaningful mental representations or output (Williams, 2014a; Bernstein, 2010). There are three levels to understand this top-down approach: a computational level, an algorithmic representation level, and an implementation level. The computational level asks what the goal is behind forming certain beliefs about place (David et al., 2004). The algorithmic level of place attachments asks what the dimensionality of place attachment is and how the dimensions affect behavior (Raymond et al., 2010). The third level is the implementation level, where the question lies with how place attachment is realized in the human brain (David et al., 2004).

The third element of sense of place research is related to affordance theory. With this area, there is a focus on the perception-action focus on place. The research strategy is from the bottom-up, with the thinking that perception is rooted in the stimulus, and it does not require higher level thinking (Gibson, 1979). There are two major research 
perspectives, that of the individual perspective and the social perspective. The individual perspective promotes that affordances are possible because of a relationship between the physical properties of the world and an individual's capacity for action (Gibson, 1979; Jongeneel et al., 2015). By contrast, the social perspective assumes that all affordances are social because they are part of a shared reality and are bound by social norms and practices (Kiverstein, 2015).

Related to this discussion of affordance theory, is the concept of place dependence. Place dependence and place identity are two facets of a two-dimensional model of place attachment. Place identity is an emotional-symbolic meaning that people apply to a place (Brickner \& Kerstetter, 2000; Proshansky, 1978; Williams \& Rogenbuck, 1989). Place identity is a bundle of beliefs, ideals, preferences, values, feelings and goals (Proshansky et al., 1983). The thinking is that people do not directly identify with the physical place but instead attribute meanings to the place (Kyle et al., 2004b). By contrast, place dependence is a functional attachment, as there is utility inherent in the setting. The functional attachment is dependent on the physical and social characteristics. (Stokols \& Schumaker, 1981). This form of functional attachment is based on the area's physical and social characteristics.

With this discussion of place dependence is the necessary elaboration of the concept of behavior settings. This term of behavior setting was first categorized by Roger Barker and Herbert Wright in 1955. Behavior settings exist at the intersection between patterns of behavior and the environment. When the behavior matches the milieu, and the milieu matches the behavior, this behavior-milieu interface is referred to as a synomorph (Barker, 1968). 


\section{Chapter 3: Methodology}

\section{Theoretical Stance}

The foundations for research, or philosophies, are balanced against the domain of research, or research methods. Both aspects must be considered when pursuing research. The foundations of research are supported by epistemologies (ways of knowing) and paradigms (world views). Some examples of epistemologies include objectivism, constructionism, subjectivism, etc. This research work extends social constructivism. The research method employed in this research is qualitative ethnography, and the data collection techniques include observations, interviews and photovoice.

This qualitative research is an ethnographic case study. The researcher, armed with master's degrees in architecture and design, as well as years of experience working in the interior design and architecture industry, spent the last eight years at the research site. She can attest to countless changes relevant to the built environment, the administration, the technology, policies, students, and overall culture that has shifted over this long interval. The primary investigator attended hundreds of faculty meetings, IEP (individual educational plan) meetings, parent conferences, county meetings, state meetings, and international conferences in addition to teaching and guiding the adolescents under her care on a daily basis.

\section{Research Goals}

Understanding student spatial preferences of learning environments is one goal of this research. Understanding self-perception of learning and use of technology is tethered to this concern, for the fact that it impacts potential affordances of these spaces. Spaces where people learn have radically transformed over the past 25 years, largely due to the 
evolution of technology, to allow for learning to happen virtually anywhere. Spaces within and outside schools have changed over time, and even what spaces can be used for learning has evolved. The hope is that if student spatial preferences of learning environments, in school and outside of school, is better understood, these environments can be optimized and replicated to promote elevated learning experiences.

\section{Methods}

\section{Ethnography}

The goal of architecture is to improve the design of buildings for inhabitants. Pavlides and Cranz (2011) combined the etic (outsider) and emic (insider) points of view to learn from inhabitants' experiences of buildings. Ethnography means describing (graphing) the people (ethno), and in practice this means describing the behavioral and material expressions of culture, including architecture. Combining the etic and emic perspectives is accomplished through photo-elicitation, an ethnographic interview technique that relies on photographs to elicit inhabitants' points of view. (Pavlides \& Cranz, 2011)

\section{Case Study}

The strategy employed is the case study. The case study is defined as "a contemporary phenomenon within its real-life context, especially when the boundaries between a phenomenon and context are not clear and the researcher has little control over the phenomenon and context" (Yin, 2002, p. 13). Yin outlines six steps for the case study: plan, design, prepare, collect, analyze, and share. Case studies allow for confirmatory (deductive) as well as explanatory (inductive) findings (Yin, 2002, p. 48). 
The intended outcome of this case study was to understand students' spatial preferences across formal and informal learning environments. Further, we examined students' self-perceptions of cognition and use of technology in these learning environments. The case study shaped the types of questions asked, the form of the data collection, and the steps of the data analysis. As spatial affordances morph due to evolution in technology, culture, and need, so the audience who may gain the most from this research may shift. Architects, designers, school administrators, and staff, as well as parents and students, will gain insight as a result of this study.

\section{Research Questions}

Q1: What are students' spatial preferences in formal and informal learning environments?

Q2: What are students' perceptions of self-regulated learning in formal and informal learning environments?

Q3: What are students' use of technology in formal and informal learning environments?

\section{Research Site Selection}

The site of the research is a suburban high school located in North Carolina, here given the name "Catamount High." The geographical region is unique for the fact that it hosts many research technology companies and prestigious universities. This intellectual environment has drawn many international residents. The population of this high school campus is approximately 2,950 and reflects an intelligent, diverse, moderate to high income population. There are approximately 200 staff from a variety of backgrounds. The school site was constructed in 2006, and the building has been well maintained. The main 
brick building features three floors with symmetrical wings that are classified as the $1500 / 2500 / 3500$ wing and the 1600/2600/3600 wing. The original design featured halfheight locker bays at each of the wings, which allowed for students to congregate and work on homework at the counter height locker islands. In the summer of 2016, a grant was provided that allowed for the removal of a significant number of these locker islands. The locker islands were replaced with six square tables that provided seating for four at each table. It was the hope that these tables would foster greater unstructured collaboration among students. In addition, teachers could bring their classes out of their classrooms to the bays to allow for easier collaboration. In addition to the main building, five large modular buildings, holding approximately 12 classrooms each, were added to the campus after 2006 in an effort to keep up with severe population growth of the region. Some of the designs of the existing classrooms are constrained due to the placement of cables, drops, and outlets.

Many of the technology classrooms are packed with computers and offer no collaborative space. Similarly, other classes might be restricted by single desks that number up to 38 in each room. 


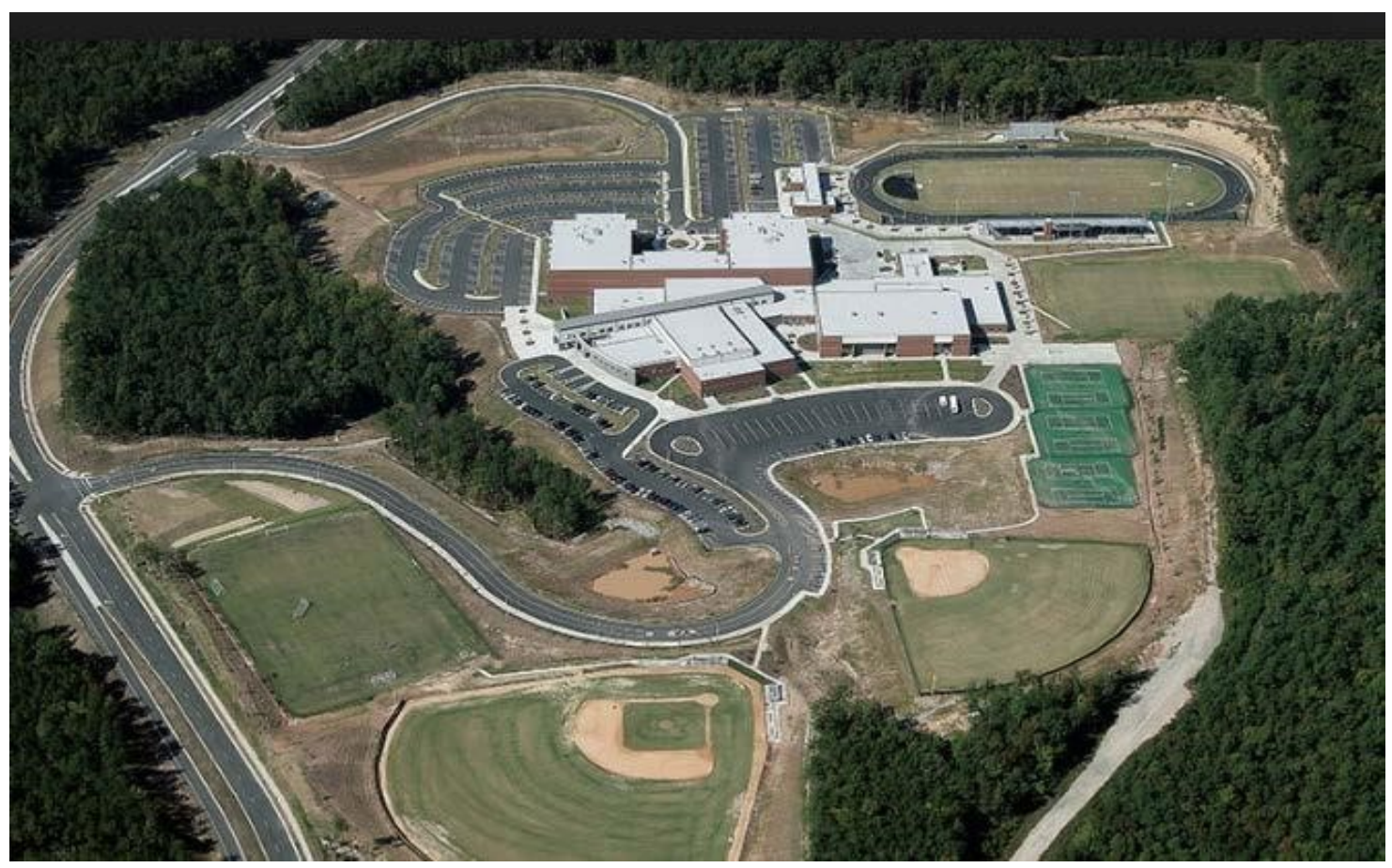

Figure 3.1: Aerial view of Catamount High

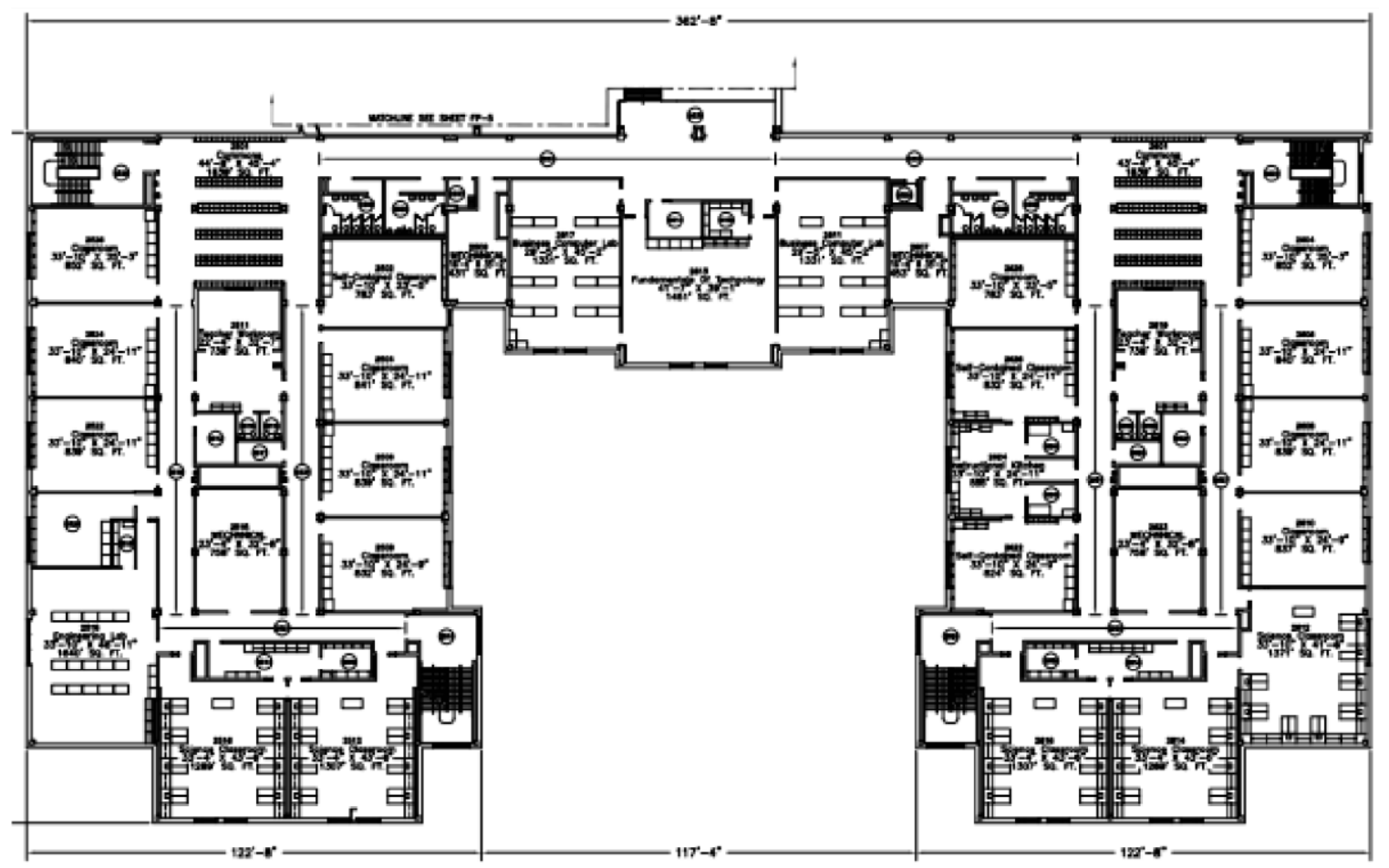

Figure 3.2: Catamount High School main building floor plan 


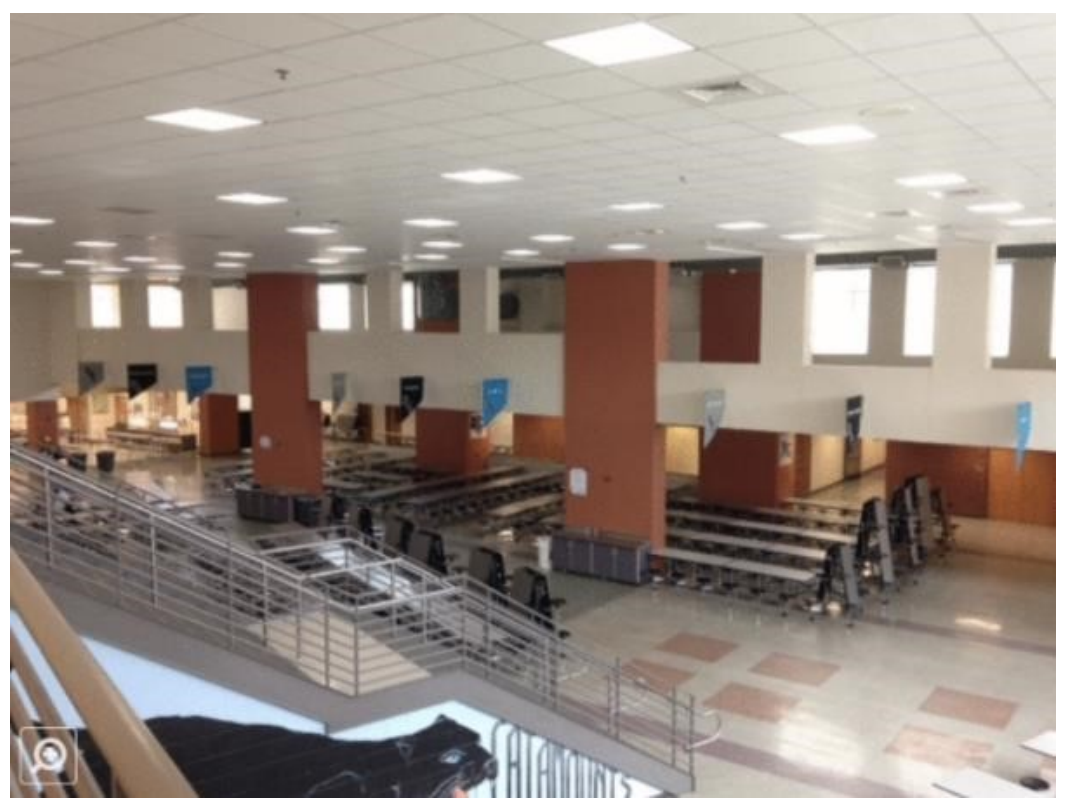

Figure 3.3: View of the commons from the second-floor balcony

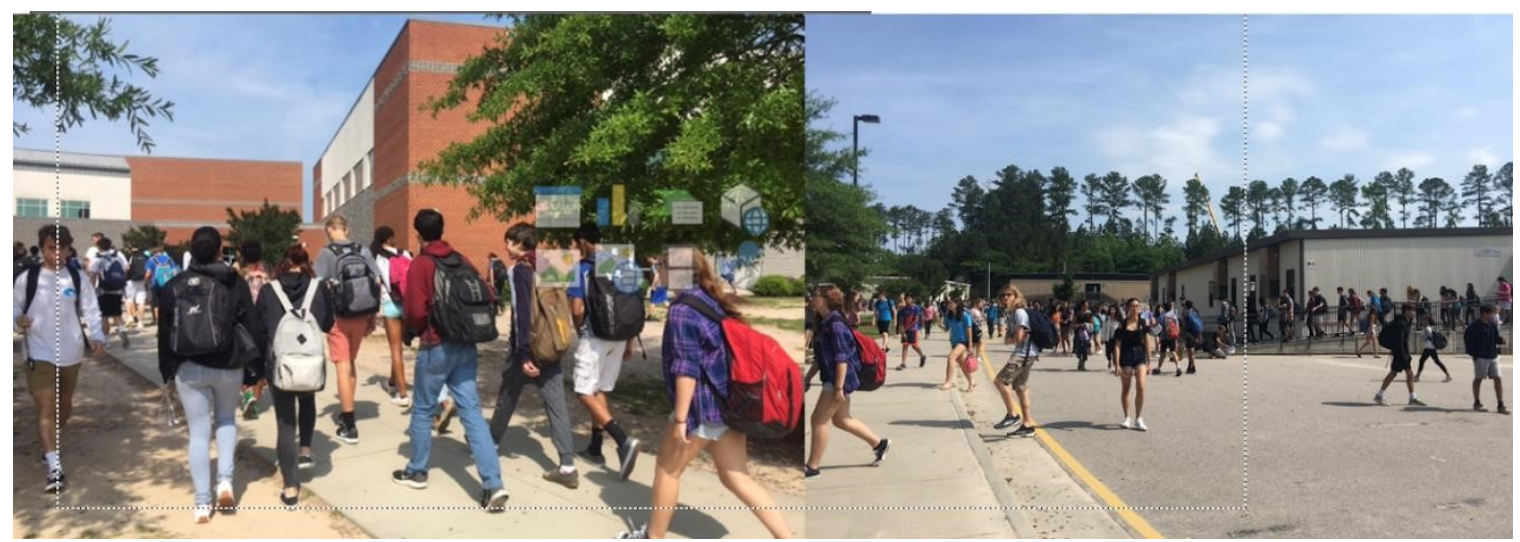

Figure 3.4: View of exterior space between modular building and main brick classroom building during busy class change

The site of this research, Catamount High, has been the workplace of the researcher for the past eight years, starting in the fall of 2012. During this time, there were countless changes, including three principals, four new assistant principals, countless teachers, and eight senior graduating classes. Some of the students who graduated high school in this interval have gone on to graduate from college and have come back to teach at Catamount High. 
In regard to the built environment, Catamount High is one of the architectural prototypes developed and rolled out in 2006. There are two other high schools in the county that have the exact same design. There are issues with this rollout method of design, but the county is huge and there is constant social communication in regard to spending. The achievement measures at Catamount High, such as graduation rate, percentage of students taking AP classes, etc. far exceed the achievement measures of the other identical schools in the county. Due to surges in extreme population growth of the area, five huge modular buildings, which each house ten classrooms, bathrooms, and a faculty meeting room, were erected over the tennis courts. The fifth modular building was set in place within the last five years. Blended learning takes place within the walls of Catamount High and extends beyond into the community that surrounds it. Of the many models of blended learning, Catamount High features a rotation model of blended learning. Students rotate though

\section{Positionality}

The researcher is a Caucasian female mother, wife, and teacher in her forties. Previously, she worked for years as a designer in the architecture industry and has taught all grades from PreK through college. She is currently employed as a high school teacher in her eighth year of service at Catamount High. She has taught students enrolled in grades nine through twelve, and some students who have graduated from Catamount High have returned to teach at the high school. She teaches in a computer lab on the third floor of the main brick building, and she "sweeps" or patrols students daily, having done so as part of her duties since her arrival. These observations have taken place in the hallways, locker bays, the commons/cafeteria area, the front, and modular building 
outdoor courtyards. Students know the researcher is a teacher, and she wears her Catamount High School badge as a sign of her position. Current students and former students spend time in her classroom computer lab during SMART lunches, and students greet her in the hallways by name. She has taught multiple siblings over the years.

\section{Participant Selection}

Convenience sampling was used to select participants. The researcher started with asking all teachers at Catamount High via letter if they were willing to participate in the research. The goal was to have at least one teacher from each department represented. In the end, the only department not represented was Social Studies. Once the teacher participants were secured, the researcher then asked each teacher if she could come to each of their three block classes to invite students to participate in the research study. Through this, she reached out to over 500 high school students of all grade levels and backgrounds. From this group, 35 indicated initial interest. Between the initial interview, the photovoice journal, and two follow-up interviews, seven students completed the research study from start to finish. All participants were provided gift cards for participating in the study. The principal of Catamount High, serving between 2014 and the spring of 2019, and the architect of the building were also represented in the sample.

\section{Data Collection}

Data collection started with interviews of teachers and students. A part of this initial interview included collection of IRB forms as well as photovoice training. Teachers and students were guided as to how to add photos, videos, and comments to a password-protected blog website. Once initial interviews were finished, the researcher moved into the middle photovoice phase. 


\section{Phase 1 (March - April 2018)}

Over two, two-week intervals, separated by one week of spring break, students and teachers documented their experiences through photovoice - photos, videos, and written descriptions shared in private website blogs. Students also completed cognitive maps of learning spaces. Cognitive mapping was completed only by eight students. On blank pieces of paper, students drew layouts of each of their classrooms, as well as the placement of their desks within the classroom environments. Given the low sample size and the thinness of the data received, the cognitive maps were not included in the current analysis.

Phase 1 conclusion interviews took place with students and teachers at the end of the photovoice process. These interviews involved sitting with each teacher or student and letting them talk and walk the researcher through the images they posted on their private blogs, for the purpose of more fully understanding the photovoice artifacts.

Observations were recorded by the researcher at the high school throughout the year.

\section{Phase 2 (2019)}

In January of 2019, the researcher sat down again with each one of her participants. They discussed any changes over the last calendar year. For the teachers, the changes ranged from sharing classroom spaces to teaching new courses to hosting new students. For the student participants, the changes were varied and included shifts in coursework, gaining a driver's license, and undertaking new strategies toward more effective learning. At the conclusion of the data collection, the data was coded. The purpose of coding was to find themes and patterns, analyze, and share the findings. 


\section{Data Collection Tools}

\section{Tool 1: Interviews}

There were interviews about spatial preferences, self-perceptions of learning, and use of technology in formal and informal learning environments. Teachers and students were interviewed as to their learning spatial preferences, where they thought they learned best, and their use of technology. The primary interview questions were

- What are your preferred learning environments in school and outside of school?

- Where do you think you learn best in school and outside of school?

- What technology do you use in school and outside of school?

\section{Tool 2: Photovoice Blogs}

Students and teachers documented learning environments over two ten-day intervals in March and April 2018 and again in the spring of 2019.

Photovoice was one of the methods chosen for data collection because it provides the opportunity for the collection of visual and verbal artifacts by a range of users across time. Photovoice fosters the creation of a living documentation of the experience being researched. This photovoice method was pioneered by Caroline Wang and was used in collecting data as part of the Women's Reproductive Health and Development program in Yunnan, China (Wang 1999). Photovoice is a process by which people can identify, represent, and enhance their community through a specific photographic technique. As a practice based in the production of knowledge, photovoice has three main goals: (1) to enable people to record and reflect their community's strengths and concerns, (2) to promote critical dialogue and knowledge about important issues through large and small group discussion photographs, and (3) to reach policymakers (Wang \& Burris, 1997, p. 
369). The process was initially utilized to promote public health and participatory needs assessment.

Photovoice projects have encompassed a variety of research endeavors, including youth and violence prevention, mothers with learning disabilities, homelessness, the stigma of HIV, family planning services for immigrants, etc. (Catalani \& Minkler, 2010). This photovoice process was also used to lead teachers through professional development of authentic literacy engagement, curriculum for language development, and selfvalidation for adolescent immigrants enrolled in English as a Second Language (ESL) programs in middle schools (Greene, 2015). "Photovoice facilitates the opportunity of observing the world from the perspective of people who lead lives that are different from those traditionally in positions of policy, power and control" (Wang 1999). Photovoice as a research tool inherently values participant knowledge as a critical component of expertise. Photovoice challenges the idea of a research paradigm of experts (researchers, specialists, outsiders, and professionals) as the only means for defining and investigating research problems (Mayfield-Johnson \& Butler, 2017).

The use of photovoice is critical in this qualitative research because it offers a voice to those in the school systems who often have no voice. Students have little control over the courses they can select, and students have absolutely no control over their school environment or the teachers of their courses. Students are assigned schools based on their address, and petitions to attend magnet schools across the county involve a rather arduous application process. Teachers, of course, have licensure areas and are hired selectively within the school district, but it is largely up to administrators what specific courses they teach and where they teach the courses across campus. Some teachers have to travel 
between classes, while others are fortunate enough to be allowed to stay in one classroom over the entire school day. There is little that teachers can do to control their environment or change their conditions. There have been numerous demonstrations within North Carolina in an effort to persuade lawmakers to improve conditions for teachers and students.

Through use of the photovoice process, teachers and students, historically allowed little to zero control over their learning environments, were offered an opportunity to share their perspectives on spatial preference, self-perceptions of learning, and technology use within their learning environments.

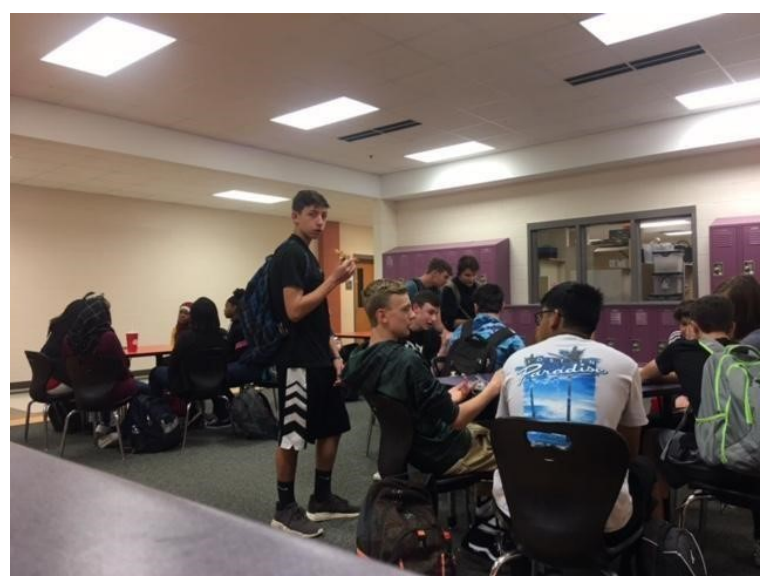

Figure 3.5: Hallway observations in the collaborative locker bays during SMART lunch

\section{Tool 4: Observations}

Observations were collected between 10:30 am and 11:18 am in hallways every Friday in the spring semester of 2018, as well as every Monday in the fall of 2018 and spring of 2019. Students maintained their same four class 90 minute block schedule, Monday through Friday, for the duration of a semester. Observations were made of informal learning spaces between classes. Observations were conducted every Friday 
during SMART lunch for the period of a semester. Two locker bays were observed in the 3500 and 2500 wings. Some observations were conducted in classrooms during bell 3 , from 11:20 am to $12: 45 \mathrm{pm}$. The observational data was not formally analyzed, but helped to buttress the researcher's interpretations about student perceptions of learning in the formal school environment.

\section{Data Analysis}

Interviews and photovoice were coded. NVivo was used for the purpose of generating themes. NVivo coding means "that which is alive" and is often used in educational settings with youth (Saldana, 91).

Interviews were audiotaped and immediately transcribed using pseudonyms to protect the identities of participants. The names of all the people the researcher met at Catamount High were changed. Qualitative data analysis software was used to sort and tag the interview data from school spaces such as classrooms, locker bays, commons, media center, and hallways; from public spaces such as libraries and coffee shops; and from residential spaces including dining rooms, living rooms, and bedrooms. Hence, there were spheres: the formal and informal school settings, the public informal learning spaces, and the private informal learning places.

After the initial data were tagged, the researcher then completed open coding of the data.

1. Interviews and photovoice blogs underwent initial coding (NVivo and descriptive) and secondary coding (axial).

2. Data was coded for consistent themes and saturation. 
3. Classrooms and home areas that are consistently high in regard to preferences were coded.

4. Classrooms and home areas that are consistently high in regard to perceptions of cognition were coded.

5. Technology patterns were coded.

\section{Credibility}

\section{Prolonged Engagement}

With prolonged engagement, characteristic of ethnographic research, there is an expectation that the researcher will be immersed in the field for an extended period of time. The researcher spent the last eight years at the research site. This prolonged engagement provides stability for the researcher to learn about the culture, blend into the environment, minimize distortion related to presence, and promotes trust with participants and informants (Lincoln \& Guba, 1985). The researcher started working at the site in the fall of 2012. She sought permission from the county and administrators in the fall of 2015. The IRB was approved in March of 2018.

Data was collected between March of 2018 and February of 2019. Even in the spring of 2020, the researcher continues to work at the research site. Because she is a member of the learning community, she did not attract attention as an outsider. The prolonged engagement is the cornerstone of triangulation.

\section{Triangulation}

There were four types of data collected relevant to this research: interviews, observations and photovoice journals. Even though the observations were not formally analyzed, they contributed to the researcher's total understanding of the context as 
findings emerged from the interviews and journals. The researcher kept a log of her work where she recorded field notes as well as the reasoning behind some research decisions. She compared her notes with photovoice documentation of teachers' and students' experiences. This practice supported the documentation in between data collection methods.

\section{Member Checks}

Teachers and students were interviewed multiple times as part of the data collection. There was an initial interview, prior to the creation of the photovoice journals. There was a second interview at the conclusion of the photovoice journals in the spring of 2018. There was a third interview in the winter of 2019 , documenting any changes over the last calendar year. All participants were encouraged to review the transcriptions as well as this copy of the research document. The researcher spoke with administrators and the architect at multiple intervals during the data collection process for the purpose of confirming their sentiments.

\section{Transferability}

Thick description was initiated by Gilbert Ryle in 1949 and was further invigorated by the work of Clifford Geertz in 1973. Thick descriptions involve the interweaving of the participants, the researcher, as well as the embedded cultural meanings relevant to time and place for an interpretive view of cultures.

\section{Convenience Sampling}

Convenience sampling was employed in this research. Convenience sampling is a type of non-random sampling where members of the target population that meet certain criteria are included in the study (Domyei, 2007). A call was made to all teachers in the 
school to participate in the study. Nine teachers volunteered to be part of the study. Each teacher teaches three courses a day. Once the teachers were selected, all students under the guidance of each teacher (approximately 3 classes of 30 students each) were invited to participate in the study, which amounted to over 500 students out of the student body of 2,950 .

The teachers ranged in age from 23 to 65 and taught a variety of content areas, including science, technology, English, math, fine arts, and special education. Students ranged in age from 14 to 18 years. Students take courses according to a block schedule, consisting of four 90 -minute bells.

Students and teachers reported on their experience of learning as it shifted across the campus for three to four classes over the course of the school day. Teachers documented how learning shifted according to the classroom space, the students, the curriculum, as well as the content management system. This research offers an in-depth view of perceptions of learning as each student encountered four different classroom environments over the course of the school day. In addition, this study provides an opportunity to view how the student participants chose to use informal learning spaces inside and outside of school. Further, there is the opportunity for the collection of perspectives of teachers about use of their classrooms that host three different classes over the course of the school day. The classes feature a diverse range of students. This reveals how students of various aptitudes perceive affordances within the same classroom environment.

This research is unique in that it offers a look into the current state of learning filtered through the perspective of the researcher, who is simultaneously a teacher at the 
research site. In spite of the unique relationship of the researcher and the site selection, there is not the motivation, per action research, to change what is witnessed. Rather, the motivation is to share the spectrum of student preferred learning spaces, self-perceptions of cognition, and technology use that can vary greatly per type of learning environment.

\section{Limitations}

The limitations are that this is a single case study conducted at a suburban high school located at a tech corridor in the contemporary Southeast of the United States. The researcher has conducted another photovoice research study with other adolescents. One study involved adolescent use of public places. Another study involved a description of the use of informal science centers by neurodivergent adolescents with Autism Spectrum Disorder.

\section{Confirmability}

\section{Reflexivity}

The researcher's research journal helped her to capture and organize her reflections. These differ from the field notes, which are relatively free of reflections.

We now place strong emphasis on beginning analysis as early as possible.

Developing theory from field note and interview data is not an easy or straightforward process and should be started early enough to allow the fieldworker to look for, find, and write up observations that will advance such analysis. (Emerson et al., 2011).

\section{Dependability}

To produce dependable qualitative research, the researcher's audit trail was organized according to the following structure: journals, field notes, tools, consent forms 
and IRB documents, and results. The appendix features interview guides, which were relevant to the research questions.

\section{Conclusion}

This third chapter shed light on the methods and data analysis employed in this research. The two chapters to follow will elaborate the themes evidenced in the work, as well as the connections to theory. 


\section{Chapter 4: Findings}

The purpose of this chapter is twofold. First, we will meet the participants in the study. Second, we will discuss some of the themes evidenced in the data. The first research question relevant to spatial preference yielded three themes of (1) gathering space versus solitary space, (2) spaces for comfort, and (3) replication and evolution. The second research question pertaining to perceptions of self-regulated learning and spatial preference yielded the theme (4) spaces to thrive. The third research question relevant to technology use and spatial preference led to the theme (5) technologically splintered spaces.

\section{Research Participants}

In this research study, the participants included eight high school students, eight teachers, one principal and one architect. First, the researcher invited the entire teacher population to participate in the study. From those teachers that voiced interest, the researcher went to each one of their classes and spoke to their students, asking for participants. Over 500 students out of a total student body of over twenty-nine hundred students were provided a QR code with which they could indicate interest in participation. The researcher began with 32 interested students, and after forms were signed and duties explained, the researcher was left with eight teens, ages 14 to 18 at the start of the data collection in the spring of 2018. The eight teens were six girls two boys, seven Asian, one Caucasian. All of the teens were very motivated and were all ranked in the top $25 \%$ of their respective classes. Missing from the student participants were those students who were not supported at home and who were not high achieving. All participants received small gift cards for their participation. 


\section{Table 1}

\section{Student Participant List}

\begin{tabular}{|c|c|c|c|c|c|}
\hline $\begin{array}{l}\text { Student } \\
\text { Name }\end{array}$ & Gender & Demographic & $\begin{array}{l}\text { Grade/Age in } \\
\text { Spring } 2018 \\
\end{array}$ & $\begin{array}{l}\text { Grade/Age in } \\
\text { Spring } 2019 \\
\end{array}$ & $\begin{array}{l}\text { Grade/Age in } \\
\text { Spring } 2021\end{array}$ \\
\hline S1-Zaha & Female & Arabic & Freshman/15 & Sophomore/16 & Senior/18 \\
\hline S2 - Priya & Female & $\begin{array}{l}\text { Indian - } \\
\text { American }\end{array}$ & Junior/17 & Senior/18 & College/20 \\
\hline S3 - Neesha & Female & $\begin{array}{l}\text { Indian- } \\
\text { American }\end{array}$ & Junior/17 & Senior/18 & College/20 \\
\hline S4 - Tya & Female & $\begin{array}{l}\text { Vietnamese - } \\
\text { American }\end{array}$ & Senior/18 & College/19 & College/21 \\
\hline $\begin{array}{l}\text { S5 - } \\
\text { McKenzie }\end{array}$ & Female & Caucasian & Sophomore/16 & Junior/17 & College/19 \\
\hline S6 - Adi & Male & $\begin{array}{l}\text { Indian - } \\
\text { American }\end{array}$ & Junior/17 & Senior/18 & College/20 \\
\hline S7 - Mike & Male & $\begin{array}{l}\text { Chinese - } \\
\text { American }\end{array}$ & Junior/17 & Senior/18 & College/20 \\
\hline S8 - Uma & Female & $\begin{array}{l}\text { Pakistani- } \\
\text { American }\end{array}$ & Junior/17 & Senior/18 & College/20 \\
\hline
\end{tabular}


Table 2

Adult Participant List

\begin{tabular}{|c|c|c|c|c|}
\hline Staff Name & Department/Courses & $\begin{array}{l}\text { Classroom } \\
\text { Dimensions }\end{array}$ & $\begin{array}{l}\text { Avg Class } \\
\text { Size }\end{array}$ & $\begin{array}{l}\text { Technology } \\
\text { Resources }\end{array}$ \\
\hline T1- Mr. Bunsen & Fine Arts - Chorus & $100^{\prime} x$ 40' & 60 & Two laptops \\
\hline T2 - Ms. White & English - English 2 & $40^{\prime} \times 40^{\prime}$ & 36 & 14 laptops on a cart \\
\hline T3-Ms. Bold & Math - AP Calculus & $40^{\prime} \times 40^{\prime}$ & 36 & 14 laptops on a cart \\
\hline T4- Ms. Crouven & Science - AP Physics & $60^{\prime} \times 40^{\prime}$ & 36 & 14 laptops on a cart \\
\hline T5-Mr. Currant & CTE - Game Design & $60^{\prime} \times 40^{\prime}$ & 24 & $\begin{array}{l}1: 1 \text { student computer } \\
\text { ratio }\end{array}$ \\
\hline T6-Ms. Hassa & $\begin{array}{l}\text { ESL - English as a } \\
\text { Second Language }\end{array}$ & $12^{\prime} \times 40^{\prime}$ & 10 & 3 desktops \\
\hline T7-Ms. Sandy & Special Education & $40^{\prime} \times 40^{\prime}$ & 6 & 3 desktops \\
\hline T8- Ms. Balto & $\begin{array}{l}\text { World Languages - } \\
\text { Spanish }\end{array}$ & $40 ’ x 40$ & 36 & 14 laptops on a cart \\
\hline A1 -Ms. Pope & $\begin{array}{l}\text { Architect for Wave } \\
\text { County Schools }\end{array}$ & N/A & N/A & N/A \\
\hline P1- Dr. Hed & $\begin{array}{l}\text { Principal of } \\
\text { Catamount High }\end{array}$ & N/A & N/A & N/A \\
\hline
\end{tabular}

\section{Adult Participants}

The teacher participants were six females and two males between the ages of 24 and 60. One teacher was in his first year of service, while the majority had been teachers over ten years. Three of the teacher participants were previous engineers who had come over from industry. There were two African Americans, one Hispanic and five Caucasian teachers. The principal and the architect were both Caucasian females in their late fifties who were born in the general location of the high school. 


\section{A1. Architect for Wave County Schools and the Catamount Campus - Ms.}

Pope - Ms. Pope is a Caucasian female architect in her late fifties. For the last 20 years, she has worked for a local architecture firm that specializes in school buildings. She helped design the 2006 Catamount Campus, which was built according to the Knight high school prototype from 2004. Even in 2020, she is still actively designing schools for Wave county, including a new high school that opened five miles down the road from Catamount High. Both of Ms. Pope's daughters attend Wave County high schools.

P1. Principal for Catamount High School from 2014-2019 - Dr. Hed - Dr. Hed is a Caucasian female principal in her early sixties. She earned her $\mathrm{PhD}$ and has worked as a teacher and administrator for the last 40 years. She is a strong leader and trusts in her abilities to guide students and others in the district through innovation and growing pains. Dr. Hed was the principal of Catamount High School from the fall of 2014 through the spring of 2019, when she moved over to a sister high school located one mile down the road from Catamount High. Dr. Hed earned the title of Principal of the Year in 2018.

T1. Teacher 1 - Mr. Bunsen - Mr. Bunsen is a Caucasian male chorus teacher in his mid-forties who has taught at Catamount High school since its opening in 2006. He is dynamic and a leader in both the county and the state. Mr. Bunsen is well liked by his students and experiments with technology, new content, and multiple room configurations to encourage student learning.

T2. Teacher 2 - Ms. White - Ms. White is a Caucasian female English teacher in her mid-forties. She teaches English to freshmen and sophomores and leads an awardwinning yearbook staff. She encourages freedom for her advanced learners and more discipline for her academic level classes. 
T3. Teacher 3 - Ms. Bold - Ms. Bold is an African American female math teacher in her late fifties. She comes from industry where she worked as an engineer. She now teaches AP calculus and one remedial-level math class. According to student and faculty, she teaches the most difficult math content in the building. Ms. Bold is also a pastor, preacher, missionary, and author.

T4. Teacher 4 - Ms. Crouven - Ms. Crouven is a Caucasian female science teacher in her early sixties. She had worked in industry as an engineer and transitioned to teaching as a second career. She teaches AP physics and AP environmental science. Her science classes are considered by students and staff as some of the most challenging in the building. She was previously the advisor for the National Honor Society.

T5. Teacher 5 - Mr. Current - Mr. Current is a Caucasian male teacher in his twenties. He teaches technology and leads the Technology Student Association. In the spring of 2018, Mr. Current was a first-year teacher. He is quiet, artistic, and well-liked by students and staff.

T6. Teacher 6 - Ms. Hassa - Ms. Hassa is an Egyptian female teacher in her midforties who teaches both math and English as a Second Language. Ms. Hassa's math classes are large with over 30 students, but the ESL classes are small, with around 10 students. Ms. Hassa mentors the Muslim Student Association and prides herself by wearing her hijab daily. She kindly allows Muslim students to pray in her classroom throughout the day.

T7. Teacher 7 - Ms. Sandy - Ms. Sandy is a Caucasian female teacher in her early sixties who has taught all over the country. She is the leader of the special education department and teaches students with autism spectrum disorder. She has one teacher 
assistant in her classroom. Ms. Sandy works with a local university in leading teaching innovation regarding autism in the classroom.

T8. Teacher 8 - Ms. Balto - Ms. Balto is a Hispanic female Spanish teacher in her early sixties. She is a native of South America and has over 30 years of teaching experience. She is one of six Spanish teachers at Catamount High School and has been assigned to teach freshmen classes.

\section{Students}

S1. Student 1 - Zaha - In the spring of 2018, Zaha was a freshman female Arab student. She is a devout Muslim and wears a hijab. She is very artistic, athletic, social, and takes her studies very seriously. Zaha participates in fall cross country and spring track. Her goal is to become a doctor. By the spring of 2020, Zaha was a junior at Catamount High School.

S2. Student 2 - Priya - In the spring of 2018, Priya was a female Indian American student at Catamount High School. She was an active member of the National Honor Society and Chorus. She was enrolled in multiple advanced placement classes and had a goal to attend an Ivy league school to study medicine. By the spring of 2020, Priya was completing her first year at a prestigious local university studying pre-medicine.

S3. Student 3 - Neesha - In the spring of 2018, Neesha was a junior Indian American female student at Catamount High School. She was very involved in the National Honor Society and student government. By the spring of 2020, Neesha was completing her first year at a local state university studying computer science.

S4. Student 4 - Tya - Tya was a senior at Catamount High in the spring of 2018. She was a female student with family roots in Thailand. Tya was very creative and 
involved in Photography Club and the National Honor Society. Her goal was to study medicine at a local university. By the spring of 2020, Tya was completing her sophomore year at a prestigious local university studying biology/pre-med with a minor in Spanish.

S5. Student 5 - McKenzie - In the spring of 2018, McKenzie was a freshman Caucasian student at Catamount High. She was very focused on her studies and on her commitment to year-round competitive swimming with RSA. She would swim every morning at 5 a.m. In the spring of 2020, McKenzie was a junior at Catamount High School and very involved in athletics and academics.

S6. Student 6 - Adi - In the spring of 2018, Adi was a junior Indian American male at Catamount High. He was very focused on his studies and loved the Technology Student Association and their competitions. By the spring of 2020, Adi was finishing his first year studying computer science at a local state university.

S7. Student 7 - Mike - In the spring of 2018, Mike was a junior Chinese American male enrolled at Catamount High as a junior. He took multiple AP courses and planned for a major in computer science. His parents were warm and encouraging of his interests and social time with friends. In the spring of 2020, Mike was completing his freshman year at a local state university.

S8. Student 8 - Uma - In the spring of 2018, Uma was a female sophomore of Pakistani descent. She was soft-spoken and lived with her family of four in a small apartment near school. She traveled back to Pakistan to visit her grandmother every summer. In the spring of 2020, Uma was a senior at Catamount High with plans to attend a local technical community college. 


\section{Physical Classroom Descriptions}

T1. Mr. Bunsen's Chorus Classroom: Mr. Bunsen's chorus classroom is on the first floor of the main brick classroom building, located directly off the main commons/cafeteria area, along a corridor referred to as the band corridor. The band room as well as the dance studios are located along the same wing. The chorus room measures approximately $100^{\prime} \mathrm{x} 40^{\prime}$. There are a few small niche spaces off of this main chorus space. There is access to the auditorium, as well as second story small classrooms. Mr. Bunsen's typical class size is approximately sixty choral students. Because these students have a range of voice capabilities, it is critical that Mr. Bunsen make use of various spatial affordances. Mr. Bunsen can arrange the chairs in large or small group configurations. He also has risers that he can set up for students to stand or sit that will allow sound to travel in different ways through the space. Mr. Bunsen also uses small niche offices as well as stairwells for small groups to be able to practice together.

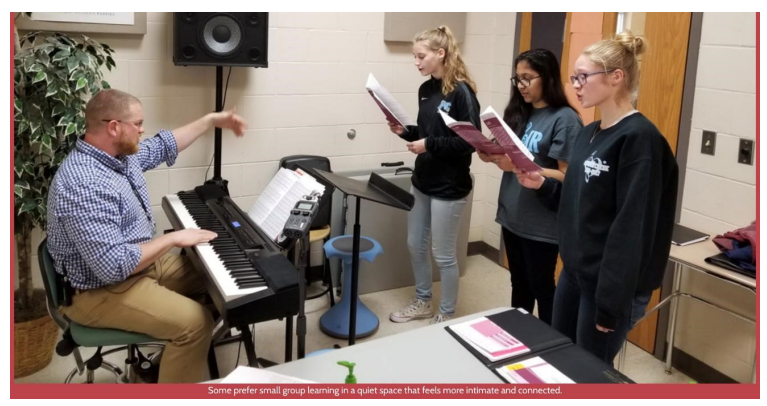

Figure 4.1: Mr. Bunsen and his chorus students

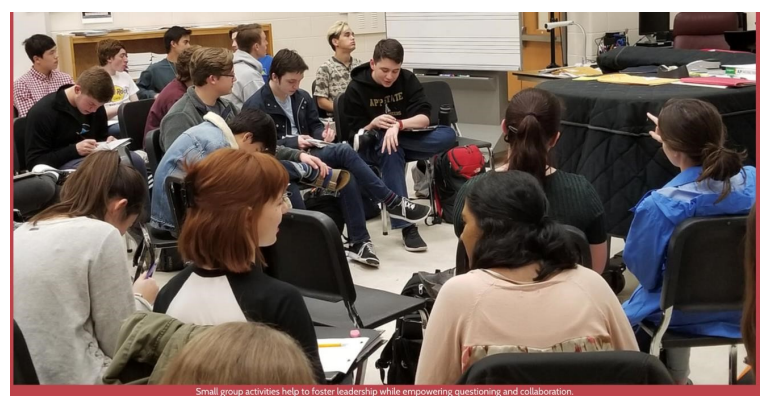

Figure 4.2: Group work in chorus 


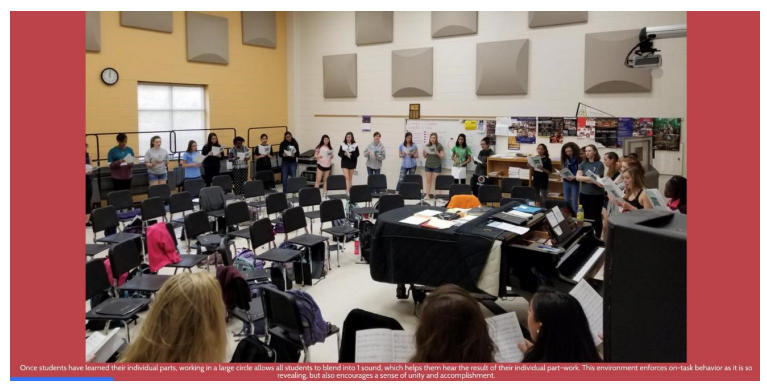

Figure 4.3: Chorus students singing from the classroom periphery

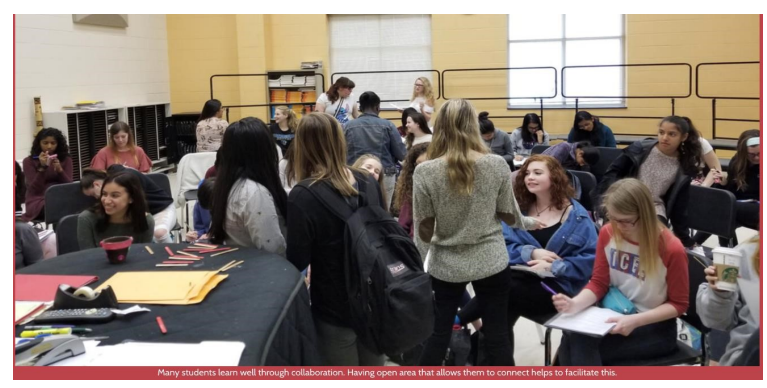

Figure 4.4: Collaborative learning in chorus

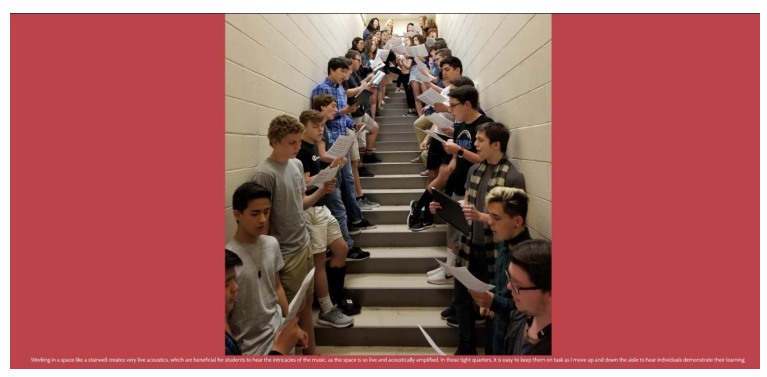

Figure 4.5: Chorus class using the acoustic affordances of a stairwell

T2. Ms. White's English Classroom: Ms. White's classroom is located on the top, third floor of the main brick classroom building, in the 3600 wing. The classroom measures approximately 40' x 40' and features one wall of half height windows. The desks and grey chairs are individual and lend to individual or clustered configurations. Ms. White teaches English 2 and yearbook. Ms.

White's desk is located in the front of the classroom near the whiteboard and large screen TV, where lessons are projected from her laptop. Students in yearbook work on 
creative layouts with laptops. English 2 classes use a variety of media, including books, notebooks and laptops. Ms. White moved her class often into the hallways collaborative spaces.

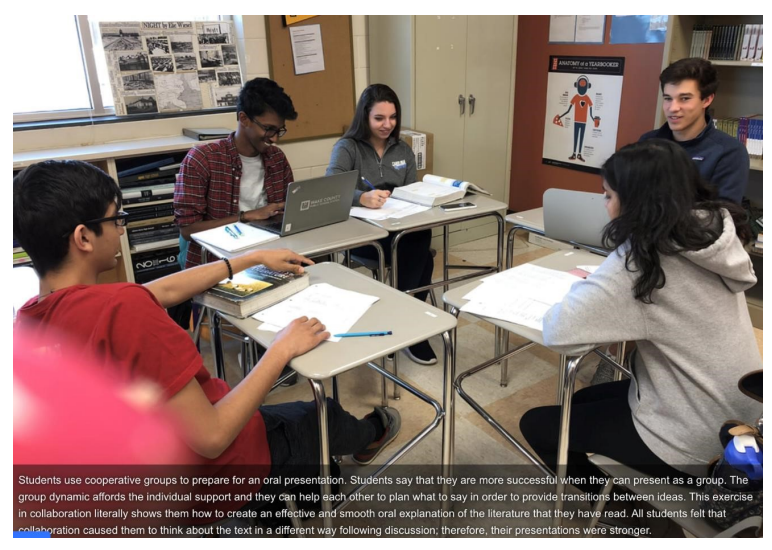

Figure 4.6: Students collaborate in Ms. White's English classroom

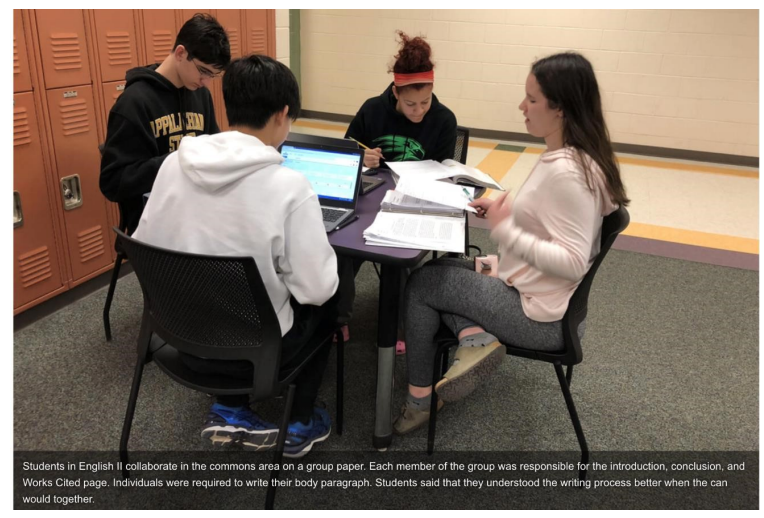

Figure 4.7: Students collaborate in the locker bay for Ms. White's English class

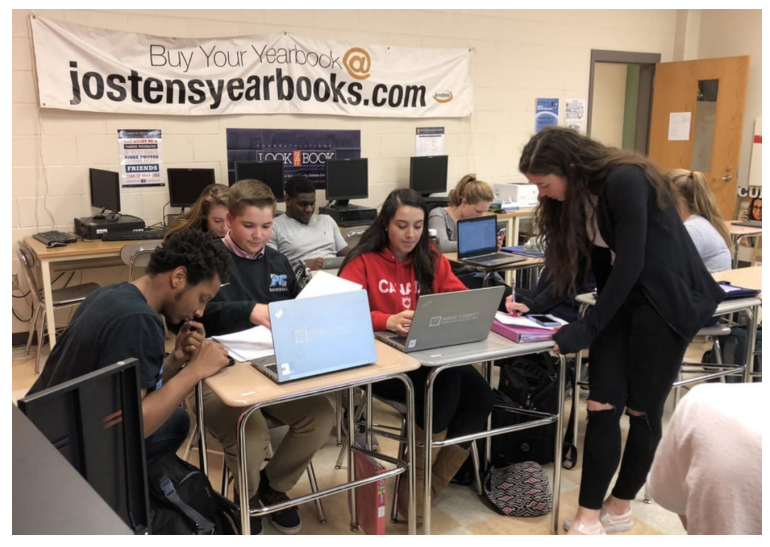

Figure 4.8: Students collaborate in Ms. White's yearbook class 
T3. Ms. Bold's Math Classroom: Ms. Bold teaches an academic level introduction to college math class as well as multiple AP Calculus courses. Her classroom is located on the third floor of the main brick building. Because the main building is symmetrical in plan, many of the classrooms on opposite sides of the building are identical. Ms. Bold's 3500 wing classroom is a mirror image of Ms. White's 3600 hallway classroom. The classroom measures approximately $40^{\prime} \times 40^{\prime}$ and features one wall of half height windows. The desks and grey chairs are individual and lend to individual or clustered configurations. Ms.

Bolde's desk is located in the front of the classroom by the white board. She writes out math problems on her computer or iPad, which is then projected up to the large screen tv. Students work with pencil and paper. Some days, Ms. Bold is able to get the math department supply of iPads to use for her class. These thirty iPads are shared by all fifteen math teachers. Ms. Bold also has an allotment of 14 laptops on a cart for her class. Only some students bring their own devices to use for her class.

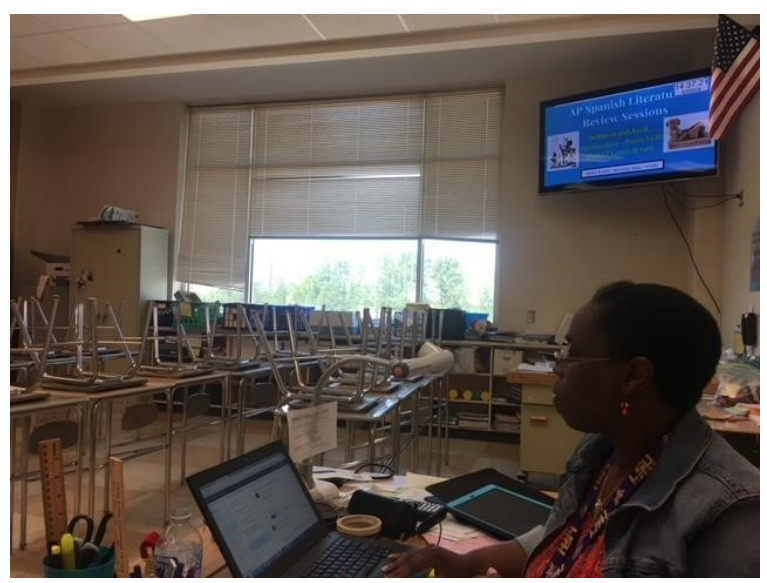

Figure 4.9: Ms. Bold working in her math classroom 


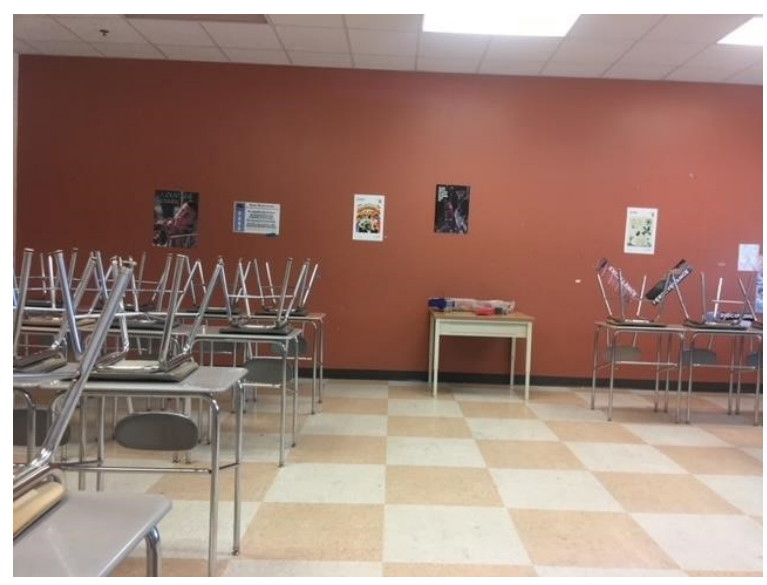

Figure 4.10: Ms. Bold's Math classroom

T4. Ms. Crouven's Science Lab: Ms. Crouven's classroom is located on the 2500, second floor wing of the main brick classroom building. Ms. Crouven teaches AP Physics and AP Environmental Science. In the front of the $60^{\prime} \mathrm{x} 40^{\prime}$ classroom is a large white board, the teacher desk and large lab desk. The periphery of the room is clad in black science lab counters. The room features 3'x 4' science lab tables that have a black top and a wood base. During 2018, Ms. Crouven had these tables configured in clusters of two. In 2019, Ms. Crouven had arranged the tables to be in single rows and columns.

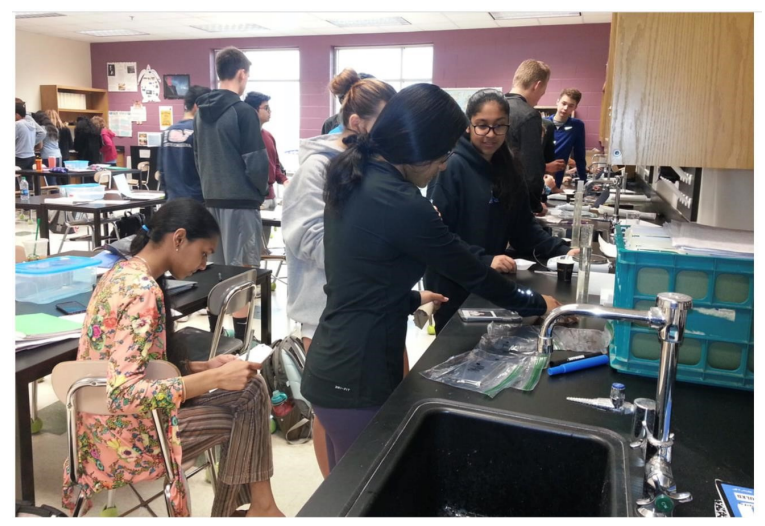

Figure 4.11: Ms. Crouven's AP Physics Lab 


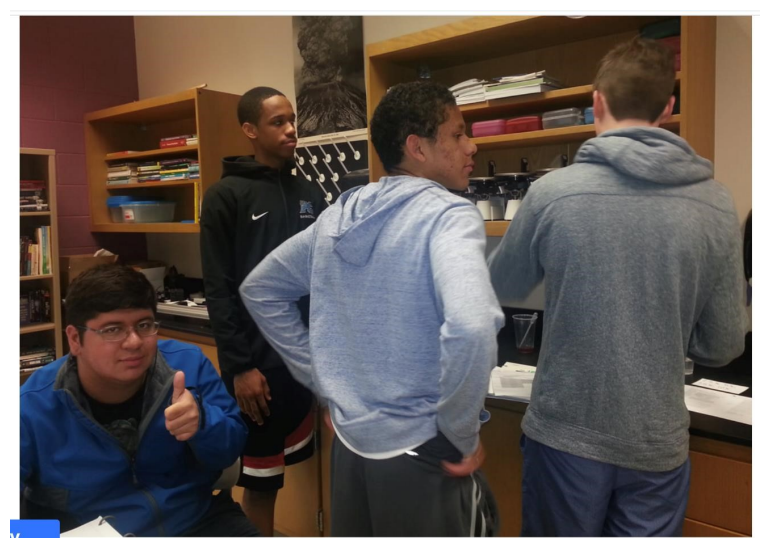

Figure 4.12: Ms. Crouven's AP Physics Lab

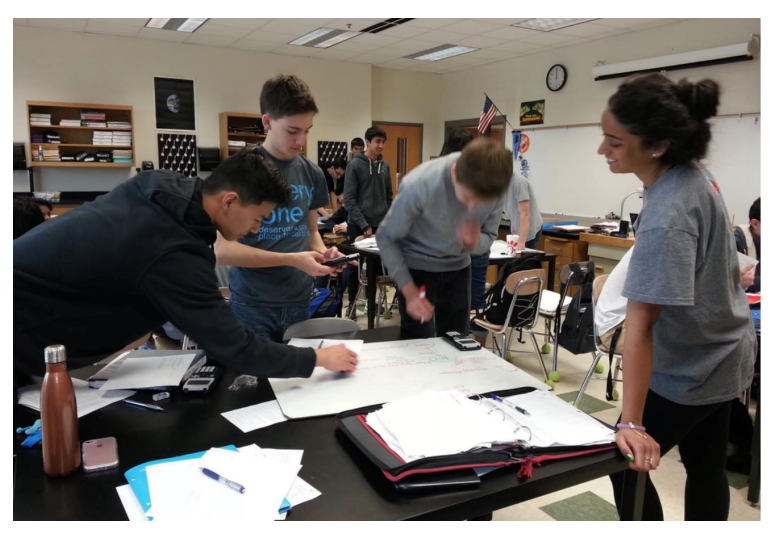

Figure 4.13: Ms. Crouven's AP Physics Lab

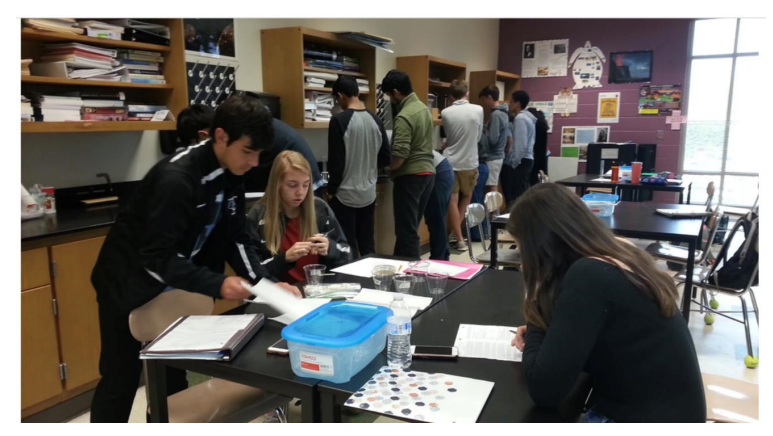

Figure 4.14: Ms. Crouven's AP Physics Lab

T5. Mr. Currant's Computer Lab: Mr. Curran's computer lab is located on the first floor, in the 1500 wing of the main brick classroom building. He has double computer monitors at each student workspace. The classroom is large and measures approximately 
$60^{\prime} \mathrm{x} 40^{\prime}$. The computers are laid out around the periphery, while the center of the space is left open for tables where students can collaborate. Students are able to get up from their computers, work in teams at the tables, and then return to their computers. Students have the opportunity to work ion shared files in google drive, even if they are not physically able to sit near one another within the classroom space.

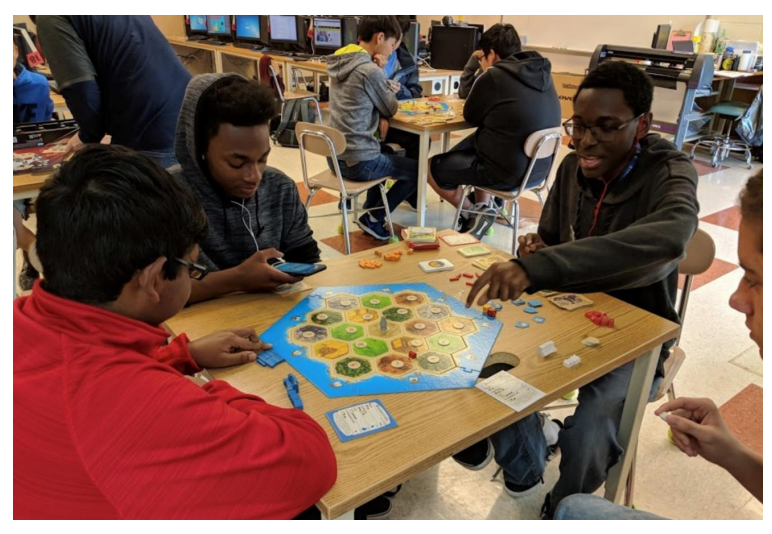

Figure 4.15: Mr. Curran's game design classroom

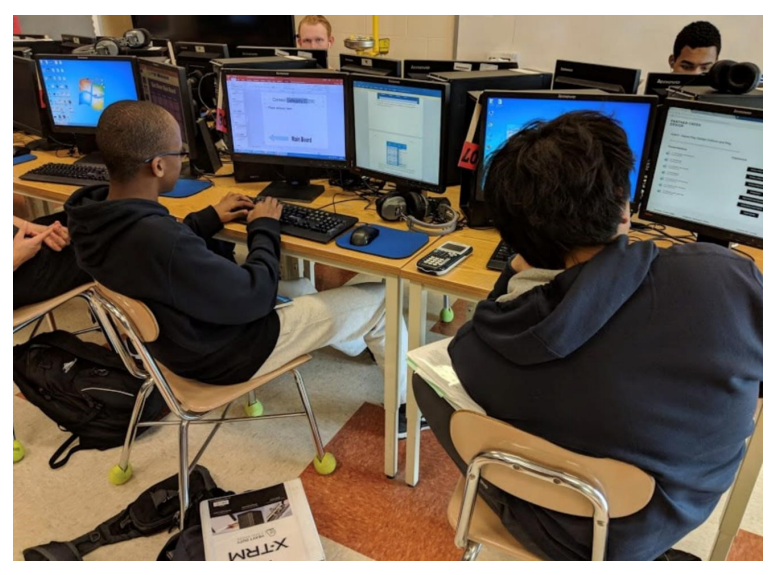

Figure 4.16: Mr. Curran's game design classroom

T6. Ms. Hassa's ESL and Math Classrooms: Ms. Hassa is one of the only faculty that has the unusual opportunity to teach within two departments. Ms. Hassa is the only English a second language teacher. Her two ESL classes meet in a small classroom on the third floor that measures approximately $12 \times 20^{\prime}$. There is room for the teacher desk as well 
as desks for approximately ten students. There is one narrow window at the far end of the long room, and Ms. Hassa often keeps the lighting low. Ms. Hassa also teaches math 3. For this class, she travels to one of the other math third floor classrooms that are larger, and measure $40^{\prime} \times 40$ ', with a wall of windows and individual student desks that may be configured as needed.

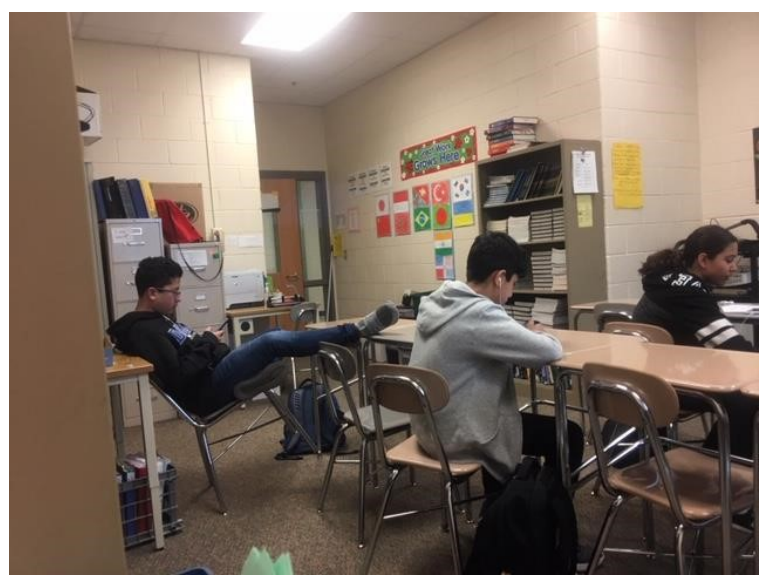

Figure 4.17: Ms. Hassa's ESL classroom

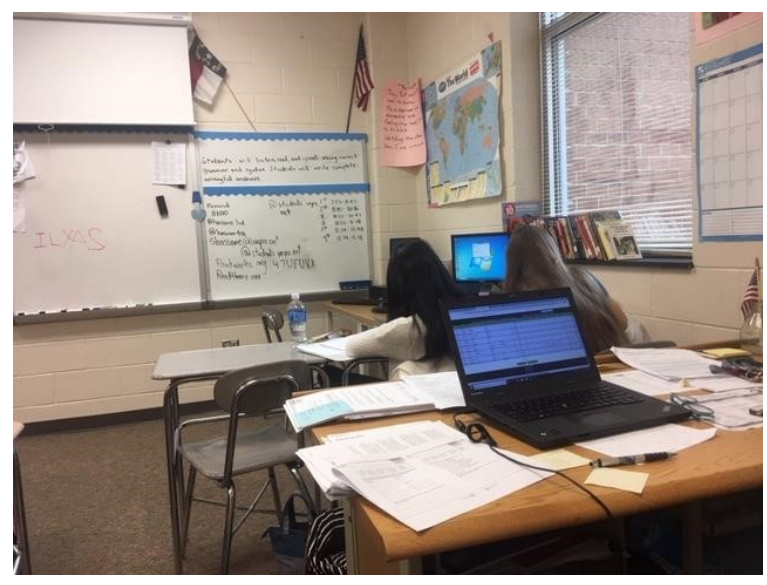

Figure 4.18: Ms. Hassa's ESL classroom

T7. Ms. Sandy's Special Education Classroom: Ms. Sandy teaches special education for high functioning autistic children. Her classroom is located on the third floor of the main classroom building. The classroom measures approximately $40^{\prime} \times 40^{\prime}$ 
and has a large bank of windows on the far side. There is a movable partition located in the classroom, so that the large space may be divided into two spaces as needed. There are two teacher desks in the room, measuring 3' x 6' each. Ms. Sands has approximately ten individual student desks in her room, that are configured in singles or groups as needed. She has multiple incandescent lamps, carpets and comfortable seating in the corner of the room, so that students may relax as needed. Many autistic students in her class seek the room as a refuge from other classrooms that are overwhelming for their level of sensory stimulation. Posters on the wall provide guidance to students regarding emotional and sensory regulation.

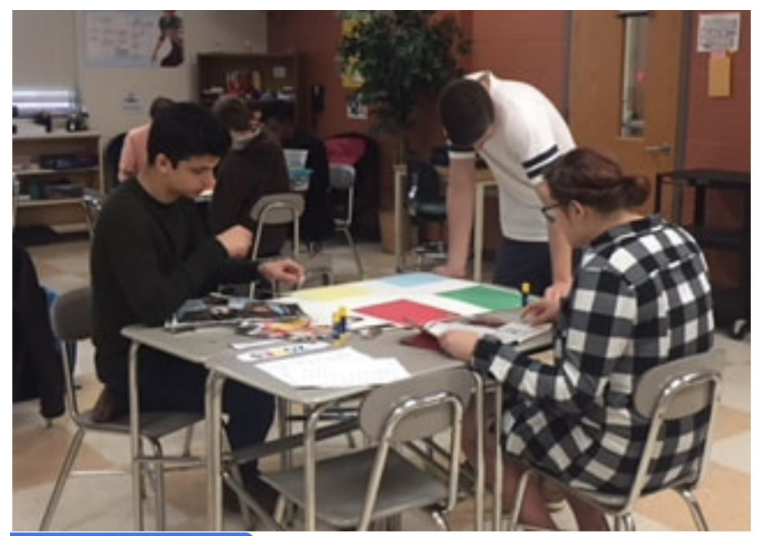

Figure 4.19: Ms. Sandy's Special Education Classroom

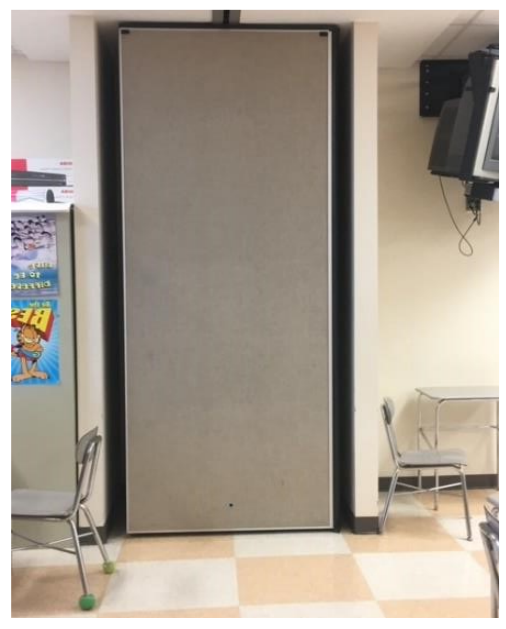

Figure 4.20: Ms. Sandy's Special Education Classroom 


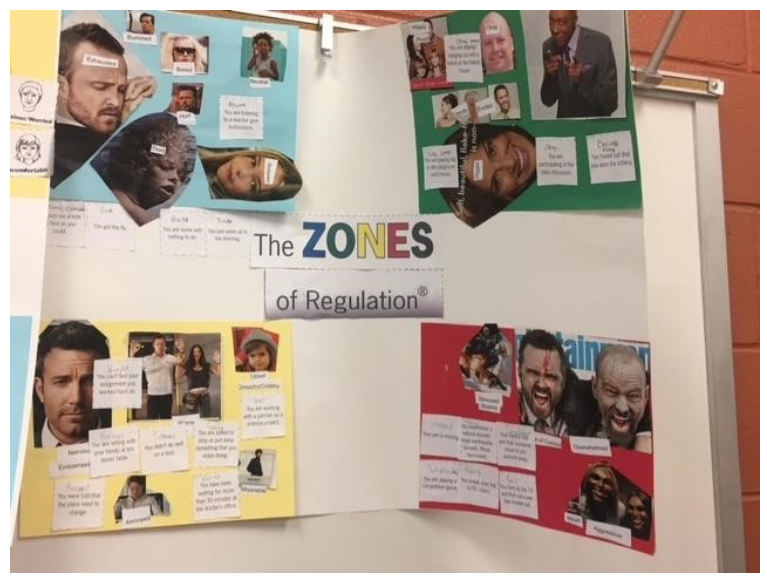

Figure 4.21: Ms. Sandy’s Special Education Classroom

T8. Ms. Balto's Spanish Classroom: Ms. Balto teaches freshman Spanish classes. Her classroom, which measures $40^{\prime} \times$ x $40^{\prime}$ is located on the first floor of the main classroom building. There is one teacher desk and forty individual student desks in the classroom. The desks can be configured in groups or rows and columns. Speaking and listening is a critical component of Ms. Balto’s class. Because of this, Ms. Balto moved her class at times to larger spaces such as the hallway or the commons, to allow students to speak in Spanish and listen as needed.

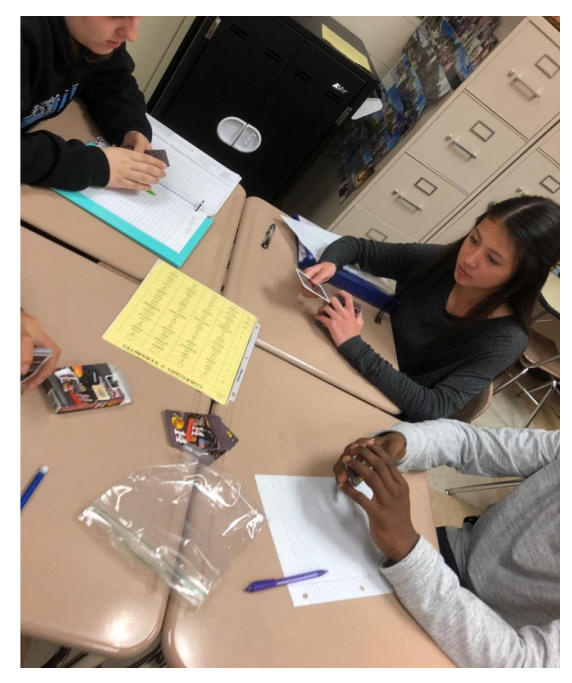

Figure 4.22: Ms. Balto’s classroom 


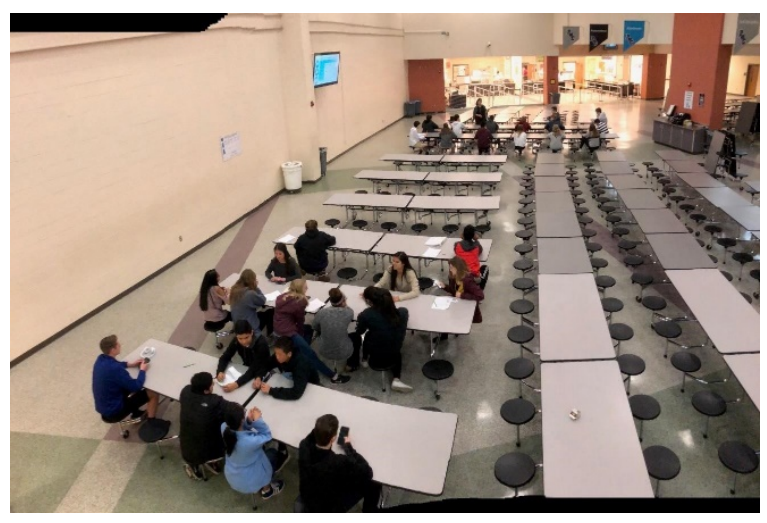

Figure 4.23: Ms. Balto's Spanish class uses the commons

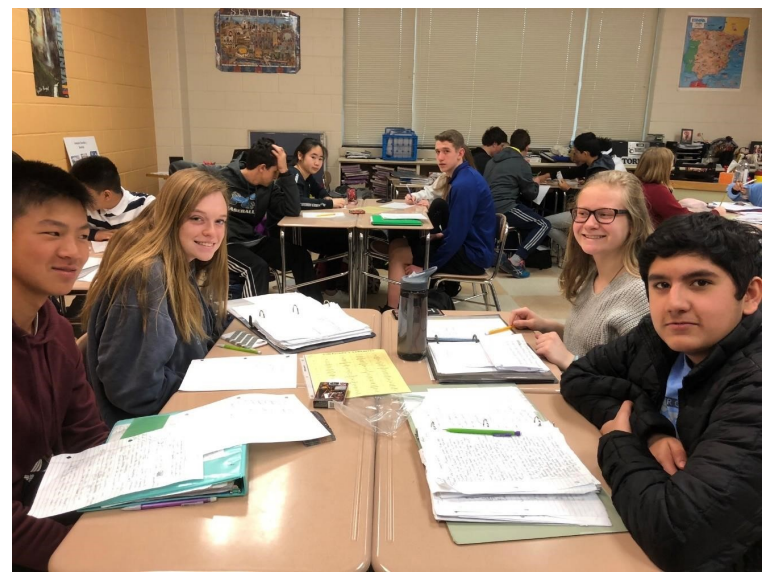

Figure 4.24: Ms. Balto’s Spanish class collaborate

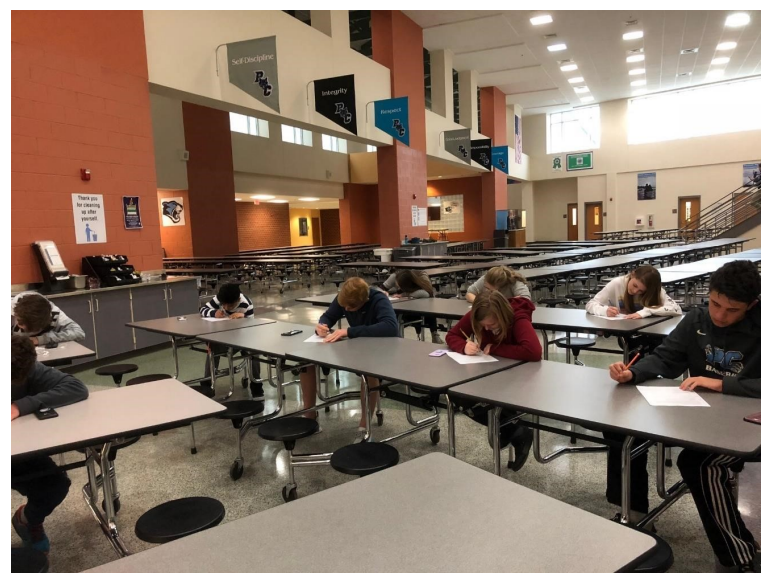

Figure 4.25: Ms. Balto's Spanish class uses the commons for sound assessments 


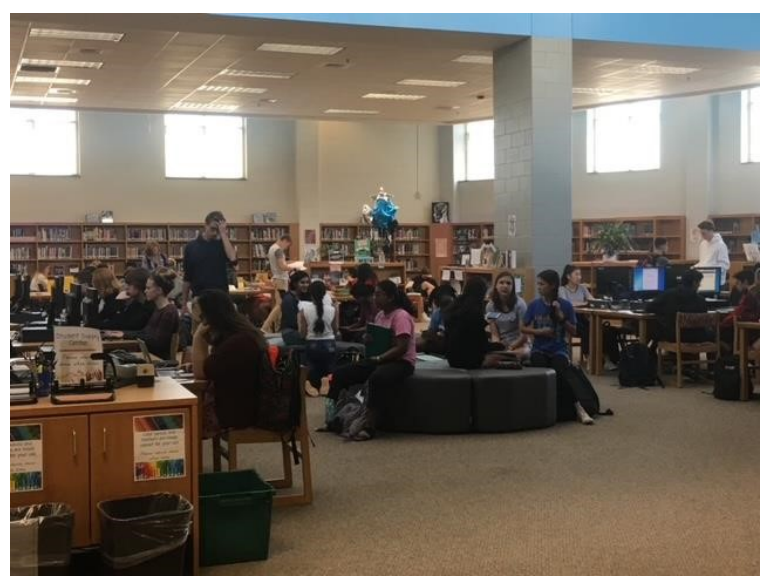

Figure 4.26: Ms. Balto's Spanish class uses the media center

\section{Table 3}

\section{Coding Matrix}

\begin{tabular}{|c|c|c|c|c|}
\hline \multicolumn{5}{|c|}{ Findings Summary } \\
\hline RQ1 & Spatial Preference & Theme & First Order Categories & Codes \\
\hline & & Gathering and Isolation & gathering & face to face collaboration \\
\hline & & & & collaboration via technology \\
\hline & & & & self-selecting teams vs. forced teams \\
\hline & & & isolation & classroom isolation for assessment \\
\hline & & & & home isolation to focus \\
\hline & & & & alone amid a crowd and on task \\
\hline & & Comfort & & sound \\
\hline & & & & lighting \\
\hline & & & & temperature \\
\hline & & & & work surface \\
\hline & & & & ergonomic seating \\
\hline & & & & sustenance \\
\hline & & replication and evolution & county level & replication saves money \\
\hline & & & & replication does not equal similar success \\
\hline & & & & replication saves on time between design and construction \\
\hline & & & school level & population growth necessitates modular additions \\
\hline & & & & population growth necessitates classroom overflow spaces \\
\hline & & & & population growth necessitates modular additions \\
\hline & & & classroom teacher level & classroom configuations change with multiple teachers in the same room \\
\hline & & & & classroom configuations change based on course content \\
\hline & & & & classroom configurations change based on student cohort \\
\hline & & & student level & students spatial choices change per semester due to course changes \\
\hline & & & & students spatial choices change per friend habits \\
\hline RQ2 & Self-Regulated Learning & spaces to thrive & & pomodoros and variation in sound choices to promote higher cognition \\
\hline & & & & use of classroom spaces to promote retention eg. whiteboard cmap \\
\hline & & SLR seek PLE (self-regulated learners seek & & proximity to parents; purposeful panopticon to increase motivation \\
\hline & & personalized learning environments) & & adjusting spatial choices based on content; eg. relaxed reading in comfortable seating \\
\hline RQ3 & Technology Use & technology as a learning conduit and inhibitor & conduit & content management systems allow students continual access to course content \\
\hline & & & & students can collaborate with classmates inside and outside of the school building \\
\hline & & & & technology allows for multiple modes of information presentation \\
\hline & & & inhibitor & phone access slows down their progress; limiting phone time \\
\hline & & & & using different devices for different functions eg. phone vs laptop \\
\hline & & & & tech does not replace face to face collaboration and spontaneity \\
\hline
\end{tabular}




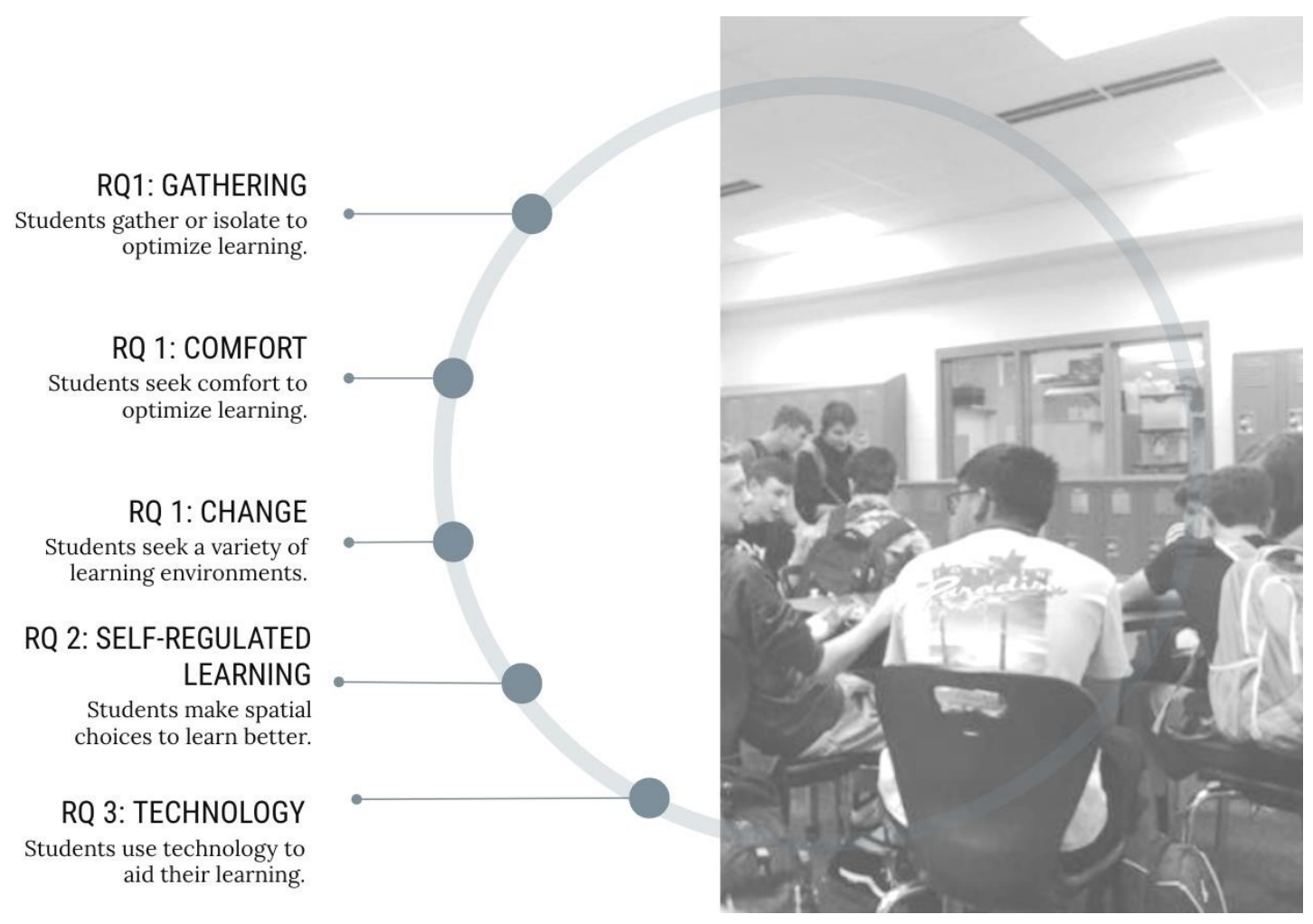

Figure 4.27: Themes

The focus of this chapter is the elaboration of themes that surfaced from the data based on three research questions. The first research question relevant to spatial preference yielded three themes of (1) gathering space versus solitary space, (2) spaces for comfort, and (3) replication and evolution. The second research question pertaining to perceptions of self-regulated learning and spatial preference yielded the theme (4) spaces to thrive. The third research question relevant to technology use and spatial preference led to the theme (5) technologically splintered spaces. The research data collection began in March 2018 and concluded in February 2019. 


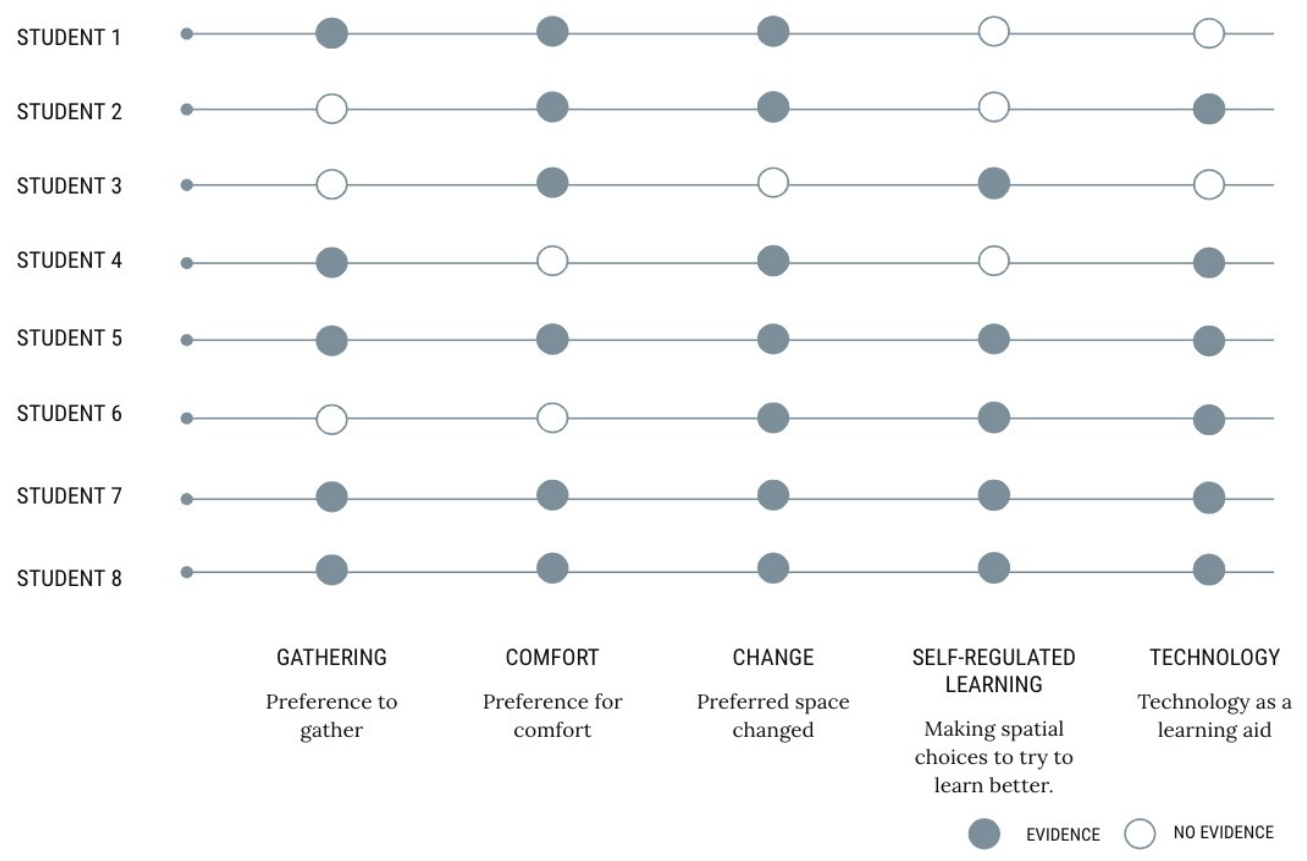

Figure 4.28: Table of Data - Students

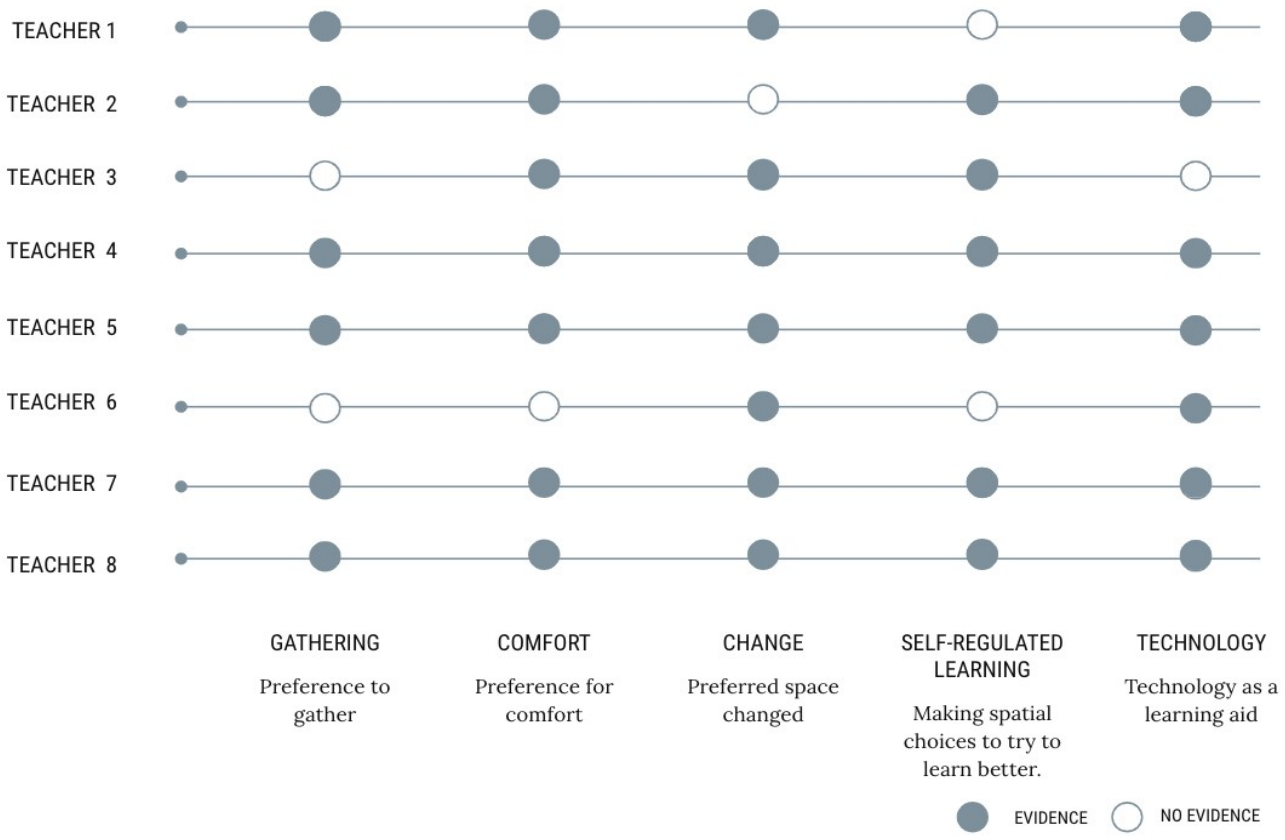

Figure 4.29: Table of Data - Teachers' Perceptions 


\section{Theme 1: Gathering vs. Isolation}

Whether subjects are in formal or informal learning environments, the activity of learning involves a dance between collaborative and independent endeavors. The theme "gathering spaces versus solitary spaces" surfaced from the data. Examples of this theme are elaborated below. Gathering may be described as an assembly or meeting, which is in contrast to solitary learning. The theme of collaboration and isolation fluctuates across formal and informal environments. Collaboration requires space to move, gather, and talk.

\section{Gathering in School}

\section{Gathering for Collaboration}

Examples of collaboration, both required and self-solicited, surfaced through the data in the observations, interviews, cognitive maps, and photovoice journals. Students sought to gather both at school and outside of school. In the formal school environments, students often worked together in collaborative teams. Sometimes the teams would be student-selected, while at other times, the teams would be teacher-selected. Students sometimes were forced to work in teams. During opportunities for studying and review, some students sought peer groups to reinforce learning, while at times, the students sought solitary environments for review.

Most of the teachers at Catamount High required their students to learn in collaborative teams for a portion of their classroom instruction. It is one of the review criteria for teacher observation ratings, whereby the teacher receives higher ratings if they require their students to work in teams. Within the review materials, AP Physics teacher Ms. Crouven required collaboration in her classroom. Tya, one of the students in Ms. 
Crouven's class, wrote in her journal about the open-ended problem solving required of the teams: "Labs are used to establish independence...The teacher gives you a packet of information, the lab instructions, and expects you (as a group) to carry out the experiment independently without much instruction."
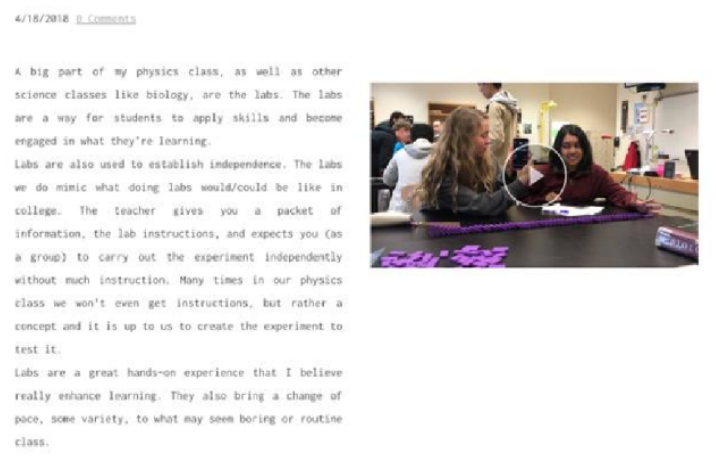

Figure 4.30: Collaboration in class according to Tya

\section{Population as an Inhibitor to Gathering}

In overcrowded classrooms full of rows of desks, there is no place to gather. This overcrowded situation has been the norm at Catamount High School since its inception. Many classes of 36 to 38 students are packed in classrooms. The administration, trying to solve this situation, made a number of changes within the school as outlined below.

The building was completed in 2006, and with the starting class, the concept of SMART lunch was initiated because the entire population in the school had lunch at the exact same time but there were not enough spaces in the cafeteria to accommodate all students. To address this population issue, classrooms were opened to accommodate students during the lunch hour. The lunch hour was split in two, and departments were 
assigned lunch days. Students go to their department classrooms during the lunch hour to receive help with their assignments and eat lunch.

\section{Locker Bays to Collaborative Spaces}

A second example of spatial accommodations included removing the majority of lockers from six locker bays and replacing them with carpet, six tables, and 24 chairs. This allowed room for nearly one whole class, or part of a class, to spread out for collaboration and work. Within school environments, both collaboration and isolated learning are evidenced in classrooms, locker bays, commons, and the media center. Isolated learning has also happened as a group and was observed to be the result of independent student decisions, sometimes in the face of very noisy and active collaborative efforts.

\section{Collaboration via Technology}

Technology has liberated spaces in the fact that collaboration can happen in spite of physical distance. Students can collaborate using content management systems, Google Drive, etc. These affordances will be elaborated on further in the technology theme section. The affordances made possible by technology allow more freedom regarding spatial choices. For example, Mr. Currant, who has a computer lab with fixed tables, promoted collaboration in his classroom environment by offering students one set of open tables to brainstorm, whereby the students could work together and draw out a problem, and then move back to the desktop computers and continue digitizing the group idea, even if the teams were not in close proximity.

\section{Self-selecting Teams vs. Forced Teams}


Priya confirmed that the days when students take charge of the content in Ms. Crouven's class, use mobile white boards to outline content, and then have "gallery walks" to review the content are much more effective than the early morning lecture PowerPoint presentations provided by the instructor.

\section{Collaboration in Spite of Obstacles: Existing Room Configurations}

Often, once collaboration is put in motion, it continues in spite of environmental variation. Ms. Balto explained:

I have large classes of 36 . All freshmen. I share the classroom with another teacher, so the configuration is determined by the other teacher. I decorated the classroom. Students like working on collaborative language games, when they push all the desks aside and use the central space. They use the commons and media center for special presentations or projects.

An irony of collaboration is that the locations of some of the desktop computers were a hindrance to physical gathering and teamwork. One of the challenges to collaborative learning within the formal school environment was the fixed nature of some of the computer labs. The students enjoyed working together, but the placement of the cables for the desktops did not allow for easy teamwork in spite of the fact that the tables were placed near one another. Mike wrote about this collaboration in his photo journal: "This is the computer pod in my AP computer science classroom. This is one of my favorite learning locations at (Catamount High) because everyone in the pod can collaborate together while also working efficiently."

In 2018, Mr. Currant was a first-year technology teacher. In Mr. Currant's class, where he teaches Scientific Visualization and Game Design, there is a one-to-one ratio of 
students to computers. The classroom is extremely large and there are additional collaboration tables where students can flow between computer workstations and group meeting tables. The classes are capped at 24 students, so it is small compared to the English and math classrooms with 36 or more students. Once students break from tables and go back to computers, sometimes they shout between computers in order to communicate with their group members.

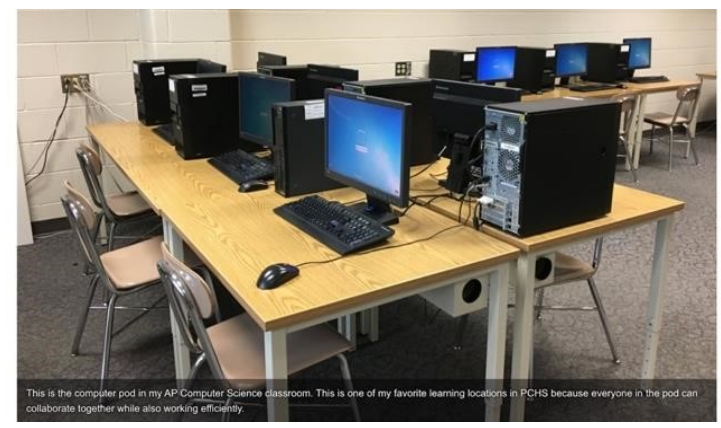

Figure 4.31: AP Computer Science table groups

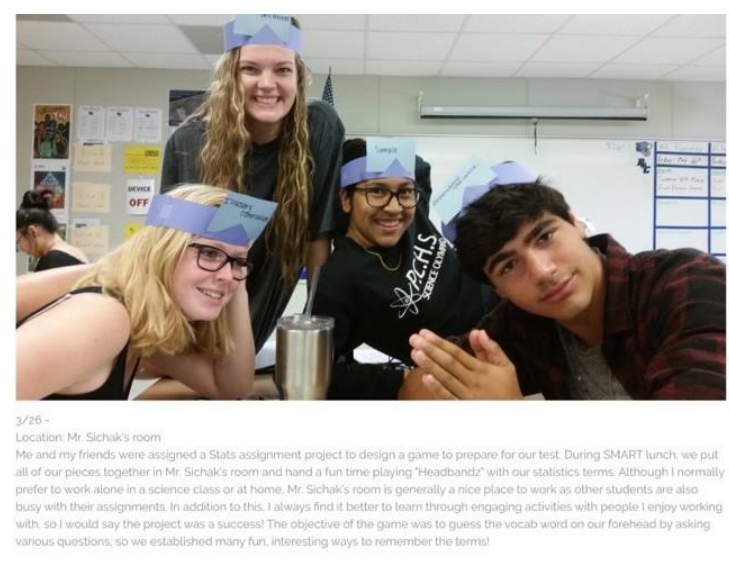

Figure 4.32: Priya and friends playing a collaborative review game in their classroom environment

\section{Collaboration with Friends}

Students at Catamount High collaborated in order to more effectively learn course content. "I always find it better to learn through engaging activities with people I enjoy 
working with...the object of the game was to guess the vocab word on our foreheads by asking various questions" (Priya). "This is a picture of my art classroom. I LOVE this class as I get to sit with my friends and express myself creatively. I love this classroom due to its constant activity" (Zaha).

\section{Collaboration Types and Course Content}

Teachers at Catamount High explained that the type of collaboration they fostered in their classrooms was related to the content. Mr. Bunsen, the chorus teacher, explained:

Students can break out into small groups and go through voice test assessments. I break students out in small groups and assign a student leader to lead each group. Students use a variety of spaces for the reason of testing sound and resonance in different spaces. Students like to break out into the small spaces.

Ms. Crouven, the AP physics teacher, explained that "the type of collaboration is linked to the content. With AP physics, there is problem solving. With AP Environmental Science there is more writing and theorizing."

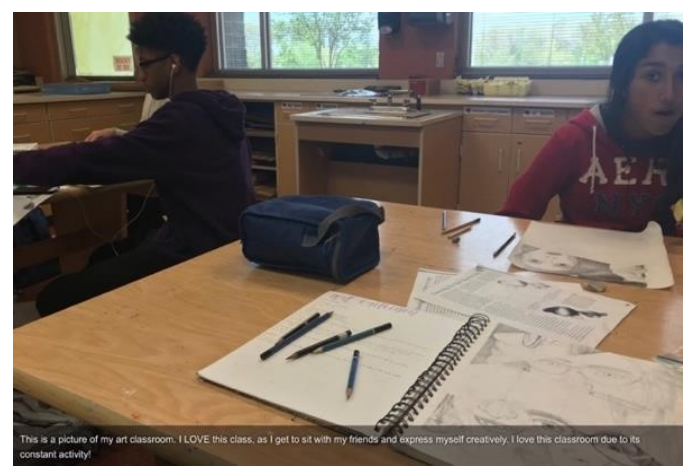

Figure 4.33: Collaboration in a Fine Arts according to Zaha

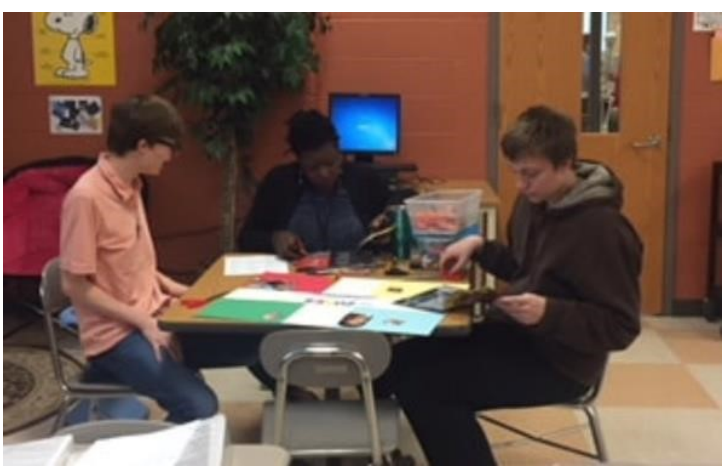

Figure 4.34: Students working class collaboratively in an autism classroom

\section{Who Gets to Collaborate?}


In speaking with the teachers at Catamount High, there was a discrepancy as to which students would benefit most from collaboration. Ms. Bold, who teaches both AP calculus and basic math classes, explained, "Low level kids need to get up, move and collaborate. High level kids can take lectures, rows of desks, etc. Low level kids need to move to stations and have time broken up for them." By contrast, Ms. White explained,

Low level kids need structure and direct instruction; high level kids can collaborate and move. I use both my classroom and locker bay spaces so that my 36 students have room to work and move, especially as relief from the compressed classroom. Spaces that are too large, like the commons (cafeteria) and media center are too distracting for students to handle.

\section{Collaboration Allows for Student-Led Instruction}

A student from Ms. Craven's class confirmed that the days when students take charge of the content and use mobile white boards to outline content and then have "gallery walks" to review the content are much more effective than the early morning lecture PowerPoint presentations provided by only the instructor. Student Neesha said,

"At school, I like lots of visuals, PowerPoints and notes on the board. I like the spaces by the locker bays, and I like to collaborate with other kids."

\section{Large Class vs. Small Class Dynamics}

Ms. Hassa taught a Math 3 class that was packed with 36 students, organized into nine groups of four. Students were busy and just wanted to get through content. Ms. Hassa was part of a math 3 PLT (professional learning team). There was a website for this math 3 PLT to ensure consistency between teachers. There was a lot of push back 
from students and parents to this teacher. The mode of instruction was largely lecture, and there was an expectation for students to follow along. There was frustration on the part of the teacher that students just wanted the right answer and did not want the challenge of working through a problem. Ms. Hassa's other two classes were English as a Second Language (ESL). These two classes were held in a different classroom that was smaller but spacious enough for only four students per class. Ms. Hassa described it as a more cordial class, and the students in the class wanted to be friends. Students needed headphones and laptops to listen to English.

\section{Gathering Outside of School}

\section{Gathering to be Near Parents}

"Sometimes I like to work in the kitchen while my mother is cooking or while my other family members are hanging out in the kitchen to keep me company while I work" (Priya). Priya also said,

Outside of school, I go to the dining room table and my room. I like the dining room because it is a larger area, and there are people around that I can socialize with. I like to go to the kitchen table because there is lots of room to spread out and get organized.

Many students reported working with siblings at home as a cohort.
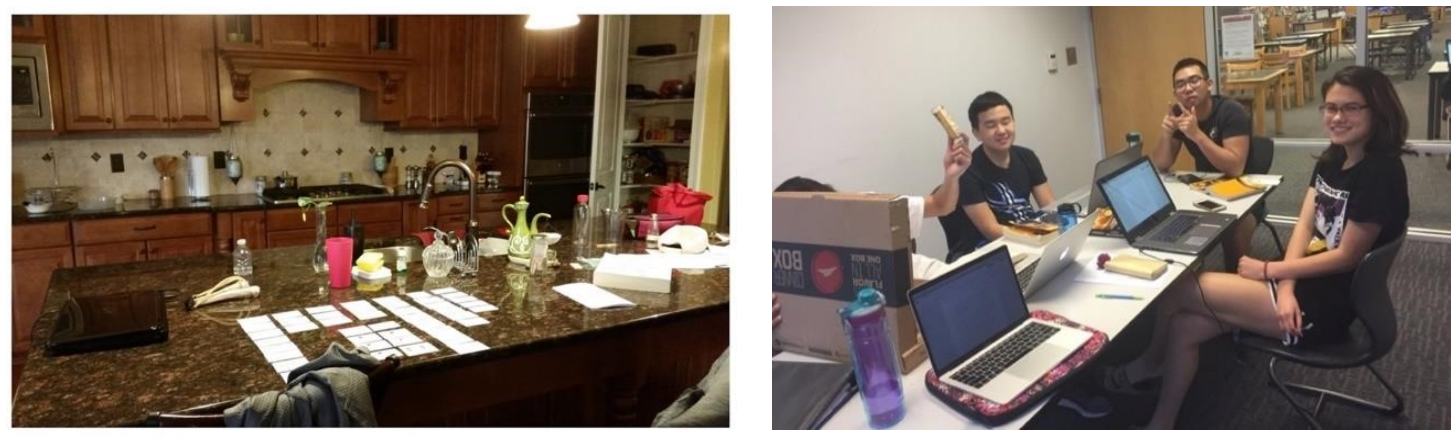
Figure 4.35: Studying in the kitchen at home to be by family members
Figure 4.36: Adi studying with friends at a local library

\section{Gathering to be Near Friends}

Outside of school, students sought collaboration in a variety of ways. Adi went with a group of peers to study for AP exams at one of the private reading rooms at the local library.

\section{Isolation in School}

\section{Classroom Isolation for Assessment Security}

Regarding isolation in the formal school environment, it is imperative for assessment security. One example from Ms. Balto, a Spanish teacher with overcrowded classrooms, explained that she needed to move students to a larger area so that her students had room to complete their audio language tests. "My students do voice recordings in the commons so that they have enough space to only hear their own voice and record into their own device. In the media center, each student uses one computer and Google doc."

\section{Self-Isolation}

During SMART lunch times, students have a choice of environments and activities. Some of the students who participated in the study sometimes selected to selfisolate so they could get more work finished. For example, McKenzie noted how she went to the library if she needed to focus: "I like to go to the library to better focus because I can't get distracted eating or talking to friends." 


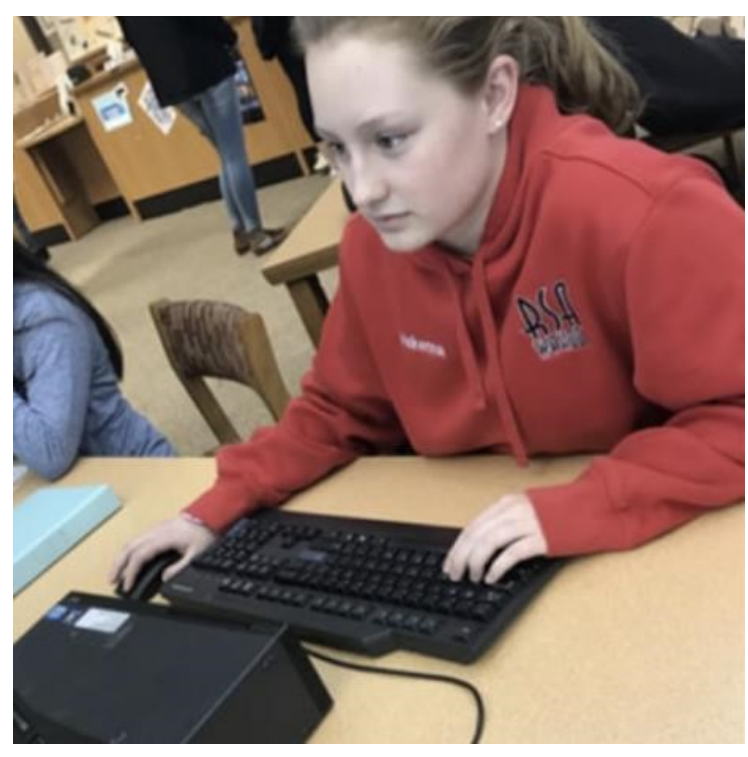

Figure 4.37: McKenzie studies in the

a library during lunch to stay focused

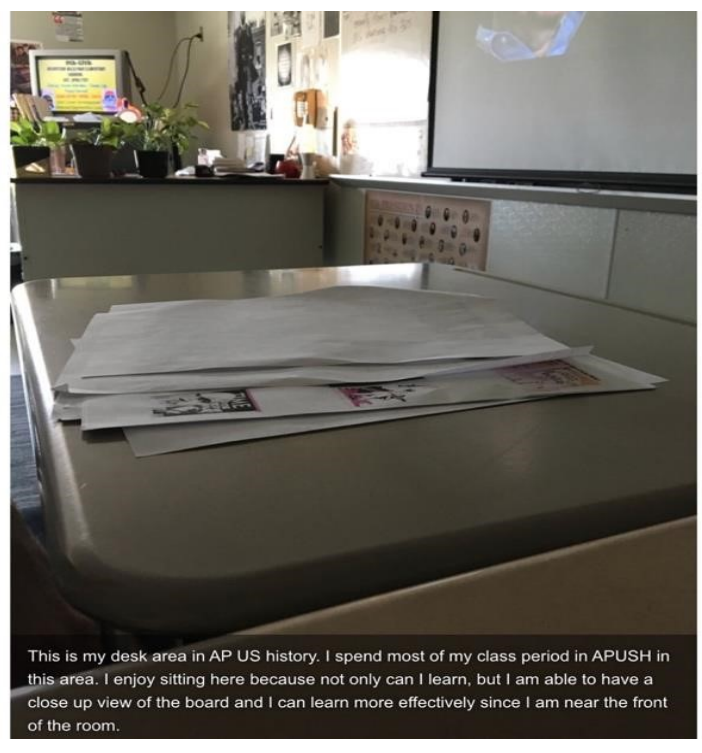

Figure 4.38: Student individual desks in classroom

By contrast, other students preferred to avoid common areas. For example, Adi explained, "At school, I do not like the library. I prefer to stay in my classes to study." Some of the students in the study had the amazing ability to focus on their own work in the middle of busy classrooms, hallways, and locker bays. In the locker bays, there was a blend of students, conversations, and activities. Some students had the ability to focus on their studies, while other students seated at the same table were having boisterous conversations.

\section{Isolation Outside of School}

Outside of school, students self-isolated for a variety of reasons. Most times, students indicated that they could focus more effectively if they were alone. "I go to my room if I have to stay up late and don't want to disturb others" (Priya). McKenzie 
indicated a preference to work alone immediately after school before other family members got home from school and work.

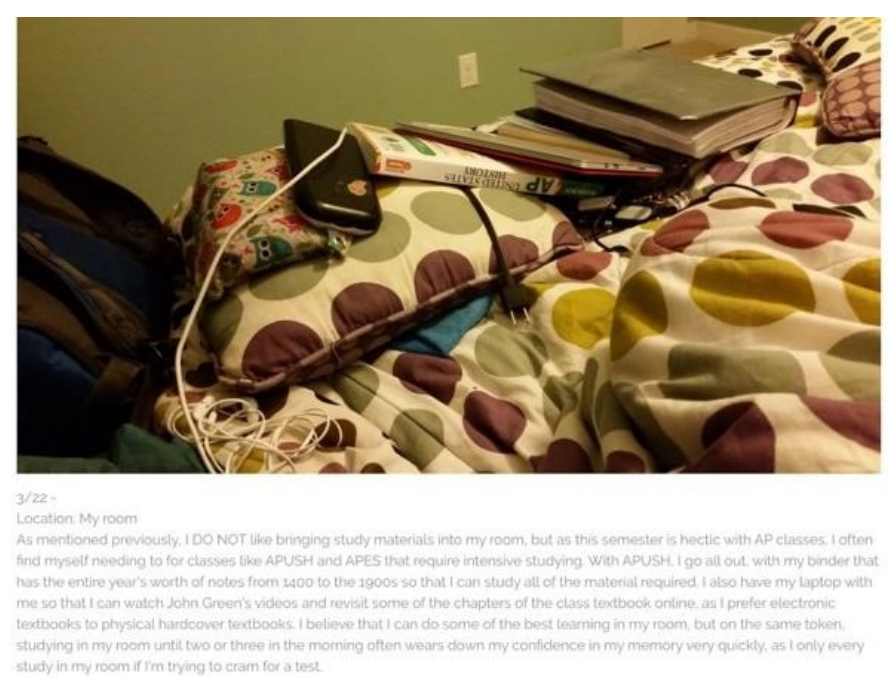

Figure 4.39: Priya working alone in her room at home

\section{Conclusion of Gathering and Isolation}

Students exhibited gathering and isolation both in formal and informal learning settings. Gathering in selective groups and purposeful isolation helped to regulate cognitions. Some students were able to self-isolate in a crowd. Gathering and isolation also was facilitated through technology. Technology is another theme that is elaborated on later in the text.

\section{Theme 2: Comfort}

Spaces for comfort relative to learning is related to place attachment. Sound, lighting, temperature, ergonomics, and sustenance were key factors contributing to student comfort in their formal and informal learning spaces. 


\section{Sound}

Sound in formal and informal learning environments is a theme that surfaced for students in this study. The types of sounds, music, and decibel levels were topics mentioned in the interviews and photovoice blogs especially. Students discussed ambient environmental sounds and music choices related to course content. Students sought a place with soft sounds and avoided complete silence.

\section{Sound in School}

Multiple students in the study discussed their preference for a gentle lull sound when at school. Pryia said,

I love (teacher's) room because of the general quiet in the room. Her room isn't overpoweringly loud like some of the math or social studies rooms and it isn't deathly silent like some of the English classrooms. The quiet mumbling background of other students is really nice.

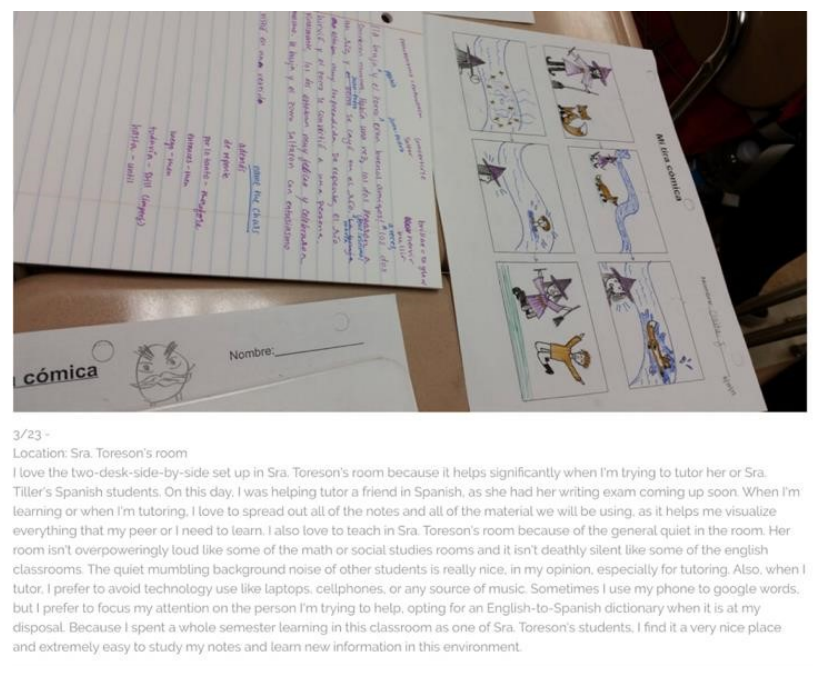

Figure 4.40: Ambient sounds in Spanish class, in between loud math and silent English classes 
Not silence, not raging sound; a moderate level. One student described the genre of music preferred based on the study content: "For math, I choose something upbeat. For English and writing, I choose something without lyrics.” A few students particularly sought classrooms with this moderate sound level; specifically, Spanish and Chorus rooms were cited.

\section{Sound Outside of School}

Students described the use of informal learning environments related to sound. Multiple students went to the public library due to manageable sound. At home, students controlled the sound levels by using earbuds or moving to quieter places within the home that would be more conducive to studying.

"Here is my work at my local library. I enjoy working here due to the open, quiet and well-lit seating areas located here" (Zaha).
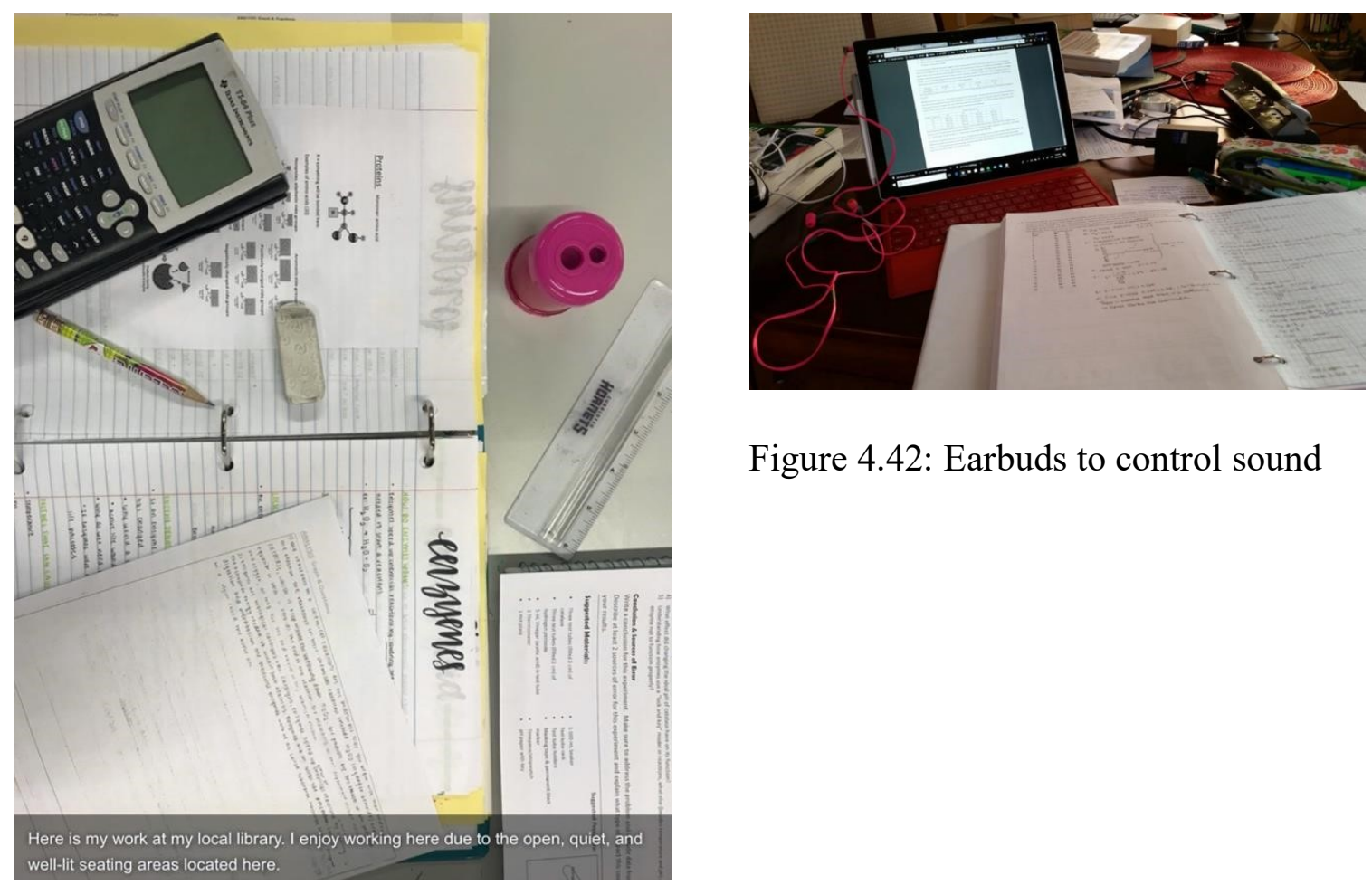

Figure 4.42: Earbuds to control sound

Figure 4.41: Zaha studying at the quiet local library 


\section{Lighting}

Students talked about views and access to natural light from their dining room tables. Also, in some of the students' favorite classrooms, the teacher had incandescent lighting around the classroom.

\section{Lighting in School}

As is true with most school environments, Catamount High has standard fluorescent fixtures paired with windows revealing natural light. Some teachers brought small incandescent lamps to place on their desk or in other areas of the classroom. A few classrooms featured little string lights suspended around the classroom. Students responded to these warm incandescent lights as a sign of comfort, calm, and home.

Ms. Hassa talked about how she uses light levels to control students' moods. In her math class, there is a whole wall of windows, but in the small ESL lab, there is only one small window. She explained, "Sometimes in ESL they just want the lights off, and I do that to comfort them."

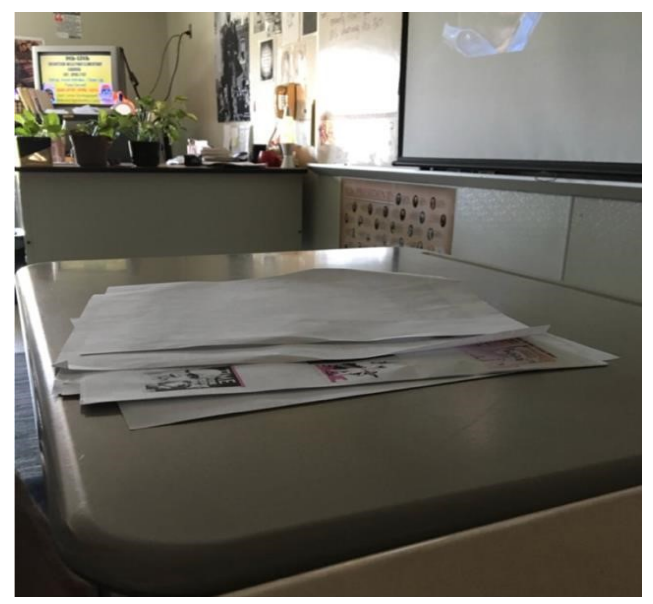

Figure 4.43: Classroom with fluorescent
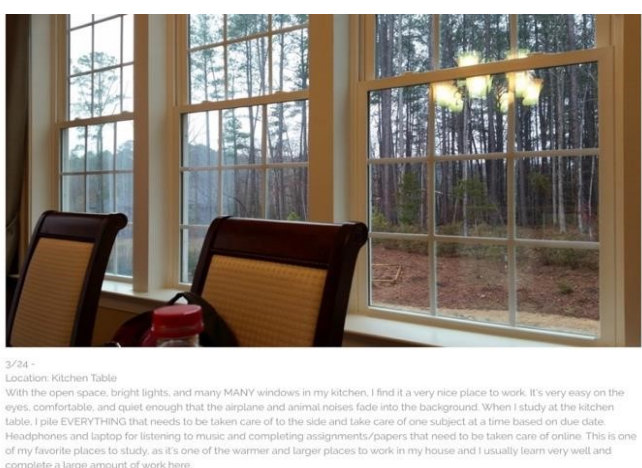

Figure 4.44: Residential preference for natural lighting

lights off, allowing for only natural and incandescent light 


\section{Lighting Outside of School}

Students involved in the study often gravitated to workspaces with natural lighting exposure.

With the open space, bright lights, and many windows in my kitchen, I find it a very nice place to work. This is one of my favorite places to study as it's one of the warmer and larger places to work in my house and I usually learn very well and complete a large amount of work here. (Priya)

\section{Temperature}

\section{Temperature in School}

At Catamount High, temperature is a discussion point. In the main building, all of the windows are fixed and there is often the complaint that the building is too cold. Staff and students wear jackets, especially in the warmer months due to the extreme air conditioning (AC). In the modular buildings, which consist of ten classrooms, each classroom has its own thermostat and $\mathrm{AC}$ unit. There is one window in each classroom that must be raised or lowered as needed. The modular classrooms have a severe range, from extreme cold to extreme heat as the seasons vary. Students and staff often wear coats in the winter and pull the one small window open in the hot months if the AC units are not working ideally. Ms. Hassa and Ms. Bold, who were located in the main building, bundled up in sweaters and coats all year long.

\section{Temperature Outside of School}

Priya's desk at home was located in the basement. She talked about abandoning her desk in the fall and winter and then coming back to it in the spring and summer. "My 
desk is one of the best places in the house, and when it isn't freezing, I can get a lot of work done" (Priya). Tia talked about studying while bundled up under her covers in her room all year long.

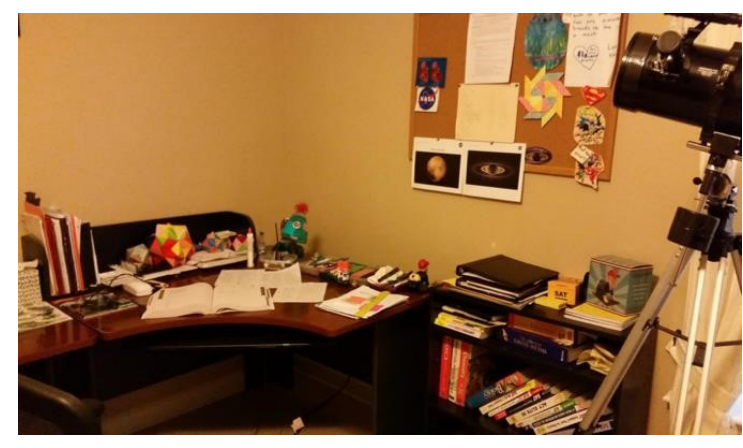

Figure 4.45: Student avoidance of personal spaces that are too cold
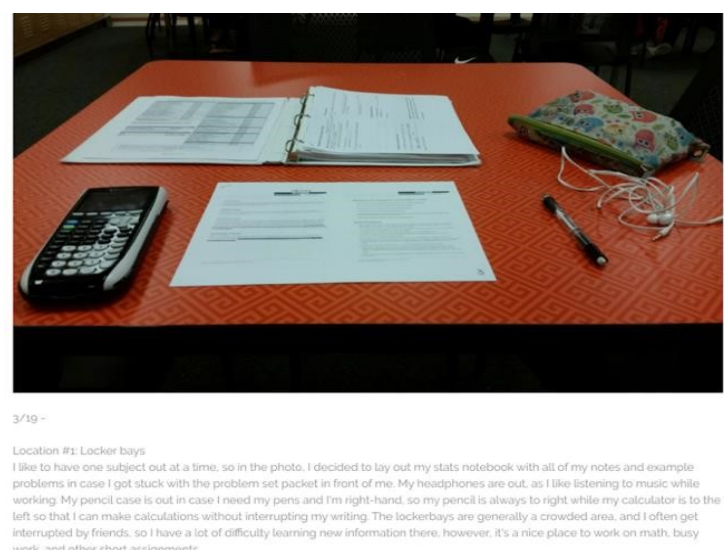

Figure 4.46: Work surfaces at school

\section{Ergonomics: Table Work Surface}

\section{Ergonomics Table Work Surface in School}

At school, students sought out desks in classrooms or large tables in open, collaborative areas. They wanted room to spread out and get organized. Students spread out their work on the large, flat laminate surfaces fastened to counter-height lockers to complete work while they stood.

\section{Ergonomics Table Work Surface Outside of School}

Multiple students sought out large table work surfaces at home. Most students reported working in the dining room. All students in the sample had both dining rooms and kitchens at home. Dining rooms were less frequently used by other members of the family. Two students reported working at the dining room table with their siblings.

"Typically, I study in my family dining room. I like this space because it is open and has a large table for me to work at" (Zaha). "I love to spread out all of the notes and all of the 
material we will be using, as it helps me visualize everything that I need to learn" (Priya). McKenzie says the following: In this picture, I am doing my homework at my kitchen table. This is where I do most of my homework after I come home from swim practice every day before the rest of my family gets home. I like to spread out and organize my papers before starting my homework every day. (McKenzie)

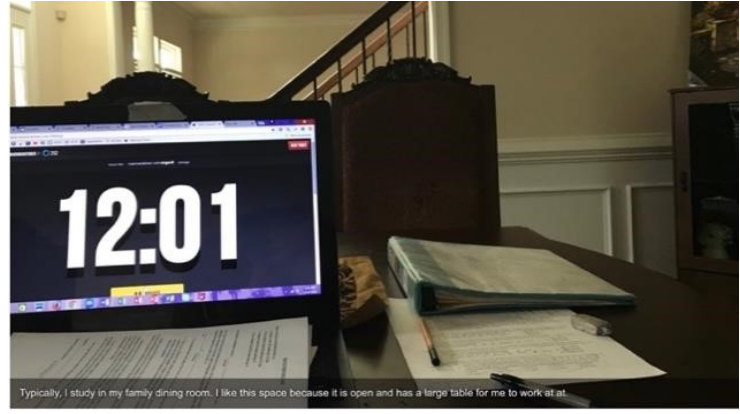

Figure 4.47: Work surfaces at home:

Zaha's workspace in her dining room

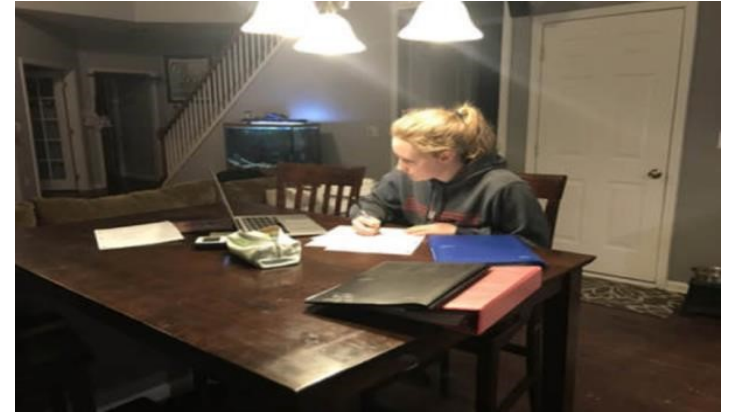

Figure 4.48: McKenzie working at her dining table

\section{Ergonomics: Comfortable Seating}

\section{Ergonomics: Comfortable Seating in School}

In the formal learning environments, students do not often get much choice regarding seating selection. The majority of classroom chairs are metal with no adjustment features. A few select classrooms may provide a handful of upholstered chairs, but it is certainly a rarity. The chorus room has padded metal chairs for purpose of sound absorption.

Although there aren't tables to spread out and many consider the room too noisy to get any actual work done, I find that the chorus room is one of my favorite places to work. Because I've been in the chorus program for a little over three 
years now, I find the room to be comfortably familiar, especially on days when I feel particularly overwhelmed...I find it easy to put myself at ease and learn new information in the chorus room. (Priya)
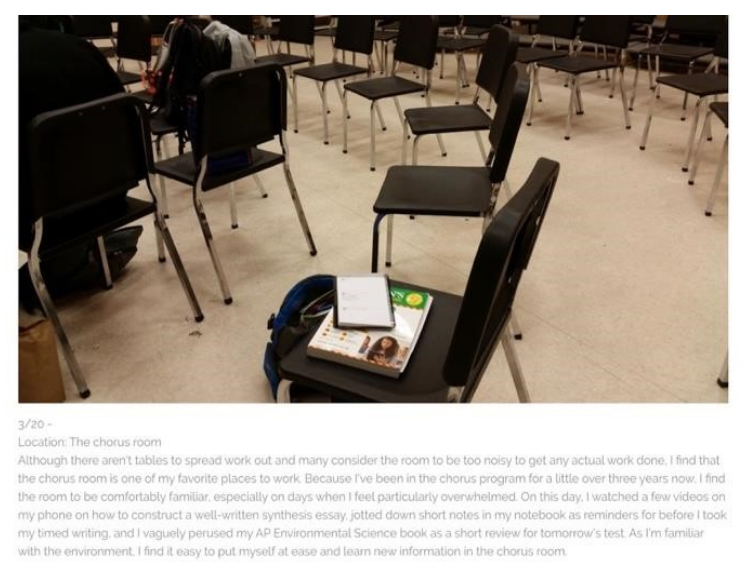

Figure 4.49: Comfortable seating at school

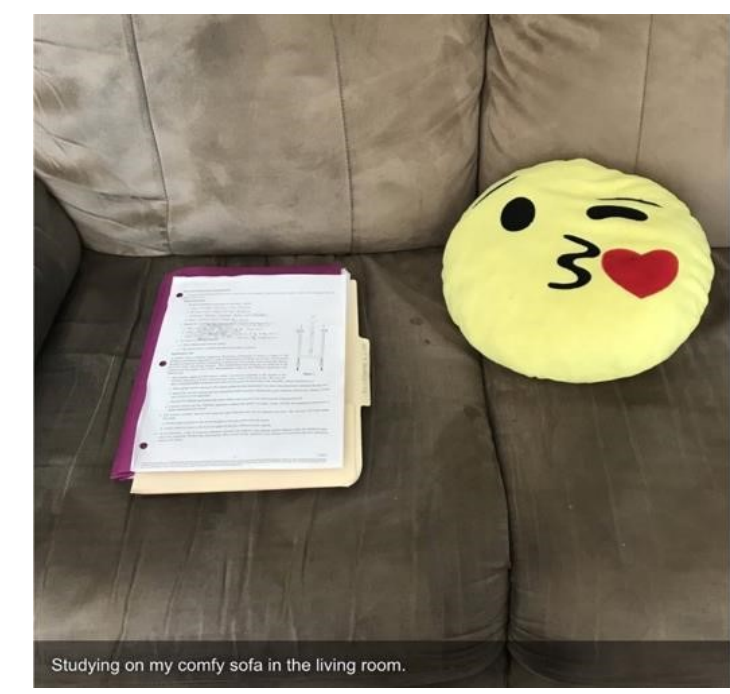

Figure 4.50: Some students sought comfortable seating at home when doing schoolwork

\section{Ergonomics: Comfortable Seating Outside of School}

When outside of school, students had more seating choices than those available at school. They had many upholstered seating options, as well as seating that was more rigid.

Sometimes when I don't have as much homework, I will relax more by doing it on the couch instead. Generally, I am best able to focus before my family gets home because I am more productive and less distracted when I am alone. (McKenzie) 
A few students reported a preference for studying from the comfort of their bed in their bedroom. One student noted a conscientious effort to avoid studying in the bedroom, only resorting to it when studying in other areas of the house late at night would be disruptive to her family members.
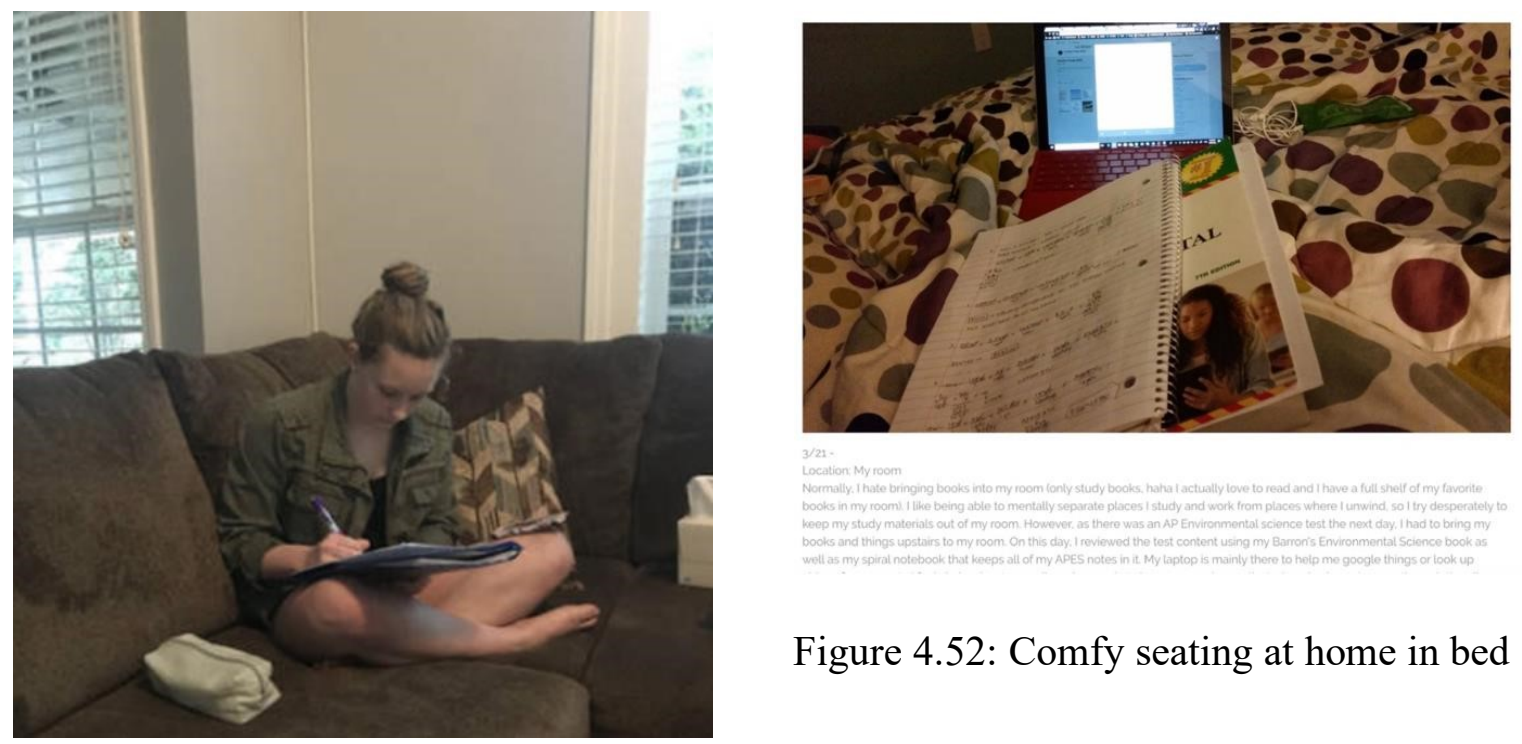

Figure 4.52: Comfy seating at home in bed

Figure 4.51: McKenzie studying on the sofa at

home when completing easier work

\section{Sustenance}

\section{Sustenance in School}

At Catamount High School, students have one hour for lunch. Classrooms are open as well as the commons or cafeteria. The commons area was extremely crowded at lunch times, with about 1,000 of the 2,800 student population converged there. Upper classmen in good grade standing were allowed to drive off campus for lunch. None of the students in the study went off campus for lunch. 
Priya indicated her preference for classrooms, stating, "At school, I don't like to go to library because I can't eat there. I prefer to go to classrooms to work.” Multiple students reported that they would go to classrooms rather than the media center because in classrooms they were able to eat. Some students reported avoiding places where they could eat because it could be distracting to them. For example, McKenzie went to the library if she needed to focus. "I like to go to the library to better focus because I can't get distracted eating or talking to friends" (McKenzie).

\section{Sustenance Outside of School}

A few students talked about their preference to work in the dining room due to the fact that it was located near the kitchen, full of drinks and snacks. Other students discussed working in the kitchen directly, as it was near both comfort food and family members.

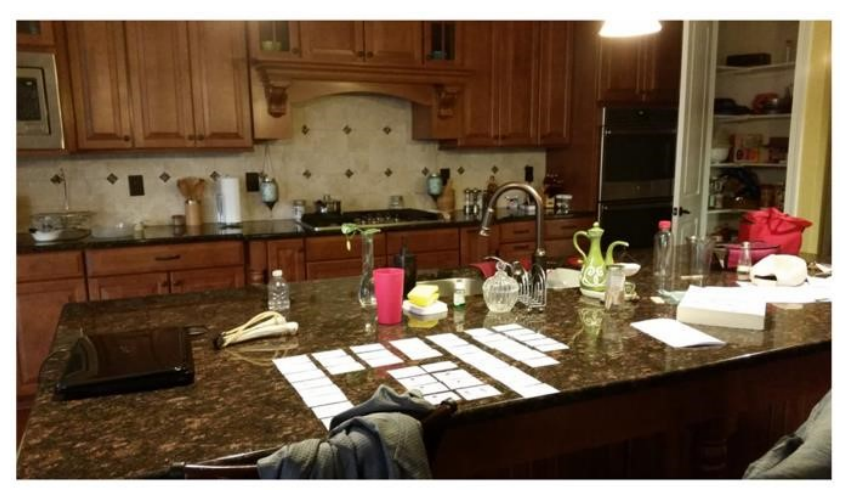

Figure 4.53: Priya liked to work in the kitchen near her mom and food

\section{Conclusion Relative to Comfort}

Students involved in the study reported that they sought out places of comfort in order to improve their learning. Teachers involved in the study tried to make students as comfortable as possible, adding graphics, posters, carpets, incandescent lighting, and 
organizational items to make the classrooms bright, clean, and organized. Teachers and students noted how students came to certain learning spaces as a refuge and to learn better. One teacher reported,

Students prefer environments where there is structure, repetition, and a lack of sensory stimulation. Some of our kids who go out to normal classrooms come back to our curriculum assistance lab if there is too much stimulation (smells, lighting, sounds, social static, etc.). (Ms. Sandy)

Six out of eight students interviewed preferred to go to the dining room at home where there is a large place to spread out and get organized. Only two students preferred to work alone in their bedrooms. One student out of these two did all her work from her bed rather than her desk in her room. One student preferred to go to the public library to meet with other students to study. These library study times were contingent upon access to transportation. None of the eight students interviewed had their own car or regular transportation to get to locations other than home and school.

Excerpt from notes from an Interview via Zoom with a student participant: It was 7 am on a Saturday morning, and it was the only time available that Zaha had in her schedule to meet with me. Zaha had been in my class the year before as a freshman. I would see her often in the halls surrounded by friends. She was always smiling and engaged in conversation. This morning, Zaha looked very tired and was talking to me from her bright turquoise room. The color reminded me of blue tiles from the mihrab (prayer niche) from my hometown art museum. Zaha looked into the computer with tired eyes and with her long, dark flowing hair framing her face. I had never seen her hair before, as it had always been neatly tucked under her hijab headscarf. I had never really 
looked at her eyes, as she always hid behind her glasses. She talked about her deluge of schoolwork and volunteer obligations. She described her mother as a social butterfly who pulled the family from one event to the next. Zaha moved the computer and showed me the bookcases in her room that were filled. She loved to read and create artwork. She loved to create calligraphy on everything she made. Zaha scolded herself for not loving science and math more. Her goal was to become a doctor and revealed that she did not gravitate to math and science the way that she loved art and literature. Zaha documented that she studied predominantly from her dining room table. She studied very hard and would look to resources that would improve her studying and cognitive ability. She worked with Pomodoro's, working for 25-minute time intervals, and taking five-minute breaks.

\section{Theme 3: Replication and Evolution}

The third theme is that of replication and evolution. Evolution is relevant to a variety of scales from (1) the administrative/county level to (2) the school level to (3) classroom/teacher-level changes and (4) student-level changes. Evolution is relevant to the research question "Where do you like to learn" in order to understand the depth and nuances of built formal learning spaces provided in this section of the country.

The Catamount campus was built in 2006. The educational building specifications for new and renovation construction had changed over the course of time. The architect of the original campus building spoke to these new changes. The old plan included lockers and multiple locker bays, specifically on each wing of the three-story, symmetrically planned main building. The principal on staff between the fall of 2014 and spring of 2019 was fearless and an experienced teacher with a PhD. She explained to me 
that she was able to take risks that others earlier in their career might be afraid to take. She also was surrounded by fellow administrators of two newly built high schools within a five-mile radius of the Catamount campus. She spoke with me about the evolution of educational space design and the reluctance of some administrators and teachers who were more comfortable with traditional environments and furniture. The principal explained how, in some of the new high school campuses being built near Catamount High, that contemporary furniture was sometimes placed in storage closets and some faculty requested old, traditional desks for their newly designed learning environments.

What is evolving? Evolution and change are the norm for the living world. The built environment endures change, whether through natural circumstance or intention. The site of this study, Catamount High, was the second iteration of a rollout design known as the "Knight Plan," which was developed in 2000. Knight High was built first, opening in 2004, and Catamount High was built and opened in 2006. The school demographics and testing data is wildly different between these morphologically identical schools that sit on two sides of the county.

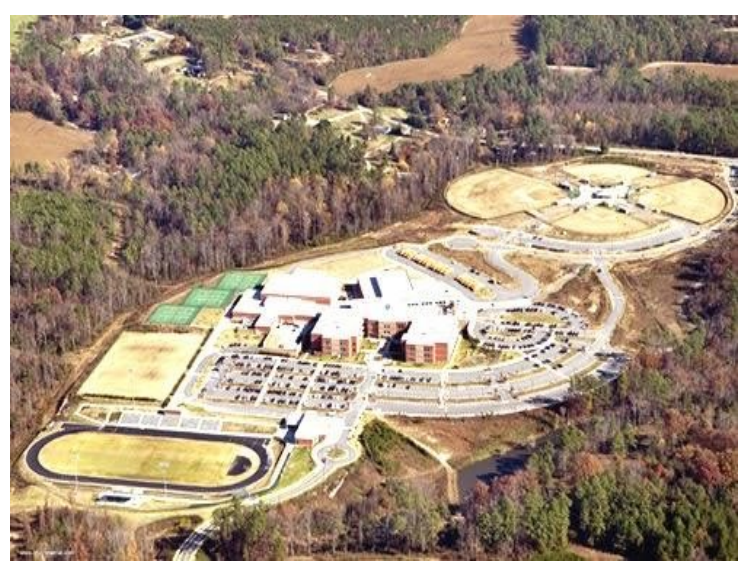

Figure 4.54: Aerial view of Knight High,

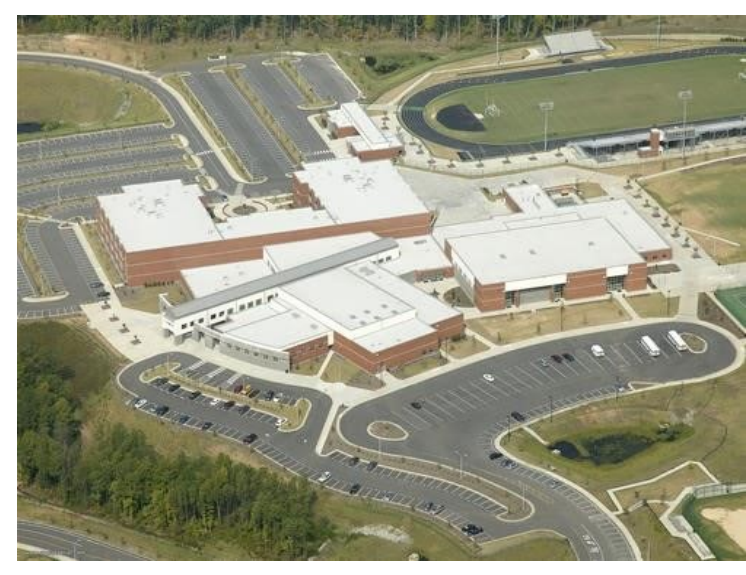

Figure 4.55: Aerial view of Catamount High

Wave County prototype for Catamount High 2006 prior to modular additions 


\section{In School Changes}

\section{District Changes}

The Tech Corridor region in this section of the contemporary North American southeast features a sprawling county with 187 schools, 30 of which are high schools. It is the largest school system in this southern state and is the $14^{\text {th }}$ largest county in the United States. The county employs 10,421 teachers and has a total student population of 160,471 . The schools in this county have been the subject of research by a number of investigators, including Pasalar (2004).

\section{Twin Schools with Divergent Academic Outcomes}

Two schools in the county received the exact same plan between 2003 and 2006 by the architectural team. By the US News and Reports' list of best high schools, Catamount High is ranked \#6 in this city's metro area and \#869 nationally. In the fall of 2019, the Catamount High population dropped to 2,720 due to the opening of a new high school five miles away. The minority population is $49 \%$ of the total and the economically disadvantaged rate is $7 \%$. Ironically, Knights High, which was built to the identical specifications as Catamount High in the extreme eastern part of the county, is ranked \#44 in this city's metro area and \#12,584 nationally. It has a minority enrollment of $81 \%$ and $56 \%$ of the population is economically disadvantaged.

This phenomenon of identical design layout and radically different achievement has happened in other parts of the same county. Green High School is located within one mile of Catamount High School and is ranked \#4 in this city's metro area and \#793 nationally. Middle High has the same building as Green High and is ranked \#14 within the metro area and \#3062 nationally. Wake High shares the same design as Green and 
Middle High and is \#18 in the metro area and \#3710 nationally.

\section{School Building-Level Changes}

After the initial construction, Catamount High evolved over the past 13 years. The built changes ranged from large building additions to small classroom changes. The Catamount High campus saw the addition of five modular buildings that have ten classrooms each. These were added to keep up with the rapid population growth of this tech region of the North American Southeast. Modifications were made to the Media Center, and six locker bays were renovated to make room for collaborative table and chair workstations. Small modifications have been made at the classroom level consistently for the last 16 years.

The area surrounding Catamount High has also changed over these last 13 years. Catamount High had been completely surrounded by trees, but especially in the last five years, the property around the school has been sold and developed. An interstate within a quarter mile of campus was created and opened in the last eight years. Figure 4.32 features a map of the areas under development.

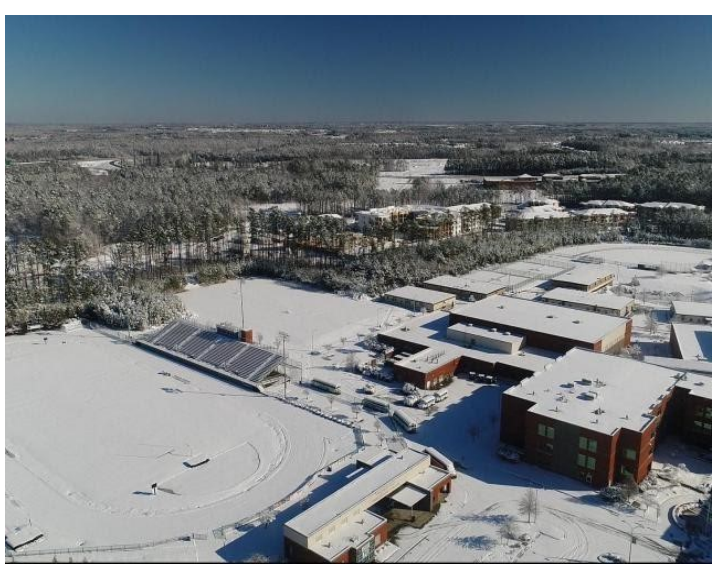

Figure 4.56: Aerial view of Catamount

High after modular additions

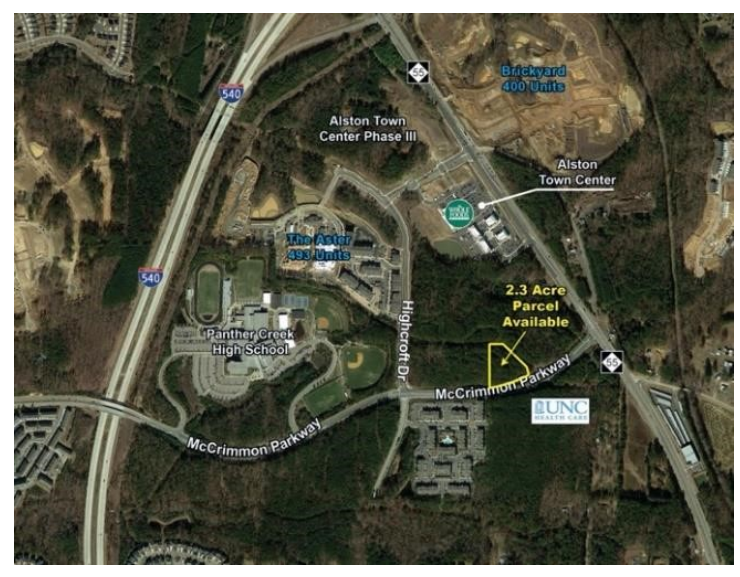

Figure 4.57: Rapid development

surrounding Catamount High 


\section{Classroom-Level Changes}

Classroom configurations evolve over time. These changes in configuration are due to a variety of pressures. Sometimes, one teacher occupies a classroom space from semester to semester and decides to change the layout based on the course content. At times, the configuration changes due to the nature of learning. For example, if there is testing, the room configuration changes to promote privacy and focus rather than wandering eyes and cheating. If there is a team assignment or daily work where collaboration is promoted, clusters of desks may be ideal. The pressures to change configuration may not be instigated by course content, or the learning task, but rather the nature of the learners themselves. For example, if the class is very chatty, so much so that it is difficult to get through instruction without interruption, then a row and column configuration rather than a cluster configuration may be promoted.

Faculty often encouraged students to get up and move. From the teachers sampled, there was a discrepancy whether those students who were encouraged to move were high achieving or low achieving. Some thought that the high achievers should sit, while other teachers thought that the low achievers should sit. This aside, students were given permission to leave their packed classrooms of 35 or more. Students were allowed to work in the renovated locker bays, which featured six tables with four chairs around each. Students actively engaged hallways and participated in "gallery walks" with activities pasted temporarily on the wall like artwork hanging in a gallery. Students individually or collaboratively huddled around each hanging artifact and used their phones to scan QR codes and conduct other research needed to solve the problem at hand. 


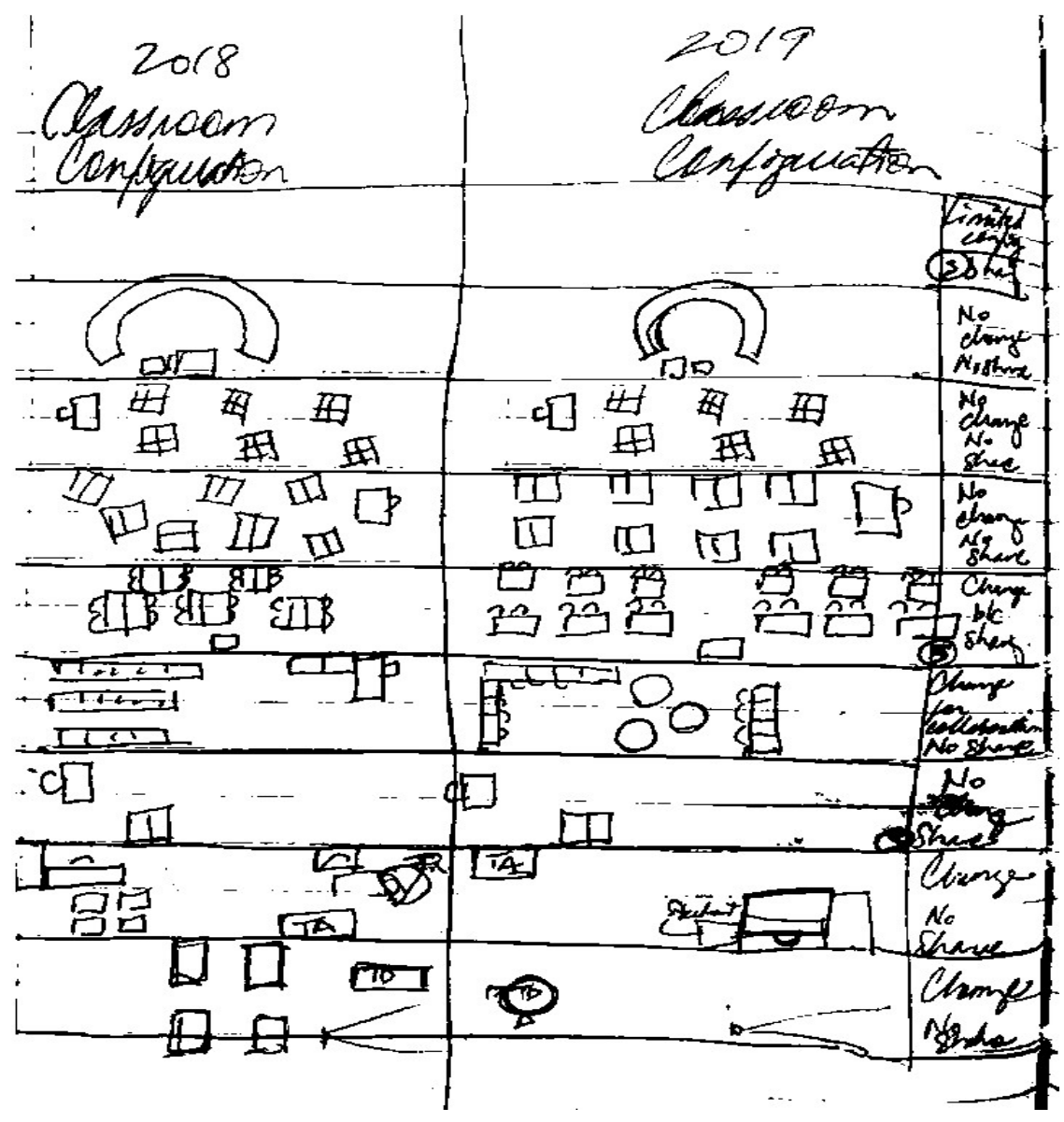

Figure 4.58. Classroom configuration evolution 2018 to 2019

Within the school environment, each one of the space types-classroom, hallway, locker bays, commons, media center, outdoor-served a variety of learning functions over the course of the school day. Depending on the time of day and instruction, the spaces served as collaborative learning space, isolated learning space, individual testing space, social space, etc. At times, some spaces served these functions simultaneously. For example, the locker bays during lunch sometimes serve as both social space and isolated learning space. This phenomenon was observed even at the same four-person table. Hallways in the building have been converted into informal learning spaces. Math and science classes, in particular, utilize these spaces, hanging problems on the wall "gallery 
style" so that students may move individually or in groups to solve the problems manually or with the aid of their personal devices.

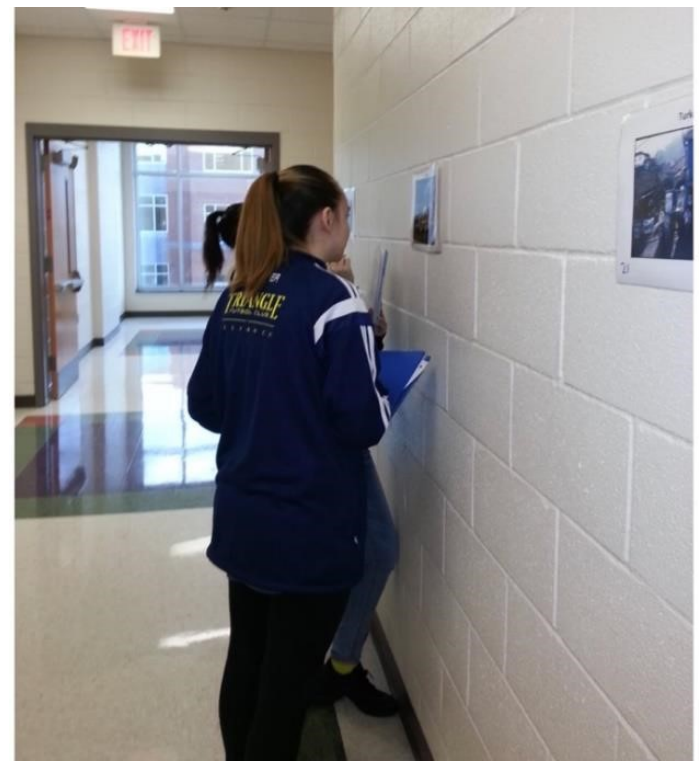

Figure 4.59: Students using the gallery collaborative format learning method

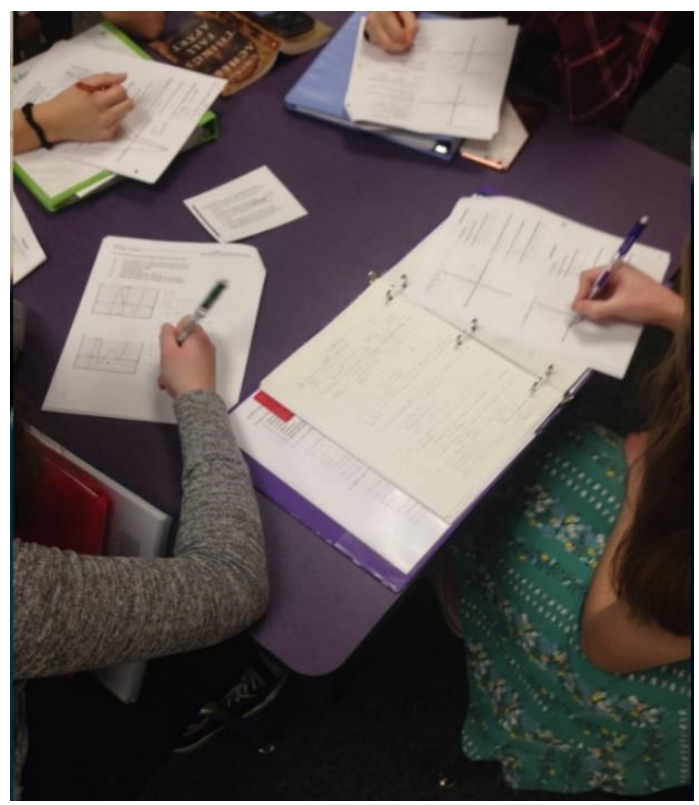

Figure 4.60: Students use the locker bay spaces as refuge from a crowded math classroom

\section{Student-Level Changes}

This subtheme is characterized by the fact that students have choices of where to go during the school day. The other subthemes relevant to school are differentiated due to the fact that the choices are made by personnel other than the students. Classroom-level changes are made by the teacher. School-wide changes are made by the administrators on site. County-level changes are made by county- and statelevel administrators. There is some overlap between each of the four subthemes. Students and teachers provided insight as to changes within a number of spaces on the school campus and outside of school. At 
school, the places mentioned include the cafeteria/commons, the outer courtyard, classrooms, locker bays, media center, and hallways. Outside of school, students mentioned learning in dining rooms, bedrooms, kitchens, living rooms, and cafes.

Cafeteria/Commons. "Here is a picture of the cafeteria within our school. Although this area is used for eating, I use this space to communicate with my friends and exchange ideas and opinions, thereby learning in a sense" (Zaha). Ms. Balto brings her Spanish classes out to the commons spaces so they can spread out and they can take listening and speaking practices and assessments. Large physical education classes use the commons areas as table spaces to take their tests, as there is not sufficient table space anywhere else in the building to accommodate their large classes.

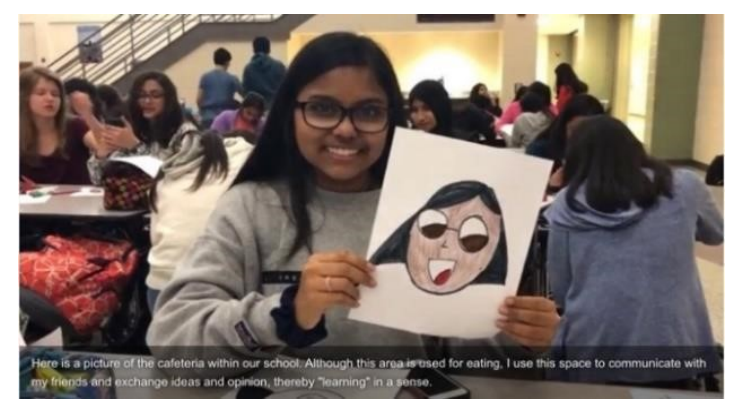

Figure 4.61: The crowded commons

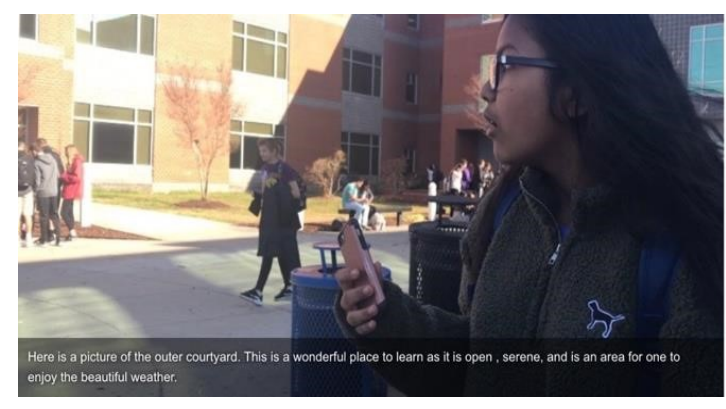

Figure 4.62: The outer courtyard lunch

Outer Courtyard. "Here is a picture of the outer courtyard. This is a wonderful place to learn, as it is open, serene, and is an area for one to enjoy the beautiful weather" (Zaha). The outer courtyard is a place that features a gently curving brick wall placed directly in the center of the two symmetrical wings of the brick building. This space is conducive to gatherings, for the wall is the perfect height to sit on, and the curving nature makes it similar to an amphitheater design in the round. Many teachers bring their classes 
to this courtyard space, especially in nice weather. During lunches, students gather in clusters to socialize and eat their lunches.

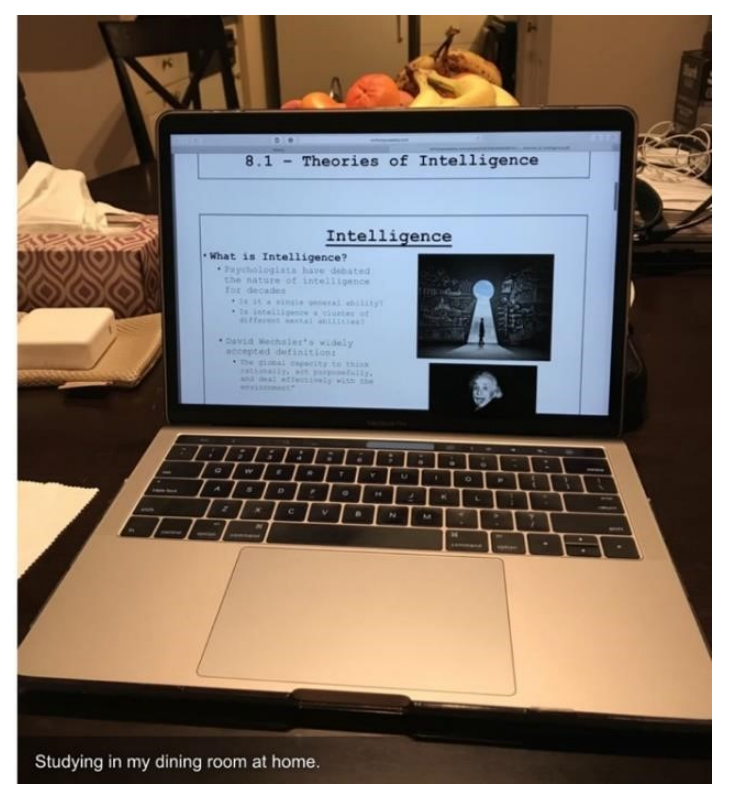

Figure 4.63: Uma works in her dining room

\section{Outside of School}

\section{Home Dining Room}

Many students involved in this research project reappropriated the family dining room table from an area for dining to an area for studying. Students commented that they enjoyed having the large surface to be able to spread out and do work. Some students were able to work in a group at the large dining room tables.

\section{Home Living Room}

Some students preferred using a more relaxed seating environment in order to do their work. Students involved in the research commented about how certain types of schoolwork were more appropriate for relaxed areas like family or living rooms. 


\section{Home Bedroom}

Zaha said the following about studying at home in her bedroom: "I additionally enjoy studying in my room. I enjoy this space because it has a relaxed area around it." Tya said, "My bed is my favorite place for studying or doing work in general. I have comfort of doing my work in my bed, especially when a lot of my work is reading." Tya also explained the following: "It's easier for me to have an open space to read and I can maneuver around in different positions since it usually requires many hours of being in one place." Uma stated, "My workstation where I sometimes read books. It is also the most comfortable place to study where I am surrounded by familiar objects. I also keep contacts and glasses over here."

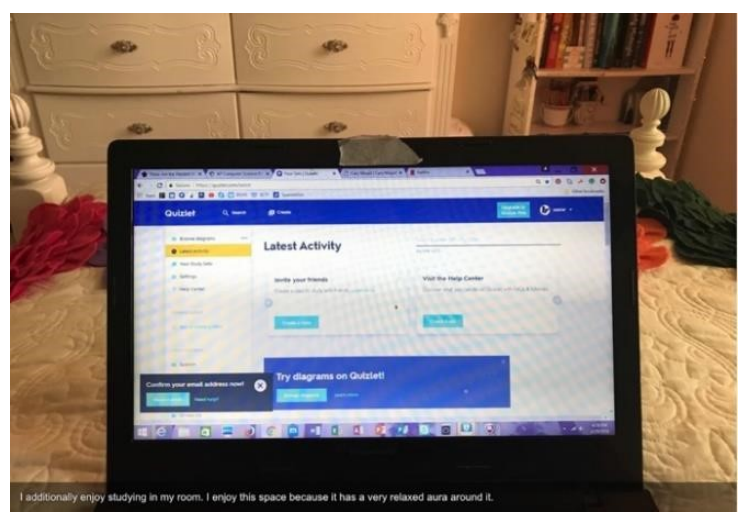

Figure 4.64: Photo of a bedroom home study environment

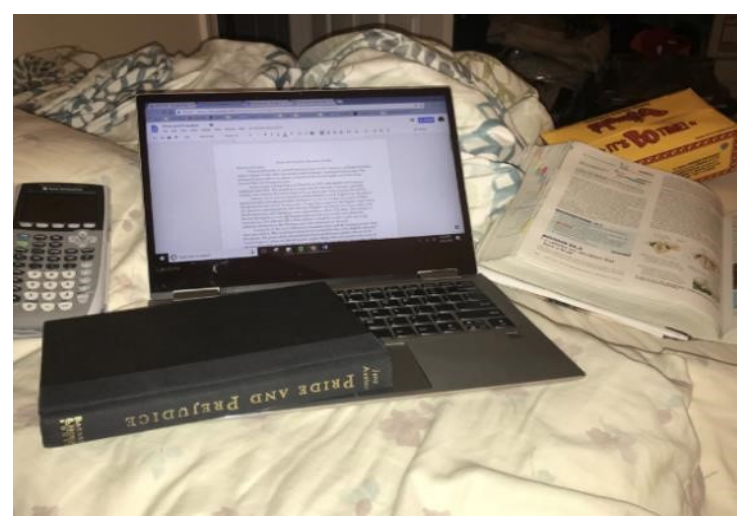

Figure 4.65: Tya's home bedroom study environment 


\section{Library/Café}

In the second round of data collection, some students indicated that they were starting to branch out regarding where they studied. These students went to the regional library and Starbucks between school and work. The contributing difference was that these few students had gained a driver's license and were able to make more choices about their informal learning environments.

\section{Awareness of Parent Panopticon}

This concept of being respectful of communal spaces was consistent across the data. Students who preferred communal spaces would often venture to their rooms to study, especially if it required very late hours. "Sometimes I study until three or four in the morning. I don't want to bother my parents, and I don't want to worry them" (Priya).

\section{Evolution: Students}

Between the spring of 2018 and the spring of 2019, the students involved in the study grew up. This manifested in a variety of changes. Freshmen students went from being immobile and unemployed to having a car, a job, and freedom to get out of the house to study at a place they preferred. The juniors who were stressing about getting grades for the college of their choice in the spring of 2018 had been accepted to colleges by the spring of 2019. Their relief and relaxed demeanor was something not evident in previous years. The one senior in the spring of 2018 who had loved to work alone in her room at home, by the spring of 2019 was living away at college and was studying exclusively at the library at all hours because of her college dorm roommate situation. Students who had been consistent dining room table studiers, with increased course load and a newly exciting extracurricular and athletic schedule, forced themselves to study in 
cars, on buses, on the bleachers, and in their rooms at odd hours. The students were highly intrinsically motivated and held themselves to very high standards. They knew themselves well, with high levels of intrapersonal intelligence.

\section{Conclusion to Evolution Theme}

Between 2016 and 2017, Catamount administration revised some of the common areas. They removed middle lockers in the twin locker bays in all wings of the main building, and within each bay created an open area with six tables and seating for 24 . These spaces are used by teachers and their classes during bells and by students informally during lunch. "We are finding that students rarely use lockers any longer...the schools are too big to allow students to access them between classes. Therefore, this is a great use of space. The open area with seating definitely reflects current trends in informal learning" (Ms. Pope, architect for Wave County).

\section{Additional Figures Related to Theme 3}

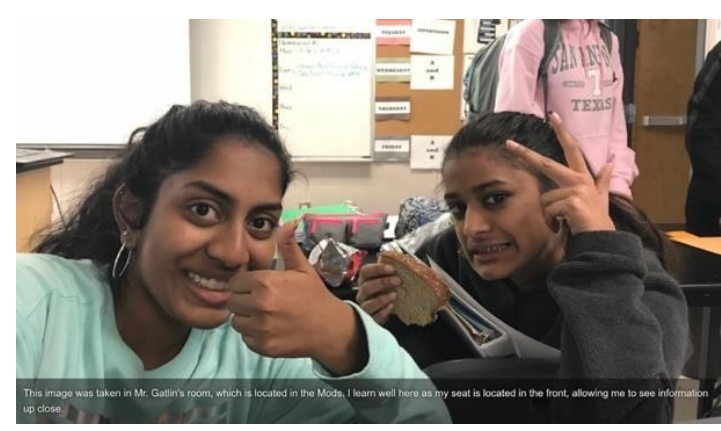

Figure 4.66: Studying at school with

friends

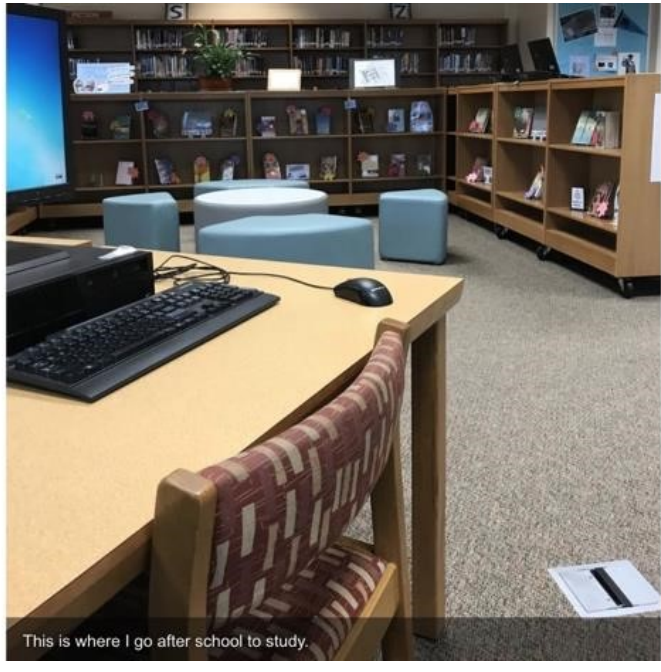

Figure 4.67: Uma's view while studying at the media center after school 


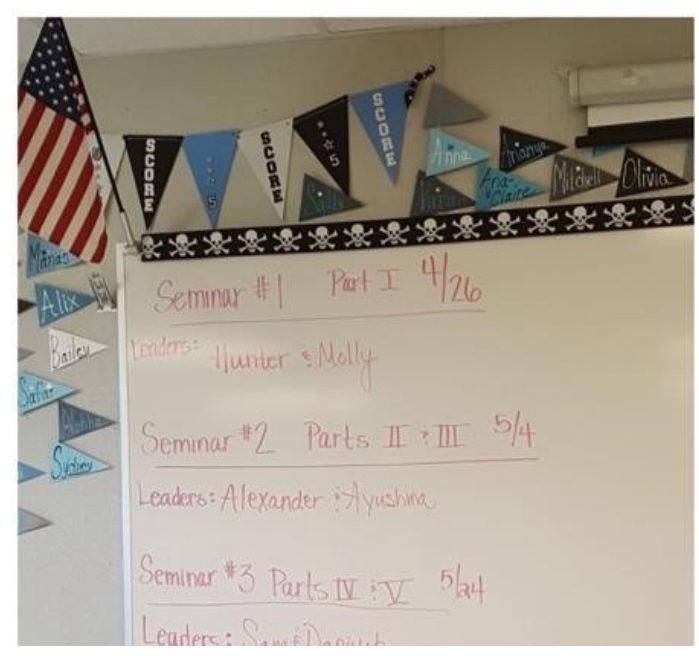

Figure 4.68: Incentivizing the class through the placement of goal banners

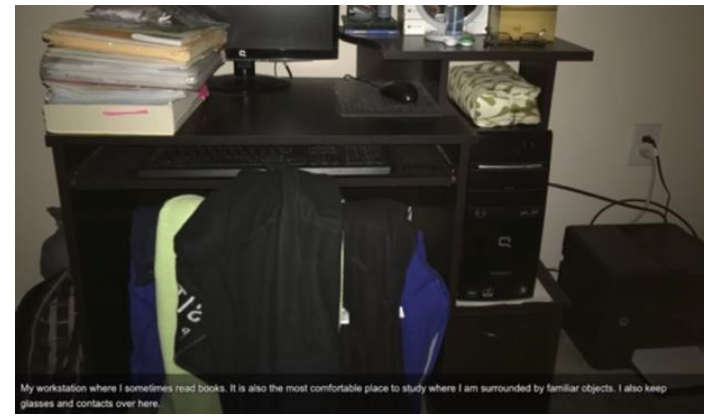

Figure 4.69: Uma's formal desk at home

\section{Theme 4: Perceptions of Self-Regulated Learning and Spatial Preference: Spaces to}

\section{Thrive (RQ2: Where do you learn best?)}

The fourth theme of perceptions of self-regulated learning is relevant to the second research question, "Where do you learn best?" Students sought a variety of places in school and outside of school for the purpose of improving their learning outcomes.

\section{Metacognition and Settings}

The purpose of this section is to show the relationship between metacognition and self-regulation, the latter of which is at the forefront of this study. As explained earlier in the text, there are multiple definitions of metacognition. One explanation is, "Critical thinking and inquiry is predicated upon an awareness and ability for learners to take responsibility and control to construct meaning and confirm knowledge" (Tobias \& Everson, 2009). This awareness and ability has been labeled metacognition. According to Tobias and Everson (2009), metacognition is "a higher order, executive process that 
monitors and coordinates other cognitive processes engaged during learning, such as recall, rehearsal, or problem solving." Research into metacognition over the last 30 years does suggest that learners with metacognitive awareness and ability are more successful in academic settings (Stewart et al., 2007). In summarizing this research, Young and Fry (2008) state: “[It] appears that when metacognition is assessed through calibration of performance measures there is support for the relationship between metacognitive skills and measures of academic achievement" (p. 4).

Metacognition has been generally accepted as consisting of two components: awareness of the inquiry process and implementation strategies (regulation). Awareness allows the learner to monitor and actively manage/regulate the inquiry process. In short, metacognition awareness and implementation abilities provide the knowledge and strategies to monitor and manage effective inquiry. Most importantly, in a collaborative learning environment, awareness and implementation strategies are developed through critical discourse and the requirement of participants to explain and justify one's thinking to self and others. The approach to developing a viable metacognition construct for collaborative learning environments is to subsume self and shared regulatory functions within a single construct. The Shared Metacognition construct (Garrison, 2017; Garrison \& Akyol, 2015a, 2015b) reflects the dynamic dimensions of self and co-regulation each exhibiting a monitoring (awareness) and a managing (strategic action) function (see Figure 4.70 below). 


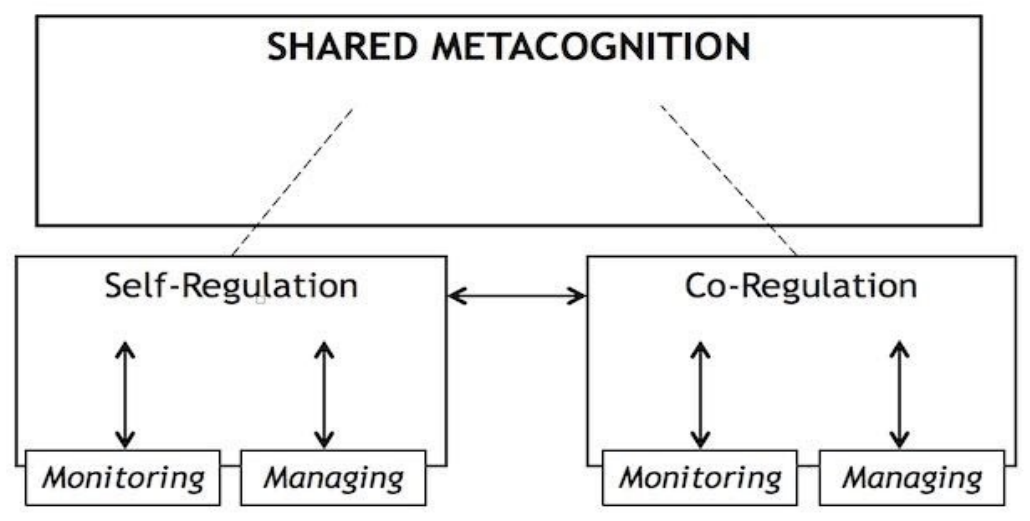

Figure 4.70: Shared Metacognition construct

Zepeda et al. (2018) provides us with some clues as to where we might begin focusing our implementation efforts. They concluded that "teachers from high-conceptual growth classrooms engaged in more cognitive talk than teachers in low-conceptual growth classrooms" (p. 13). The idea is that cognitive talk (discourse) gets students to think about their understanding and become open to sharing their thinking. This, of course, resonates very much with the essence of a community of inquiry. More specifically, the study suggests that questioning more easily supports metacognition. Of particular interest, here, is that planning is considered to be a key metacognitive skill.

\section{Self-Regulation in School}

\section{Self-Regulation and Formal In-School Environments}

"The locker bays are generally a crowded area, and I often get interrupted by friends, so I have a lot of difficulty learning new information there; however, it is a nice place to work on math, busy work, and other short assignments" (Priya). 


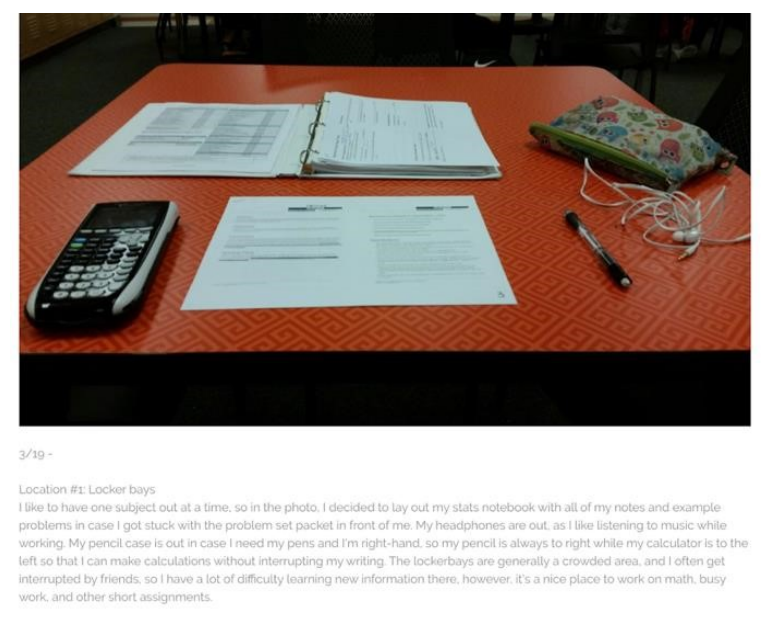

Figure 4.71: Priya's view of getting organized and working in the locker bay alone

Student participants noted ways in which they sought out particular spaces iun order to improve their learning function. For example, Priya explained how she and her friends would go to the AP Statistics classroom on the day of a test. She explained, "We wrote everything we could remember about that particular test across the board... I could almost picture the board with all of our notes later on in the morning when I went to take my stats test" (Priya).

Neesha explained a situation where she remembered specific content written in various colors on the board by her teacher. "One of the best ways I learn is with notes that are color coded. The way (my Spanish teacher) helps me learn the language the best because she is very visual and gives many examples" (Neesha).

McKenzie explained her habit of reviewing at school in the morning before her classes for the day began. "I often like to study right before school begins in my first period classroom" (McKenzie).

One of the teacher participants discussed her observations of students, their use of the school building and their use of the formal school time. "High level students prefer 
to get work done during the school day, while low level students socialize during

SMART lunch" (Ms. White).

\section{Motivation and Learning Environments}

Over 500 students out of a student body of 2,900 were invited to participate in this research study. All of them were offered financial incentives to participate in the study. Of this large group who was invited, only eight students pushed through to complete the study. Each of the students involved in the study, at the beginning of the data collection, did not work during the school year. None of them had a car and they did not go off campus during SMART lunch. This group was also highly intrinsically motivated and all but two were National Honor Society members.. As a whole, their grades were exceptional and even those students in their freshman year of the study had colleges and their careers in mind.

\section{SMART Lunch}

All 2,900 students at Catamount High took a lunch break at the same time. The cafeteria/commons could not accommodate all students during this time. The innovative strategy, termed "SMART" lunch, stood for "Students Maximizing Achievement, Resources and Time." This was a novel practice that was developed by the first principal at Catamount High. This practice has since been adopted by many high schools across this southern state. SMART lunch only works if all students spread out across campus and work in classrooms, hallways, and locker bays during the lunch hour. Some of the most incredible work that I observed was when groups of loud students sat down next to a single or small group of students who were focused and working intently. In spite of the laughter, hollering, and general shenanigans, the anchored students were able to 
persevere with their studies. This ability to focus and push through distractions was evidenced with some of the students participating in this study.

\section{Empowering Students Through Freedom of Movement}

As mentioned previously, faculty often encouraged students to get up and move, though there was a discrepancy whether those students who were encouraged to move were high achieving or low achieving. Students were also afforded freedom of movement during the SMART lunch. Ms. White made the following statement about where she though students learn best: "I feel that students learn best in school during SMART lunch in the teacher's classroom. This is the perfect time to conference with a student about a skill that needs clarity." Architect Pope also shared her thoughts about where students learn best. Regarding the 2004 Knight Prototype:

I'm not sure if I have an opinion as to "where students learn best." Every student has a different learning style; some students are visual learners...others are more auditory, hands on, etc. I think providing a variety of spaces is important - both formal and informal. As previously mentioned, there were not a lot of informal learning spaces incorporated into these prototype designs, per the WCPSS program at that time.

Regarding the 2018 design, Pope said, "I would hope that the recent incorporation of informal and collaboration spaces are providing more environments for varied student learning."

Principal Perspective: Encouraging Self-Regulation

Dr. Hed provided the following perspective on self-regulation: 
Sometimes what they think is performing at a high expectation is doing what teachers want. We also want them to give us what they want. So sometimes that is about us doing a better job of presenting the expectation in a way that is open ended. Open ended is hard for everybody. It is not our problem; it is a national problem. It is a professional problem. It is very hard to grade open-ended work. ...I would say, highly motivated students are practical, they are to check it off their list, to get their credential, to get what they need, to get the next thing they need. They are not going to care. They are not going to give up (their school), but they are looking for that internship that has what they need to meet their goals. What they do is incredible. I am astounded. They make use of resources. Their parents give them resources, and I respect that...our kids can't spontaneously go volunteer because they are scheduled three months out. Our regular kids can. Looking at use of SMART lunch, Dr. Hed said the following:

This group is using SMART lunch to check it off the list. This group doesn't need SMART lunch. They may be tutoring during SMART lunch because it gets them the NHS hours. But this group does not need SMART lunch. They are going to go to their work so not to lose any points for their teachers, then they are going to get the tutoring hours, then they are going to be where their club is...it is the most convenient use.

Regarding SMART lunch for the kids who are not highflyers, Dr. Hed said the following:

Those are the kids that need to hold their hand and walk them to your classroom...the ones who are failing get mandatory SMART lunches. Then we 
talk to parents. We don't have the manpower to provide actual escorts unless there are safety issues. For that group, I won't say that they fall through the cracks, but it takes constant intervention to get them to where they need to be. SMART lunch is not the only answer for those kids. There is lots of talking with those kids. Eventually it is still a choice. ... think our kids know how to quickly get things done. They know how to please us. And they know that they know how to please us. For example, the (Catamount High) way of students, walking up, shaking hands, and introducing themselves. Our students have learned that from us. They know what it takes to make us happy. They know that about themselves... whatever we ask of them, they will give us, it is still back to us asking enough of them.

\section{Self-Regulated Learning Outside of School}

From a teacher's perspective, Ms. White thought the following: "Outside of school, many students say that they learn best at tutoring centers, the library, and places like Panera." Below are student comments about their own cognition and what works best for their studies outside of school:

Sometimes when I don't have as much homework, I will relax more by doing homework on the couch instead. Generally, I am best able to focus before my family gets home because I am more productive and less distracted when I am alone. (McKenzie)

I believe that I can do some of my best learning in my room, but on the same token studying in my room until two or three in the morning often wears down 
my confidence in my memory very quickly, as I only ever study in my room if I'm trying to cram for a test. (Priya)

A lot of times when I'm reading, I'll have music or TV playing on my laptop in the background. Music is usually preferred because I will get distracted by what's going on in a video. (Tya)

I will place my phone upstairs, so that I can focus on my work downstairs. Downstairs I will do work near my parents, because I know they are near. I work better when they are close. (Mike)

Normally, I hate bringing books into my room (only study books, haha I actually love to read and have a full shelf of my favorite books in my room). I like being able to mentally separate places I study and work from places where I unwind, so I try desperately to keep my study materials out of my room. However, as there was an AP Environmental Science test the next day, I had to bring my books and things upstairs to my room. On this day, I reviewed the test content. (Priya)

Many of the students used common family areas, such as the dining room, for a variety of reasons. Some of them noted "the large, flat open workspace where they could spread out all their materials." The dining room also offered them proximity to sustenance in the kitchen. Third, the dining room table offered enough room for siblings to work together. Others sought a panopticon, whereby the student knew that they would be more productive if they were in proximity to their parent. A few students talked about the pleasure of being bathed in large areas of natural light, spilling onto their dining room work area. A few students discussed the fact that the dining room was one of the pretty 
areas of the home that needed to be kept nice. There was mention from one student that their parent did not support their need to use the dining room table for learning, as it "cluttered up the whole space."

\section{Parent Panopticon: Avoidance and Desire.}

Technology can be a source of difficulty not just for the high school level, but also students in college. Parents try to control, and end up monitoring through all use, it just creates animosity, as the students need access to technology to complete homework. (Ms. White)

\section{Sensitivity to Others}

This concept of being respectful of communal spaces was consistent across the data. Students who preferred communal spaces would often venture to their rooms to study, especially if it required very late hours. "Sometimes I study until three or four in the morning. I don't want to bother my parents, and I don't want to worry them" (Priya).

\section{Students Change Over Time}

As mentioned previously, between the spring of 2018 and the spring of 2019, the students involved in the study grew up. Their circumstances changed their study habits and, in some cases, added complexity to finding time to study. Those who went to college had to find new places that worked well for their studies due to their roommates and campus environment. Students who were still in high school found their availability of study times impacted by having a car, a job, or being part of new or additional activities at school. 


\section{Conclusion to Self-Regulated Learning}

The students who participated in the study were highly intrinsically motivated and held themselves to very high standards. They knew themselves well, with high levels of intrapersonal intelligence.

\section{Additional Figures Related to Theme 4}

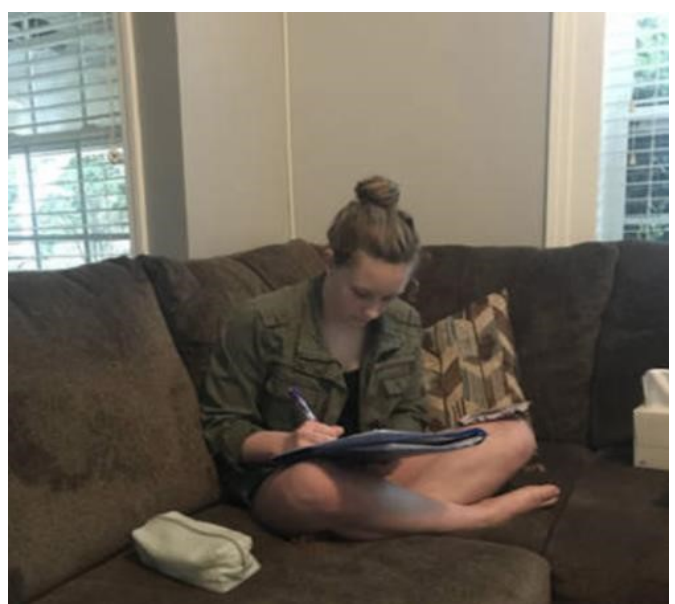

Figure 4.72: Getting work done on the comfy sofa before family members get home
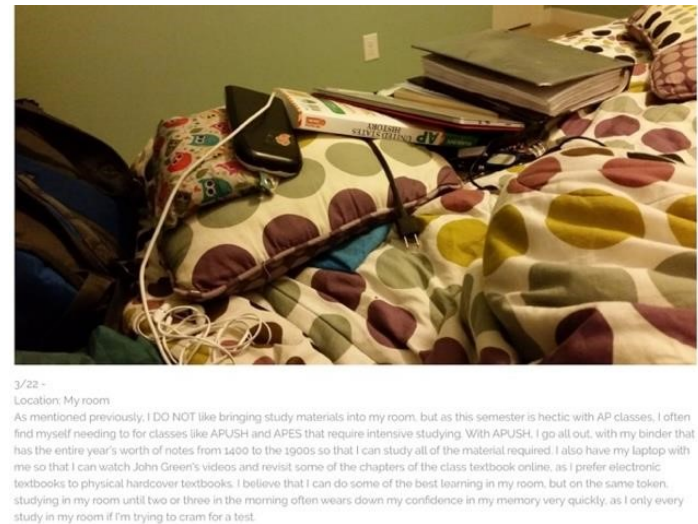

Figure 4.73: Phone proximity and notebooks to get the learning done

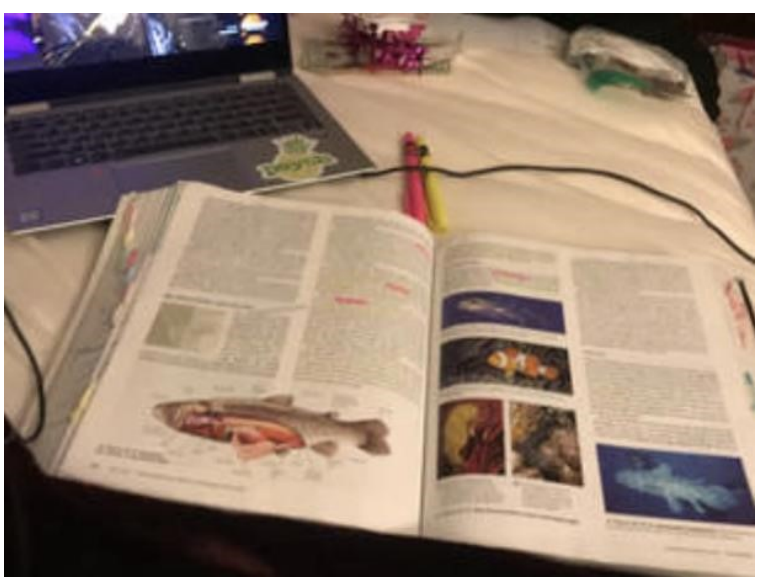

Figure 4.74: Working with music, on a comfy bed

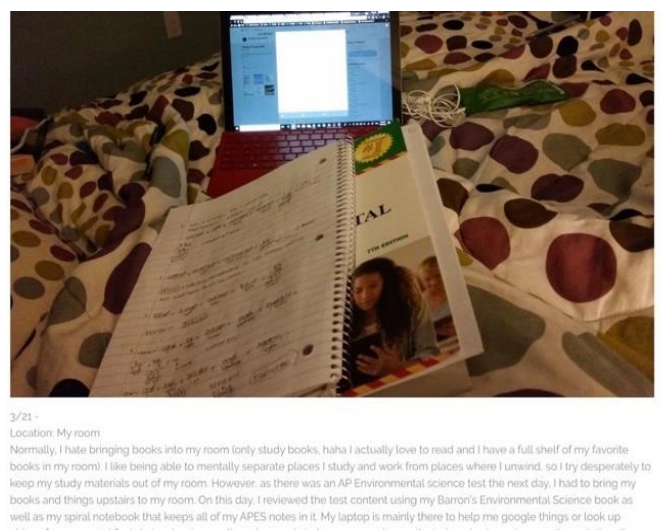

Figure 4.75: Laptop, textbooks and studying 


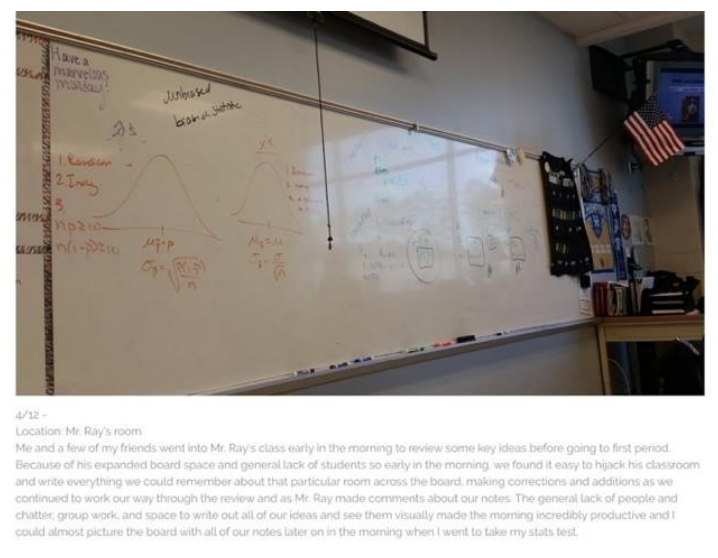

Figure 4.76: Writing the content out on

the board to review before an exam in

the same room

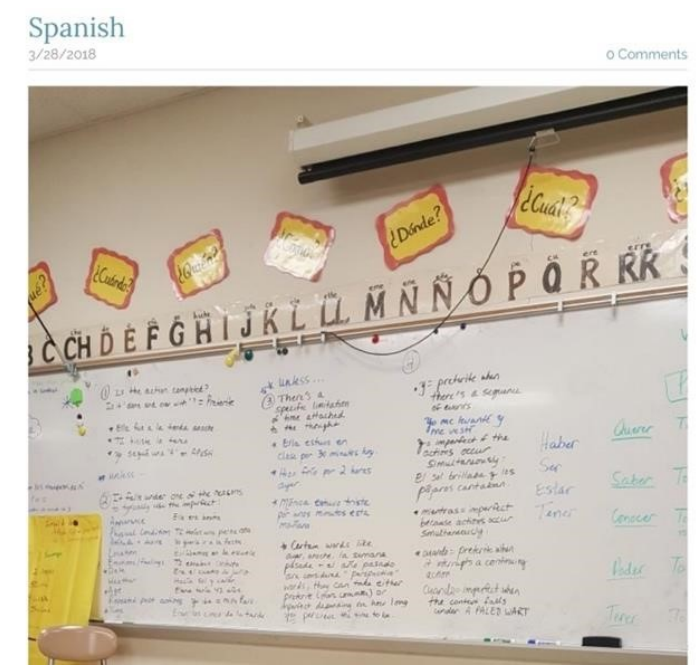

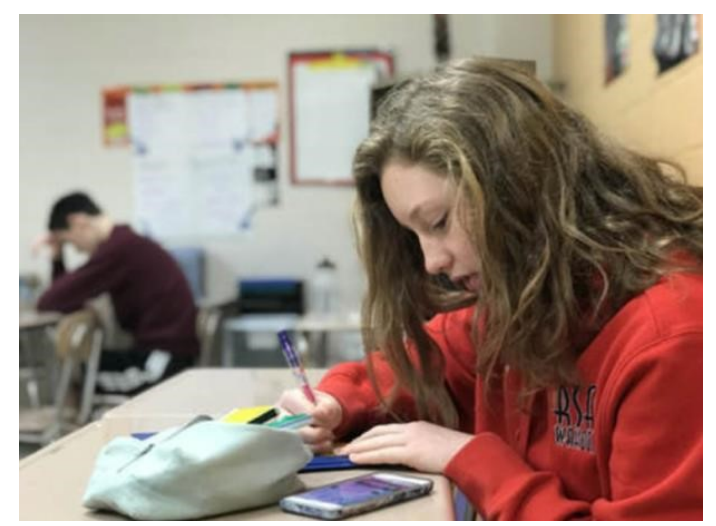

Figure 4.78: McKenzie doing work in her homeroom at $7 \mathrm{am}$ before the start of the school day

Figure 4.77: Spanish teacher color coding terms on the board for better cognition

\section{Theme 5: Technologically splintered spaces}

Technology is the element that has helped to facilitate spatial freedom. Learners are not confined to a formal learning environment. In 2015, Wave County initiated a bring your own device policy. Because the county did not have funds available, students were allowed to bring their own device to facilitate learning. Because the devices are the 
personal property of the students, it is up to the students to manage the communication on the devices. Students are left to negotiate social content and course content. Often, teachers struggle to help students maintain focus while using the devices to access the curriculum. Themes and subthemes relevant to technology surfaced from observations, photovoice blogs, interviews, and cognitive maps completed by students.

\section{Technology as Aid}

\section{School Provision of Technology}

Wave County has attempted to keep up with the technological demands of contemporary society. Teachers are required to maintain a website for their course in addition to managing Canvas, the current content management system selected by the county. Each classroom is equipped with either a projector or a large screen monitor that is connected to the teacher laptop. The number of laptops provided to each class depends on the course. Core courses such as English and math are allotted 14 computers per class, the population of which usually numbers between 30 and 40 . Non-core classes, such as world languages and social studies, have 10 laptops for their classes of 30 to 40 . It is up to the students to close the technology gap. This is a huge issue that will be elaborated further.

\section{Technology has Changed Education}

Educators in the study commented on the way in which access to technology has changed education, including the content, delivery, and access. Technology has also changed the way in which learners think. Mr. Bunsen commented on the changes in technology and education: 
Environments have changed since my time in education, which was a space of projectors, direct instruction, rows, and columns. Students' access to technology has relieved tension over needing answers and resolution. It has changed the way I teach. Students can break out into small groups and go through voice test assessments.

\section{Types of Devices}

The types of technological devices available impact learning. The math department achieved a grant and was able to purchase a class set of iPads. These iPads helped to supplement the county allotment of 14 laptops for core courses (math, English, etc.) regardless of the class size. The iPads had to be shared within the math department of approximately 30 staff members. Ms. Bold used the class iPads from a math grant for students to write on pads and complete problems. Ms. Bold used her personal iPad to project on the classroom screen as she worked through math problems.

\section{Technology to Distribute Course Content: Websites and Content Management Systems}

Beyond consideration of devices, teachers manage the content for their courses through websites as well as content management systems. Ms. Bold maintains websites for both AP calculus (high level) and ICM (Introduction to College Math; low level) courses. The websites feature the rubric for projects as well as examples of what students have accomplished. Teachers who are teaching the same course content will use the websites designed by the lead teachers. Each teacher maintains their own Canvas content management system for each class. For Wave County, another grade tool known as PowerSchool allows for the maintenance of the gradebook, attendance, and report cards. New Technology Impacts School Building Design

Ms. Pope, the architect for Catamount High School, discussed the way that 
technology impacted the design of the high school according to the 2004 prototype: These prototypes were designed before "wireless" had been widely adopted. Therefore, the approach at that time was to provide large conduits throughout the building to allow both the current and future wiring for technology. The approach was to sequester technology in specific lab settings (computer labs, marketing labs, media center) instead of spreading it out throughout the building. This was mostly due to the need for wired connections. While most of the core classrooms were wired for a certain number of computers, it did not necessarily support ubiquitous technology, everywhere.

Ms. Pope explained further how design of schools 15 years after this prototype has changed due to technology:

The approach, today, is that technology lives everywhere. My own daughters attend a high school in (this area of Wave County) - the policy is "BYOT" (bring your own technology) and they are allowed to have cell phones and laptops in the classroom. Therefore, the schools need to have adequate wireless bandwidth to allow this to happen. The incorporation of tools such as smart boards, virtual reality, 3-d printing, etc., are further necessitating strong wireless and wired communication networks.

\section{Technology to Address Differentiation in the Classroom}

Dr. Hed discussed the use of technology to address differentiated learners. I think that technology is a fantastic tool and it has to be used that way by both the teacher and the student....we are supposed to use the tool, to make the content accessible, and to make it as seamless as possible, no matter who the student is. If 
I already know stuff that you are teaching, I should be able to assess something else. It means that you (the teacher) have to know that I already know it. You can use a classroom library. Or use Canvas. There has to be a way for me to not waste my time, because that is disrespectful to me as a learner. There has to be a way for learners to access the same knowledge, whether they are highly collaborative or not highly collaborative. There has to be a way for both of those things. If someone is a discovery learner, they need to be able to do that on a computer, but with you. Some of our worst behavior issues are when the kids need to argue, and have it proved to them....you (the teacher) are not the font of knowledge.

\section{Technology has Helped to Foster Collaboration}

Technology has fostered the opportunity for collaboration across physical distances. Learners can collaborate on a range of file types and platforms. Even when there is the luxury of proximity, it is advantageous to have a digital format within which to work. Mr. Bunsen, choral teacher, had this to say about technology:

Environments have changed since my time in education, which was a space of projectors, direct instruction, rows and columns. Students' access to technology has relieved tension over needing answers and resolution. It has changed the way I teach. Students can break out into small groups and go through voice test assessments. I break students out in small groups and assign a student leader to lead each group.

\section{Devices Provide Consistency Across Formal and Informal Learning Environments}

Tya commented about how she used technology: 
Something new that I started this year, mainly this semester, is bringing my laptop to school. A big part of this is that it is much faster for me to type up notes or things we do in class rather than writing them out...Another pro of using my laptop is that even when I can't pull up my laptop, I have my phone with Microsoft, Adobe, and Google apps that can easily access all of my files on the go.

\section{Technology as Interference}

\section{Technology as a Friend}

For a range of learners, having access to technology is a form of comfort. It is a distraction, a connection and a security blanket. "Technology and autism are best friends. They get lost in the technology. They can drift. They will sit and watch videos and play video games. They don't do social media" (Ms. Sandy).

\section{Technology and Parental Control}

With learners of many ages, the battle to effectively use technology for good rather than distraction is a struggle. In an effort to keep their student focused and off of inappropriate sites, parents may end up being too controlling, inadvertently causing difficulties with school work.

Technology can be a source of difficulty not just for the high school level, but also students in college. Parents try to control and end up monitoring through all use; it just creates animosity, as the students need access to technology to complete homework. (Ms. White)

Parents struggle to help their students achieve. They try limiting phones or turning off internet access for certain hours of the day. Some students try to maintain this 
discipline themselves. It is a fine line between how much trust to give them and how much to monitor — both over their social and academic environments.

\section{Technology and Problem Solving}

With technology, the activities of research and inquiry have shifted. There is expectation that the problem can be Googled instantly.

Students need access to technology. I'm not convinced...Students now show an impatience for the answer rather than (what we knew) in working through a problem. Regarding technology, Google has changed the way problem solving occurs. (Ms. Crouven)

\section{Competing Interests of Tech in the Classroom}

The struggle to compete with phones is outrageous. In every class, with every teacher, there is a constant battle for students' attention and focus. Even the most highly motivated students are tempted to reply to friends' texts regarding where to go to lunch or what to do over the weekend. Students are addicted and not able to focus.

Students learn best when they don't have distractions. They need to be able to focus on the materials or concepts. They need their technology--but not access to texting where to go to lunch. They need their pictures and videos. They think they learn better with music--I'm not convinced. They do learn better when they can discuss or share their ideas. Their learning has to be broken into 15-20-minute segments--and they need to move around. Their learning space has to be conducive to movement and communication with easily accessible technology. (Ms. Crouven) 
Dr. Hed, the principal of Catamount High, discussed the issue of personal devices in the classroom:

Technology is like a pair of jeans. I don't care if you wear jeans, as long as it does not get in the way of teaching....technology should not get in the way of a student. For instance, if a student is on his phone, ask a student, turn your phone over please. Your class should be more engaging than whatever is happening on the phone. If it is not, that is a quick email later to mom. They lost today. Keep moving. There is no fight. Eventually a guidance counselor is involved, and an administrator is involved. It is the same as the jeans thing. Technology is a tool. Like a hammer. Don't make kids learn in a way that makes them miserable all day. They need to be better collaborators. They need to be able to listen, but listen for five or ten, collaborate for five or ten, and discover for five or ten. If somebody can only learn that one way, then keep them going that one way, then at some point move them over a little bit...technology isn't the thing, it is the people.

\section{Affluence, Access, and the Digital Divide}

Dr. Hedrick addressed the digital divide:

I think the important piece is to make sure that students can learn in both places with as much equity as we can manage for them. We can't change who their parents are or what their resources are at home. We can do our best to make sure that their resources at home or lack of resources at home don't hold them back any more than necessary. That is what we try to do. 
In the spring of 2019 , the media center began a policy that students were to sign into the media center digitally using iPads. The previous procedure was that students were simply asked to sign in using pen and paper. The electronic sign-in process was time intensive and resulted in long lines outside the library. The long lines meant that students had less time to use the library during lunch time, and so less students used the library and computers due to the belabored iPad sign-in procedure. There are approximately 300 computers in the library for a student population of approximately 2,800 . There is one printer to which students may print for a fee. The media center offered no morning hours and was open for 30 minutes only after school. After 3:00 p.m., the entire school, other than the athletic wing, shut down and was inaccessible to students. Dr. Hed explained that Catamount High was a three to one school in that there was a device for every three students. Though this number sounded low, the devices were divided across the school by department. This distribution was uneven and was based on the course and county funding. Therefore, you could not find a repository of devices that students could easily check out or access. It was up to the student and the parent to address any digital gap that Wave County could not address.

\section{Conclusion to Technology}

Technology proved to be a doubled edged sword, in the fact of the necessity of it to promote learning, but also a reliance on it as well as technology as a source for social or entertaining distractions. It required utmost discipline on the part of students to be able to use one device for learning while the device simultaneously offered a source of distraction from the curricular task.

\section{Figures Related to Theme 5}




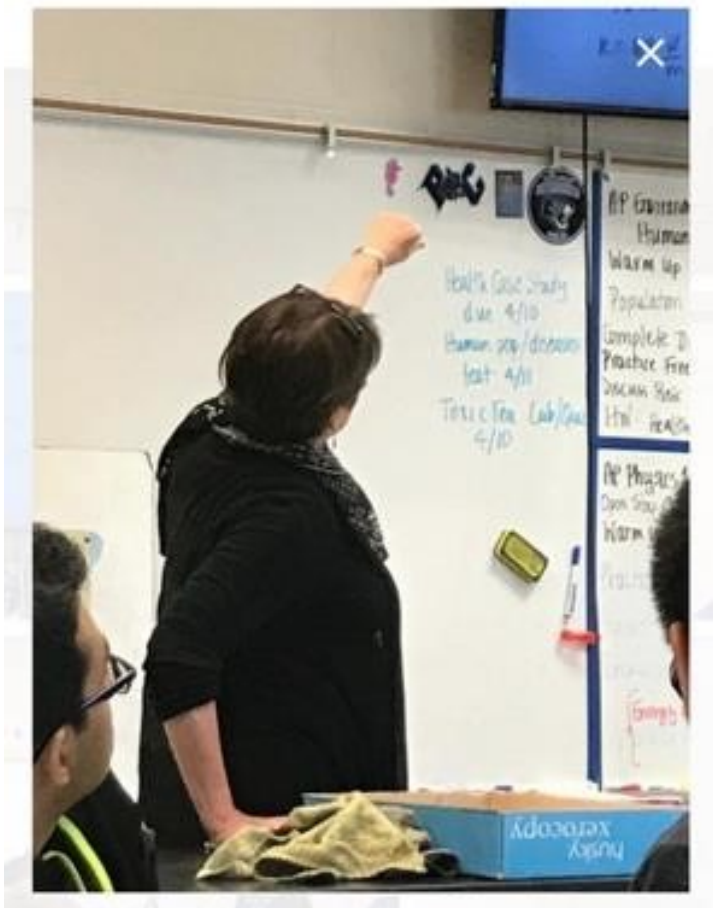

Figure 4.79: Teacher's use of both the white board and new led tv screens for instruction

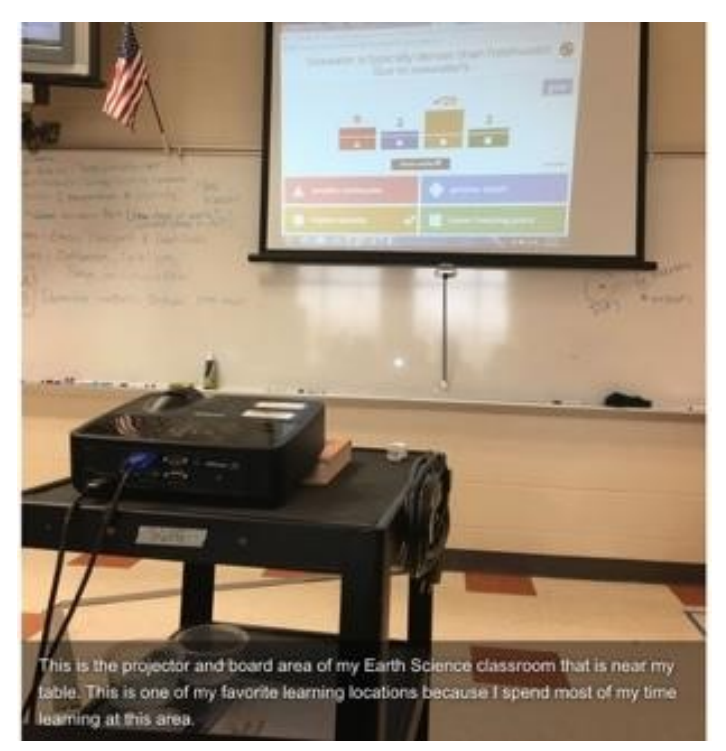

Figure 4.80: Classroom projectors, retractable screens and white boards

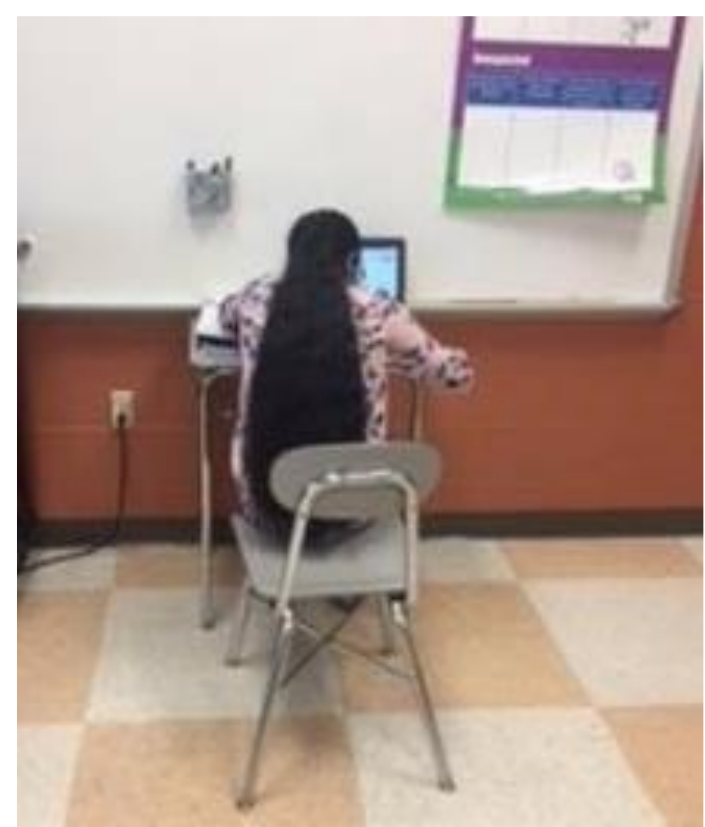

Figure 4.81: Student using technology

alone in an autism classroom

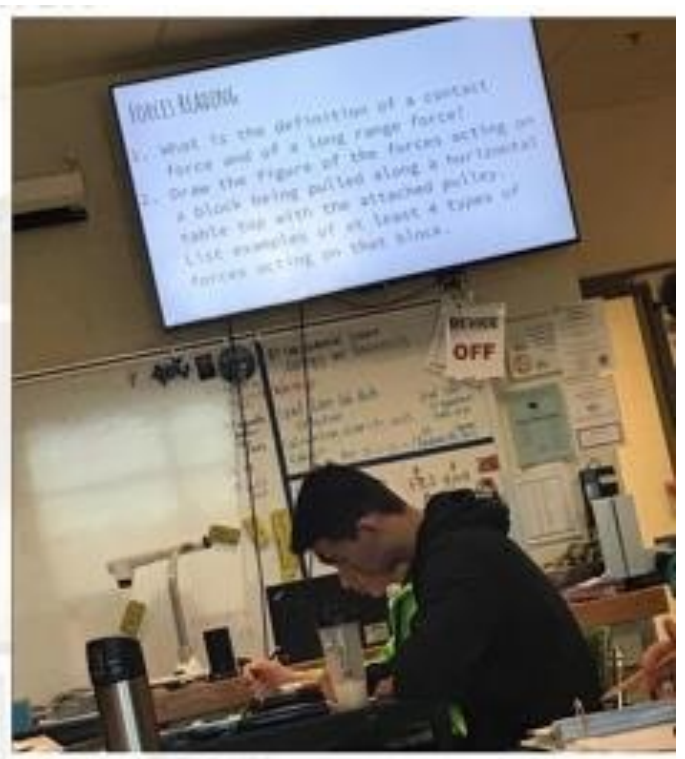

Figure 4.82: Students taking notes from the large led screen and the white board 


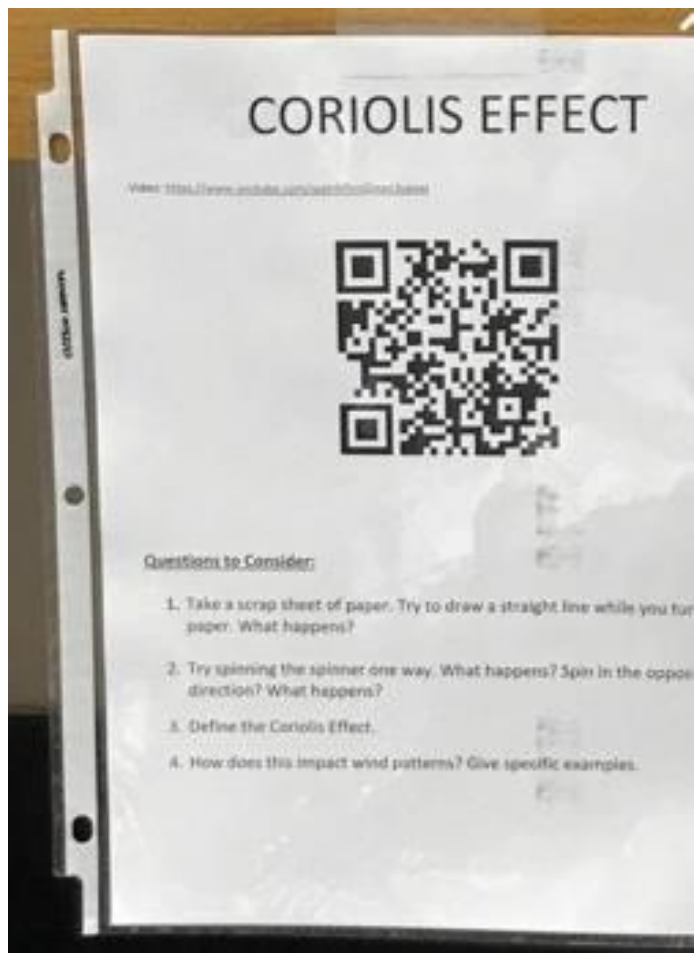

Figure 4.83: Collaborative hallway

gallery activity $\mathrm{QR}$ codes 


\section{Chapter 5: Discussion}

This research relevant to learning environments commenced with the hope to show the entire gestalt view of learning inside and outside of school as experienced by students and facilitated by teachers and administrators. Learning is not limited to the sphere of school but continues after the school day ends. What happens after the school day ends impacts student performance. These two learning spheres of informal and formal learning environments make up a whole. This dissertation research offers a window into that dynamic. There is learning that happens at school, and some of the components of that environment can be controlled by administrators, architects, teachers, etc. In the informal learning environments, students and parents may have more control than in a formal school setting. Students might have a high level of intrapersonal knowledge and understand what they need to do to learn best. Consistent elements, when moving across spheres of workspaces — formal to informal — are self-regulated learning and access to technology.

The researcher did not adhere to an explanatory framework or attempt to generalize about the condition of schools. The goal was to explain the dynamic learning environments of adolescents as they moved back and forth between their formal school environments and their informal home environments. The formal school environment has a range of affordances, interpreted and elaborated by learning facilitators and students.

In the previous chapter, connections relevant to spatial preference, self-regulated learning, and technology usage were noted. The researcher elaborated the way in which themes emerged from the data around the topic of spatial preference, including replication and evolution, gathering space and solitary spaces, and spaces for comfort. 
Relevant to self-regulated learning, there is the focus of students seeking spaces to

thrive. Relevant to technology use, the main objective is the balance between the usage of technology as a conduit to learning and technology as a deterrent to learning. In this discussion chapter, the researcher will summarize the findings, make a conclusion according to each of the three research questions, provide a discussion, and outline suggestions for future research.

\section{Summary of Findings}

\section{Gathering Spaces}

The research points to collaboration to invigorate and promote innovative learning strategies. Creating environments to promote collaboration is best. In packed classrooms, this has meant using overflow spaces such as hallways, locker bays, and other common areas to ease density and promote unencumbered gathering. Relevant to home gathering, some of the participants in the study worked with siblings in common spaces as a means of support. Some worked near parents to feel encouraged, motivated, or to have a sense of family.

Regarding solitary work at school, some of the participants prioritized work over social and selected particular learning environments if they wanted to be more productive. For example, some students went to the media center to focus rather than more crowded social areas. Other students could work fastidiously by themselves in the middle of a noisy mob of students. Regarding solitary work outside of school, participants would often use work surfaces that were not needed by many in their family or they would sequester themselves in their bedrooms. Students were sensitive to the needs and concerns of their family, often shifting from a common space to a solitary 
space like their bedroom, so as not to concern parents if they needed to work very late into the night. Students in this study used gathering time to facilitate their learning. If they were not studying with friends, all noted the fact that they would prioritize work and move to another location in school or outside of school to be able to better focus on academic work. Both gathering spaces and solitary spaces were used to promote work. The use of space could be used to promote socialization over learning with another student sample population.

\section{Comfort Spaces}

In the research, students sought comfortable environments at school in order to do their work. This comfort was defined by a number of different factors, including the relationship the student had with the teacher and the atmosphere of the room, whether warm and inviting or cold and sterile. Students sought spaces with ambient temperatures, sufficient lighting, and moderate sound levels. Students responded to the use of incandescent and accent lighting in the classrooms, citing the warm lights to be comfortable.

Outside of school, students sought access to large, open work surfaces, comfortable seating, natural lighting, moderate sound, and access to food and drink. Designated student desks were often not used because of limited surface area, being placed away from the heart of the home, and uncomfortable temperature and light fluctuations.

\section{Evolving Spaces}

The data showed that evolution within school settings, from the state level down to the individual classroom, historically changed at a relatively slow pace. Design 
changes may be ahead of educational practices or vice versa. Sometimes the educational innovation precedes slow moving design innovation that is tethered to funding and a belabored approval process. The evolution process outside of school was nimbler, as students initiated the change patterns and moved fluidly between common areas and isolated areas, dancing between parent expectations and demands.

\section{Self-regulated Learning: Finding Spaces to Learn}

Self-regulated learning is an attribute whereby students make conscious choices regarding their learning environment, as well as the population and technology that is included in the learning space. The students were able to move themselves to less social spaces or adjust things like music and sound level according to the course content. Students were able to motivate themselves through actions such as placing their work areas near parents and limiting cell phone use.

\section{Technology}

Catamount High had a less than a 1:1 ratio of students to computers. All classes used a Content Management System (CMS) such as Canvas. All students were required to use the CMS, in addition to the class websites, to retrieve and submit information.

Prior to 2014, students were not allowed to use personal devices at Catamount High. After 2014, a "Bring Your Own Device" or BYOD policy was put in place. Students would bring their phones, iPad, and laptops to supplement their learning. Technology classes offered a 1:1 student to device ratio, while core classes were at a 10:1 ratio and world languages were at a 14:1 ratio. Because students need to bring their own devices to supplement learning, there has been the continual issue of balancing the devices for personal use with educational use. Technology is part of this research on 
spatial preference because it is through the use of technology that learning has been freed from restricted locations.

\section{Discussion}

In this discussion section, the meaning of the results and the way in which they relate to the literature will be elaborated. Dewey's (1933) practical inquiry model involved pre-reflection, reflection, and post-reflection. This is a model based on experience as the heart of the issue, that was instigated by curiosity at the start, and resolved with a unified situation at the close.

\section{Operationalization of Affordance Theory}

\section{Findings and Theory}

The themes that surfaced in this research - gathering, comfort, change, selfregulated learning, and technology—have connections to two main areas of theoretical research: sense of place and affordance theory.

This study is unprecedented because it has provided a unique window into the soul of adolescent learning sense of place. The data revealed beautiful and consistent use patterns as student struggled against so many challenges while attempting to master their course content. The students reflected self-knowledge related to their environments, as they performed a dance between isolation and gathering, structure and comfort, silence and sound, until the environment was not a deterrent, but rather served its function in easing the body and sharpening the mind to allow for mental flow. Teacher participants brought us into their classrooms, as well as the other spaces throughout the school that they have adopted for the purpose of facilitating learning for hundreds of differentiated adolescent learners. This research carved intricacies into the monolith that is affordance 
theory. The way in which adolescents use space and perform learning is unique to them. This teen cohort, caught in the tide between childhood and adulthood, while pushing ahead through content mastery, takes solace in the repetitive cycle that is school and home.

Prior research documented that learners perform better in a preferred environment compared to a non-preferred environment (Hattie \& Watkins, 1988; Wong \& Watkins, 1996). Wong and Watkins (1996) found that the impact of the learner-environment fit was more critical among low self-monitoring individuals than among high selfmonitoring individuals. High self-monitoring individuals can more easily adapt themselves to different situations.

The current study found that students seemed to form a bond with settings that support their functional needs. Multiple students sought out particular space types based on the content. This finding relates to the concept of place dependence, which is the person-place bonding with spaces that support human needs such as productivity. This research study allowed a view into the lives of students and teachers as they embodied and performed the natural behavior setting in the formal environment of "school." Through technology, this formal learning environment of school, and the inherent structured behavior setting, informal learning environments may echo the synomorphic qualities of the behavior setting that is school. However, the simple introduction of technology does not implicitly transform informal learning environments to have the same behavior setting fidelity as the formal learning environment that is school. There is significant work that needs to be done on the part of the learners in order to extend this behavior setting that is school outside of the confines of the physical school building. 
This work means that learners require self-regulation of learning to extend this behavior setting. The high self-monitoring students involved in this study detailed how they were able to extend affordances from formal to informal learning environments. Similar to Wong and Watkins (1996), low-self monitoring individuals may face more challenges in extending the affordances from formal to informal learning environments.

\section{Conclusions About the Research Questions}

\section{Conclusion 1: Having choice: Students have spatial preferences for specific learning environments}

Earlier in the chapter two literature review, we read about the relationship of the physical learning environment and cognitive load theory. We read about investigations where certain types of learning spaces are more fitting for certain tasks. Participants in this study followed these varietal trends, seeking out specific physical learning environments that would idealize their learning for a range of diverse tasks. This means that learning spaces make a difference and, when given a choice, some self-regulated students choose specific learning environments to maximize their learning potential. Specific learning spaces are sought out for their learning affordances. Spatial preferences should be a consideration for a variety of learners at school and outside of school. A discussion of spatial affordances points to inequality. Some students have plush spaces dedicated to their individual focus and study. Other students have very little private space dedicated to their learning. When possible, learners should be offered some choices of learning environments. Teachers in the study disagreed as to the type of student that could handle spatial choices as well as the type of student that should be allowed freedom to move as they learned. 


\section{Conclusion 2: Having variation: Students seek a variety of learning environments to impact self-regulated learning}

Students should be asked to reflect upon how they are learning and where they are learning. The students involved in the study were very aware of their learning patterns and would change learning settings to optimize their learning. In both formal and informal learning environments, students should be encouraged to experiment and be flexible regarding their learning environments. Also, students may have a few preferred learning environments that might shift relative to the course content or activity. A range of different environments might be preferable depending on the course content. Comfort indicators such as temperature, decibel levels, light levels, etc. are relevant to these preferred learning environment choices.

\section{Conclusion 3: Technology helps and hinders}

The third conclusion is that technology is necessary, especially for blended or remote learning. Simultaneously, because students are relying on their own devices, technology is also serving as a distraction from learning. The use of technology, and control of it, ties into the self-regulated learning piece. Students need to develop an awareness not only of how they use learning spaces, but also the way in which technology is promoting learning.

\section{Future Research}

There are five main areas of future research related to this investigation. These five research areas include formal and informal learning environments, self-regulated learning, technology impact, an expansion of scope and a longitudinal study. 
This spatial study relevant to the relationship of spatial preference, self-regulated learning, and technology was conducted at one mid- to upper-class suburban high school located in a southeastern state. Students reflected on the research in school and outside of school settings. Future research could include multiple high schools in this region or surveying multiple high schools across the country from a broader socioeconomic range. Another research endeavor could feature a longevity study. This would involve a similar study but could track student progress over time, from elementary school through high school, tracking spatial preferences, self-regulated learning, and technology use. Impact of this research:

This research has impact on a variety of disciplines including the domains of education and the design of learning environments. Educational administrators and teachers can make a variety of learning environments available to their learners. They can be reminded that even the same learner will choose a variety of learning environments. Providing choice and variety are key.

For designers of formal learning environments, this study serves as a guide for the provision of a multitude of types of learning environments. Providing for a variety of types of worksurfaces, seating, lighting as well as individual and collaborative spaces, will allow students options when selecting their preferred learning environment. For designers of residential environments and parents, this study reinforces the guideline to provide for a variety of learning spaces to support learners of all ages.

Implications Research indicates that students seek out specific places in order to idealize their learning. Over the year of data collection in Wave County schools at Catamount High, students indicated a variety of preferred places based on learning content and 
learning tasks. It is critical for designers, administrators, teachers and parents to support a range of learning environments.

Implication 1: Encourage learning affordances of non-traditional classroom spaces on campus. Schools should harness the potential of the whole school campus, and avoid classroom compartmentalization. Effective schools support a range of learning environments. Administrators encourage the use of non-traditional classroom spaces to continue learning. Prior to data collection, locker bays were ripped out and collaborative centers were put in their place. The collaboration bays act as relief for students in overcrowded classes. The movement between formal classroom and the collaboration bays in formal class time helps promote both movement and group work. Other nontraditional spaces in the school were transformed into learning spaces. Hallways were turned into content galleries, where students moved in groups from problem to problem, solving in groups as they moved problem to problem. Stairwells were needed by chorus students in order to understand how their sounds reverberated together. Autistic students sought out their familiar and sensory-aware home classroom, in the case that one of their mainstream classroom environments was overstimulating. Language classes that were in need of space for language listening and speaking assignments overflowed into the commons area. This implication involves buy in not only from teachers and school administrators, but also designers revolutionizing schools and learning environments. Designers should extend the routine programmatic confines and typical square footage allotments when designing schools. Designers should embrace the notion that learning spaces are fluid and nontraditional classroom spaces have the potential to serve as learning affordance strongholds. 
Implication 2: Spatial affordances are integral to self-regulation. The selection of certain learning environments and conditions to foster learning of particular content. Learners who have strong self-regulation skills may be more in tune with the nuances of the environment that idealize learning. In the research, students sought out particular spaces for the fact that they would help them learn better. Students went to particular classroom environments for certain subjects because they could retain information more effectively. Students adjusted their worksurfaces, seating, lighting and sound according to the content that they were trying to master.

Implication 3: Teachers and school administrators are gatekeepers to permitted spatial affordances within formal learning environments. Perceptions of the self-regulation skills of students factored into the range of allowed spatial affordances. Student movement and self-regulation were linked. Some teachers who perceived students to be highly selfregulated allowed students more freedom to move outside the classroom while students with weaker self-regulation skills were restricted to only the classroom. By contrast, other teachers who perceived students as having weaker self-regulation skills, were encouraging of these students to move freely within the classroom and outside of the classroom, while students with strong self-regulation skills were thought to be able to sit for an extended time at desks in rows in a traditional classroom.

Implication 4. Aspects of the behavior setting of the formal learning environment can be extended into informal learning environments, but they are not identical. Students have a need to learn content with as little interference as possible. Participants within the study noted a place dependence on the formal learning environment. There was a fit between 
the environment and learning behavior. This convergence of built form and use yield synomorphy. With onset of the COVID pandemic, the sudden emergency transition to a predominant use of informal learning environments, and relative loss of the formal learning environment as had been known, the formal learning environment has proved to be a critical player in the ability of students to effectively self-regulate and perform at school.

Implication 5. Technology is a necessary bridge in linking formal and informal learning environments. The continuation of learning outside of the formal learning environment is hinged upon the ability for students to seamlessly connect to the course content. This same technology that serves as a bridge can also serve as interference if social media and other content are permitted

Implication 6. Students should be encouraged to strengthen self-regulation skills as they pertain to spatial affordances. Similar to the photovoice journaling used in this research, as part of their introductory high school curriculum, students should be encouraged to journal about their perceived affordances of the built formal and informal learning environments. Through this journaling, effective use patterns may be revealed.

Implication 7. Parents are gatekeepers to informal learning environments. Participants in the study frequently mentioned the role of their parents in relation to the use of spaces at home. When it was available, many students claimed large open work surfaces in dining rooms that would allow them to spread out and work with access to sufficient lighting as well as nourishment from adjacent kitchens. Participants were sensitive to parents' feedback regarding their use of spaces, and would move to other learning environments 
in the case that there were timing issues or conflict of use. Multiple students noted a reluctance to work in their bedrooms, but would move to these areas so as to be less disruptive. Guidance should be provided to parents regarding the support of learning affordances and self-regulation practices outside the formal school environment. As an extension of this current study, tools can be developed to aid with the support of student learning affordances and self-regulation practices.

\section{Conclusion}

This study provided a glimpse into learning settings both in school and outside of school. The three elements of spatial preference, self-regulated learning, and technology usage have surfaced to be the framework for upholding distance learning. Kutsyuruba (2015) advocated that researchers should facilitate investigations around educational experiences that naturally happen within nested structures of classrooms, peer groups, neighborhoods, etc. This work facilitated a view into the detailed learning worlds of adolescents as they journeyed across informal to formal learning environments. This story also involved a view from the learning facilitators, those who helped to establish the presence that is school, in all its interpretations and implications. Earlier in the text there was the discussion of place dependence. The formal school environment helps to foster learning function and productivity. There is something inherent to the behavior setting of the formal school environment. This "something" is the fact that the milieu is synomorphic to the behavior. (Heft, 2001). The challenge that faces us now in 2021 is that the world has shifted. Informal learning environments have become heavily, if not completely, the singular environment for learning. With this shift, the Pavlovian cognitive responses to formal learning environments have been set adrift. With the 
temporary loss of the formal learning environment, the implicitness that is learning in a school building has now become a task that is enigmatic and contested. Access to technology, devices and an uninhibited user experience, regardless of age or demographic, is the expectation. Making the informal learning environments mimic the synomorphy of formal learning environments requires supporting and strengthening learners' self-regulation skills. In this unprecedented time in our history when thousands of formal learning environments around the world have been shuttered, let us remember what a precious gift it is to be able to physically gather and proliferate the light of each learner. 


\section{Appendices}

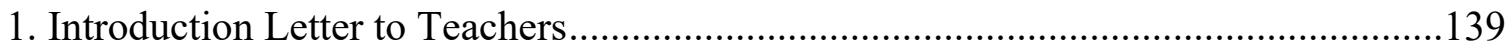

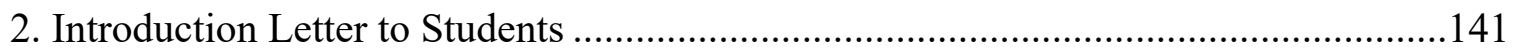

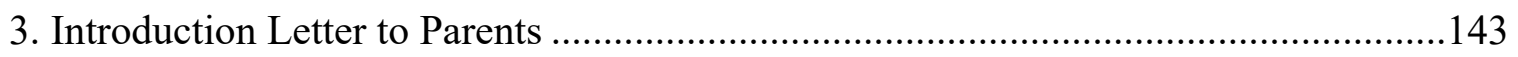

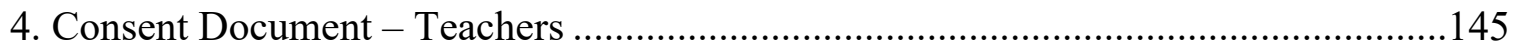

5. Consent Document - Students 18 and older ............................................................149

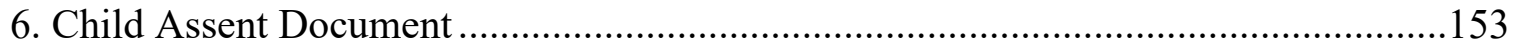

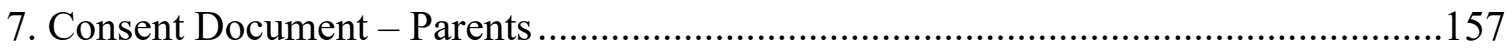

8. Photo Release Form for Subjects Not in the Study, But Who Will Have Their Photo

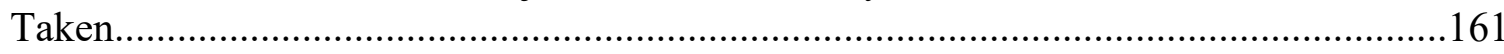

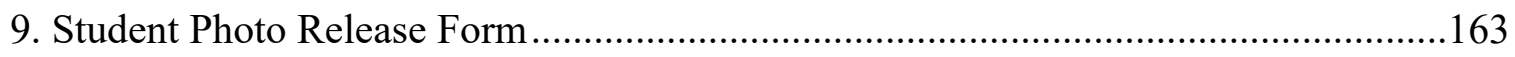

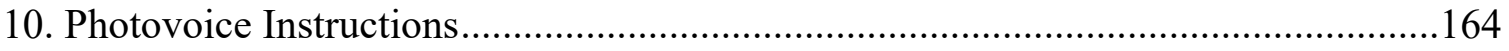

11. Teacher Interview Questions ...............................................................................165

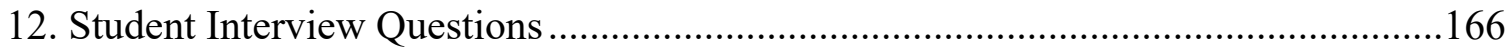

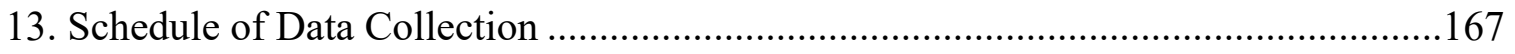




\section{APPENDIX 1. Introduction Letter to Teachers}

Researcher's Name(s): Amy Frisz-Conlon

Project Number: 2009139C

Project Title: Stitching Cognition: An Investigation of Formal and Informal Learning Environments

Dear Panther Creek faculty,

My name is Amy Frisz-Conlon and I am a Digital Media teacher here at Panther Creek High School. This is my sixth year here at the school and my computer lab is located in 3511. In addition to being a teacher, I am also a doctoral student candidate at the University of Missouri. My PhD will be in Architectural Studies with Emphasis Areas in Environment and Behavior/Digital Media. My specific doctoral research topic involves an investigation of learning in formal and informal learning environments. Dr. Hedrick, Principal at Panther Creek High School, as well as Mathew Lenard from WCPSS Research have granted me authority to collect data. You are receiving this letter inviting you to participate in the research study. The research will commence in February 2018 and should conclude by February 2019.

The purpose of the research is to investigate three things:

- Students' preferred learning spaces at school and home

- Students' perception of their own cognition in these preferred learning places at school and home

- Students' use of technology in these preferred learning places at school and home

There will be two ways in which we will gather data:

- Interviews with teachers and students

- Photovoice

Interviews will take place at the beginning and the end of the research. The interview at the beginning will be a group interview. The interview at the end will be individual for the purpose of understanding more about each photovoice project. Photovoice provides an opportunity to use images and text to reveal patterns. You will take photos and videos at school (formal learning environments) and outside of school (informal learning environments) with your phone. The photos and videos you take should feature places where you feel that students are learning best. You will also reflect on your selfperception of students' cognition (learning) in these spaces. The photos and videos will feature the technology used in these learning spaces. You will have the opportunity to take photos and videos over two, ten-day intervals. It is advised at the end of each school day, that each participant download photos and videos from their phones and add them to their password-protected website blogs. When uploading photos and videos to the blogs, it is advised that participants add a note or two regarding their perception of student cognition and technology use relevant to the photo of the learning space. The photos and videos may include images of other students and teachers. The blogs will be anonymous 
private, password-protected sites managed by the researcher. The purpose of the blogs is to show the variety of the learning environments and establish easy visual comparison across places and times. It is hoped that patterns will surface through examination of place, perceptions of cognition and use of technology. The photos and videos may include other students and teachers.

The study will commence in February 2018 and should conclude by February 2019. Students will be asked to provide feedback for two two-week intervals. Each two-week interval consists of 10 school days. Students will be able to provide feedback at school and at home. The amount of time required should be no more than five minutes per day over the two ten-day intervals. The interviews at the beginning (group) and end of the research (individual) should take no more than thirty minutes.

What is my incentive?

First, you have the incentive of helping to advance knowledge about cognition and learning environments at the K-12 level. In addition, at the end of the semester, you will receive a $\$ 30$ gift card for your participation in the study.

Sincerely, Amy Frisz-Conlon

afrisz-conlon@wcpss.net 


\section{APPENDIX 2. Introduction Letter to Students}

Researcher's Name(s): Amy Frisz-Conlon

Project Number: 2009139C

Project Title: Stitching Cognition: An Investigation of Formal and Informal Learning Environments

My name is Amy Frisz-Conlon and I am a Digital Media teacher here at Panther Creek High School. This is my sixth year here at the school and my computer lab is located in 3511. In addition to being a teacher, I am also a doctoral student candidate at the University of Missouri. My PhD will be in Architectural Studies with Emphasis Areas in Environment and Behavior/Digital Media. My specific doctoral research topic involves an investigation of learning in formal and informal learning environments. Dr. Hedrick, Principal at Panther Creek High School, as well as Mathew Lenard from WCPSS Research have granted me authority to collect data. You are receiving this letter inviting you to participate in the research study. The research will commence on February 2018 and should conclude by February 2019.

The purpose of the research is to investigate three things:

- Your preferred learning spaces at school and home

- Your perception of your own learning in these preferred learning places at school and home

- Your use of technology in these preferred learning places at school and home

There will be two ways in which we will gather data:

- Interviews with teachers and students

- Photovoice

First a group interview process in the beginning of the study will be conducted with participants in order to allow for greater understanding of your spatial preferences, perceptions of cognition and use of technology. A second individual interview will take place at the end of the study to learn about individual photovoice projects.

The photovoice process in the second way in which we will collect data. You will take photos and videos at school (formal learning environments) and outside of school (informal learning environments) with your phone. The photos and videos you take should feature places where you feel that you are learning best. You will also reflect on your self-perception of your cognition (learning) in these spaces. Lastly, the photos and videos will feature the technology that you use in these learning spaces. You will have the opportunity to take photos and videos over two, ten-day intervals. It is advised at the end of each school day, that each participant download photos and videos from their phones and add them to their password-protected website blogs. The blogs will be anonymous private, password-protected sites managed by the researcher. The purpose of the blogs is to show the variety of the learning environments and establish easy visual 
comparison across places and times. It is hoped that patterns will surface through examination of place, self-perception of cognition and use of technology.

You will be asked to provide feedback for two two-week intervals. Each twoweek interval consists of 10 school days. You will be able to provide feedback at school and at home. The amount of time required should be no more than five minutes per day over the two ten-day intervals. The interviews at the beginning and end of the research should take no more than thirty minutes.

The research will take place during the spring semester 2018. It is my expectation that data collection will start during February 2018 and conclude by April 2018.

Share this letter:

If you are willing to participate, you will need to present this letter and attached forms to your parents to make them aware of your participation in the project. Complete the forms with your parents and return them to the researcher, Amy Frisz-Conlon, no later than $3 / 18 / 18$. You may bring the forms to lab 3511 or deliver them to the main office. No names will be utilized in this study and all identities will be protected.

What is my incentive?

First, you have the incentive of helping to advance knowledge about cognition and learning environments at the K-12 level. In addition, at the end of the semester, you will receive a $\$ 30$ gift card for your participation in the study. Your gift card amount will be pro-rated if you complete only a portion of the study.

We look forward to your participation, and please do not hesitate to contact me.

Sincerely,

Amy Frisz-Conlon

afrisz-conlon@wcpss.net 


\section{APPENDIX 3. Introduction Letter to Parents}

Researcher's Name(s): Amy Frisz-Conlon

Project Number: 2009139C

Project Title: Stitching Cognition: An Investigation of Formal and Informal Learning Environments

My name is Amy Frisz-Conlon and I am a Digital Media teacher here at Panther Creek High School. This is my sixth year here at the school and my computer lab is located in 3511. In addition to being a teacher, I am also a doctoral student candidate at the University of Missouri. My PhD will be in Architectural Studies with Emphasis Areas in Environment and Behavior/Digital Media. My specific doctoral research topic involves an investigation of learning in formal and informal learning environments. Dr. Hedrick, Principal at Panther Creek High School, as well as Mathew Lenard from WCPSS Research have granted me authority to collect data. You are receiving this letter inviting you to participate in the research study. The research will commence on February 2018 and should conclude by February 2019.

The purpose of the research is to investigate three things:

- Your child's preferred learning spaces at school and home

- Your child's perception of their own cognition in these preferred learning places at school and home

- Your child's use of technology in these preferred learning places at school and home

There will be two ways in which we will gather data:

Interviews with teachers and students at the beginning and end of data collection. Introductory interviews will be in a group format and will include information such as how to take photos and how to add the images and comments to password-protected blogs. The interviews at the end will be individual and will be for the purpose of seeking additional information in regard to the blog.

Photovoice. Students will have the chance to take photos, videos, etc., documenting their learning in some of these preferred learning places at school and home. Teachers will document where they think students are learning best. Participants will then add photos, videos and comments to private, password-protected blogs.

No names will be utilized in this study and all identities will be protected.

What is your child's incentive?

First, your child has the incentive of helping to advance knowledge about cognition and learning environments at the K-12 level. In addition, at the end of the semester, your child will receive a $\$ 30$ gift card for participation in the study. If your child does not complete the study, they will be provided a prorated gift card amount. 
If your child wants to participate in the study:

Complete the attached assent and consent forms and return to the researcher, Amy FriszConlon, in lab 3511, or bring to the Panther Creek main office. Your child then will be contacted for an introductory group interview session, scheduled to take place at the end of February 2018.

Sincerely,

Amy Frisz-Conlon

afriszconlon@wcpss.net 


\section{APPENDIX 4. Consent Document - Teachers}

Teacher Consent Form to Participate in a Research Study

Researcher's Name(s): Amy Frisz-Conlon

Project Number: 2009139C

Project Title: Stitching Cognition: An Investigation of Formal and Informal Learning Environments

\section{INTRODUCTION}

This consent may contain words that you do not understand. Please ask the investigator or the study staff to explain any words or information that you do not clearly understand. You are being asked to participate in a research study. This is a study about understanding students' spatial preferences of learning environments across formal and informal environments. Further, it will address student perceptions of cognition, and the use of learning technologies across these formal and informal learning environments. When you are invited to participate in research, you have the right to be informed about the study procedures so that you can decide whether you want to consent to participation. This form may contain words that you do not know. Please ask the researcher to explain any words or information that you do not understand.

You have the right to know what you will be asked to do so that you can decide whether or not to be in the study. Your participation is voluntary. You do not have to be in the study if you do not want to. You may refuse to be in the study, and nothing will happen. If you do not want to continue to be in the study, you may stop at any time without penalty or loss of benefits to which you are otherwise entitled.

\section{WHY IS THIS STUDY BEING DONE?}

The purpose of this research is to understand students' spatial preferences of learning environments across formal and informal environments. Further, it will address student perceptions of cognition, and the use of learning technologies across these formal and informal learning environments.

You are invited to be in this study because you are a teacher at Panther Creek High School. We have received permissions from Dr. Hedrick and Mathew Lenard at WCPSS Crossroads to conduct this research at Panther Creek High School. Some of your students may also elect to participate in this research. As part of this research, you will have the opportunity to reflect on your perceptions of students' spatial preferences of learning environments at school and home. Further, you will have the opportunity to reflect on your perceptions of students' cognitive levels and students' use of technology in these formal and informal learning spaces.

HOW MANY PEOPLE WILL BE IN THE STUDY? 
About 25 people will take part in this study at Panther Creek High School.

IRB Approved Date 3/1/2018 Expiration Date 3/1/2019 Project \#2009139

\section{WHAT AM I BEING ASKED TO DO?}

You, other teachers and other students will participate in a research study. A group interview process in the beginning of the study will allow for greater understanding of your perception of students' spatial preferences, your ideas of students' self-perceptions of cognition and student use of technology in these learning environments. A second individual interview will be conducted at the end of the study for the purpose of understanding more about each photovoice entry.

Complete a photovoice blog. This password-protected blog will offer an opportunity for teachers and students to upload their photos, voice recordings and videos about their formal and informal learning environments. The photos and videos may include images of other students and teachers. The blogs will be anonymous private, password-protected sites managed by the researcher.

The study will commence in February 2018 and should conclude by April of 2018. Teachers and students will be asked to provide feedback for two two-week intervals. Each two-week interval consists of 10 school days. Teachers and students will be able to provide feedback at school and at home. The amount of time required should be no more than five minutes per day over the two ten- day intervals. The interviews at the beginning and end of the research should take no more than twenty minutes.

\section{HOW LONG WILL I BE IN THE STUDY?}

The study will commence in February 2018 and should conclude by April 2018. You can stop participating at any time without penalty.

\section{WHAT ARE THE BENEFITS OF BEING IN THE STUDY?}

Your participation will benefit the way in which you perceive students' spatial preferences, students' self- perceptions of their cognition related to these spaces, and students' use of learning technologies in these spaces. You will be compensated with a $\$ 30$ gift card at the end of the data collection. Gift cards will be pro-rated based on the length of participation time.

\section{WHAT ARE THE RISKS OF BEING IN THE STUDY?}

The risks of the research are that you may become tired of participating. You may come to understand that students prefer certain spatial configurations and learn best in these environments. The challenge might be to endure less ideal spatial preferences. There will be the use of photography, audio or video recording by subjects in their learning 
environments. Risks will be minimized because identities will not be revealed in the study.

Another risk is possible invasion of privacy, as subjects will be documenting their learning environments inside and outside of school. Risks will be minimized because identities will not be revealed in the study.

\section{CONFIDENTIALITY}

nformation produced by this study will be stored in the investigator's file and identified by a code number only. The code key connecting your name to specific information about you will be kept in a separate, secure location. Information contained in your records may not be given to anyone unaffiliated with the study in a form that could identify you without your written consent, except as required by law. In addition, if photographs, audiotapes or videotapes were taken during the study that could identify you, then you must give special written permission for their use. In that case, you will be given the opportunity to view or listen, as applicable, to the photographs, audiotapes or videotapes before you give your permission for their use if you so request.

\section{WILL I BE COMPENSATED FOR PARTICIPATING IN THE STUDY?}

You will be compensated a $\$ 30$ gift card for completion of the duration of the study. A pro-rated amount will be provided for partial completion of the study.

\section{WHAT ARE MY RIGHTS AS A PARTICIPANT?}

Participation in this study is voluntary. You do not have to participate in this study. You will also be informed of any new information discovered during the course of this study that might influence your health, welfare, or willingness to be in this study.

\section{WHO DO I CONTACT IF I HAVE QUESTIONS, CONCERNS, OR COMPLAINTS?}

Please contact Amy Frisz-Conlon at amyfrisz@gmail.com or Dr. Benyamin Schwarz at bschwarz@missouri.edu if you have questions about the research. Additionally, you may ask questions, voice concerns or complaints to the research team.

\section{WHOM DO I CALL IF I HAVE QUESTIONS OR PROBLEMS?}

If you have any questions regarding your rights as a participant in this research and/or concerns about the study, or if you feel under any pressure to enroll or to continue to participate in this study, you may contact the University of Missouri Campus Institutional Review Board (which is a group of people who review the research studies to protect participants' rights) at (573) 882-9585 or umcresearchcirb@missouri.edu. 
You may ask more questions about the study at any time. For questions about the study or a research- related injury, contact Amy Frisz-Conlon at 919.623.8775.

A copy of this Informed Consent form will be given to you before you participate in the research.

\section{SIGNATURES}

I have read this consent form and my questions have been answered. My signature below means that I do want to be in the study. I know that I can remove myself from the study at any time without any problems.

Subject

Date

IRB Approved Date 3/1/2018 Expiration Date 3/1/2019 Project \#2009139 


\title{
APPENDIX 5. Consent Document - Students 18 and Older
}

\author{
Consent Form for Students Over Age 18 to Participate in a Research Study
}

Researcher's Name(s): Amy Frisz-Conlon

Project Number: 2009139C

Project Title: Stitching Cognition: An Investigation of Formal and Informal Learning Environments

\section{INTRODUCTION}

This consent may contain words that you do not understand. Please ask the investigator or the study staff to explain any words or information that you do not clearly understand.

You are being asked to participate in a research study. This is a study about understanding students' spatial preferences of learning environments across formal and informal environments. Further, it will address student perceptions of cognition, and the use of learning technologies across these formal and informal learning environments. When you are invited to participate in research, you have the right to be informed about the study procedures so that you can decide whether you want to consent to participation. This form may contain words that you do not know. Please ask the researcher to explain any words or information that you do not understand.

You have the right to know what you will be asked to do so that you can decide whether or not to be in the study. Your participation is voluntary. You do not have to be in the study if you do not want to. You may refuse to be in the study, and nothing will happen. If you do not want to continue to be in the study, you may stop at any time without penalty or loss of benefits to which you are otherwise entitled.

\section{WHY IS THIS STUDY BEING DONE?}

The purpose of this research is to understand students' spatial preferences of learning environments across formal and informal environments. Further, it will address student perceptions of cognition, and the use of learning technologies across these formal and informal learning environments. You are invited to be in this study because you are a student at Panther Creek High School. We have received permissions from Dr. Hedrick and Mathew Lenard at WCPSS Crossroads to conduct this research at Panther Creek High School. One of your teachers has also elected to participate in this research. As part of this research, you will have the opportunity to reflect on your spatial preferences of learning environments at school and home. Further, you will have the opportunity to reflect on your cognitive levels and use of technology in these formal and informal learning spaces. 


\section{HOW MANY PEOPLE WILL BE IN THE STUDY?}

About 25 people will take part in this study at Panther Creek High School.

\section{WHAT AM I BEING ASKED TO DO?}

You and other students will participate in a research study. A group interview process in the beginning of the study will allow for greater understanding of your spatial preferences, perceptions of cognition and use of technology. A second, individual interview will happen at the end of the study for understanding more about your individual photovoice project. Photovoice will be explained next.

You will take photos and videos at school (formal learning environments) and outside of school (informal learning environments) with your phone. The photos and videos you take should feature places where you feel that you are learning best. You will also have the opportunity to reflect on your selfperception of your cognition (learning) in these spaces. Lastly, the photos and videos will feature the technology that you use in these learning spaces. You will have the opportunity to take photos and videos over two, tenday intervals. It is advised at the end of each school day, that each participant download photos and videos from their phones and add them to their password-protected website blogs. When uploading photos and videos to the blogs, it is advised that participants add a note or two in regard to their selfperception of cognition and technology use relevant to the photo of the learning space.

Complete a photovoice blog. This password-protected blog will offer an opportunity for students to upload their photos, voice recordings and videos about their formal and informal learning environments. The photos and videos may include images of other students and teachers. The blogs will be anonymous private, password-protected sites managed by the researcher. The purpose of the blogs is to show the variety of the learning environments and establish easy visual comparison across places and times. It is hoped that patterns will surface through examination of place, self-perception of cognition and use of technology.

The study will commence in February 2018 and should conclude by April 2018. Students will be asked to provide feedback for two two-week intervals. Each two-week interval consists of 10 school days. Students will be able to provide feedback at school and at home. The amount of time required should be no more than five minutes per day over the two ten-day intervals. The interviews at the beginning and end of the research should take no more than thirty minutes.

\section{HOW LONG WILL I BE IN THE STUDY?}

The study will commence in February 2018 and should conclude by April 2018. You can stop participating at any time without penalty. 


\section{WHAT ARE THE BENEFITS OF BEING IN THE STUDY?}

Your participation will benefit the way in which you describe spatial preferences, perceptions of your cognition related to these spaces, and your understanding of your use of learning technologies in these spaces.

\section{WHAT ARE THE RISKS OF BEING IN THE STUDY?}

The risks of the research are that you may become tired of participating.

Students may come to understand that they prefer certain spatial configurations and learn best in these environments. The challenge might be to endure less ideal spatial preferences.

There will be the use of photography, audio or video recording by subjects in their learning environments. Risks will be minimized because identities will not be revealed in the study. As part of the photovoice procedure, students and teachers will be documenting through photos and video, formal and informal learning environments, as well as their perceptions of cognition and use of technology in these spaces. There is the possibility that in documenting the environments, that they include imagery of other students and faculty.

Another risk is possible invasion of privacy, as subjects will be documenting their learning environments inside and outside of school. Risks will be minimized because identities will not be revealed in the study.

\section{CONFIDENTIALITY}

Information produced by this study will be stored in the investigator's file and identified by a code number only. The code key connecting your name to specific information about you will be kept in a separate, secure location. Information contained in your records may not be given to anyone unaffiliated with the study in a form that could identify you without your written consent, except as required by law.

In addition, if photographs, audiotapes or videotapes were taken during the study that could identify you, then you must give special written permission for their use. In that case, you will be given the opportunity to view or listen, as applicable, to the photographs, audiotapes or videotapes before you give your permission for their use if you so request.

\section{WILL I BE COMPENSATED FOR PARTICIPATING IN THE STUDY?}

You will be compensated $\$ 30$ for completion of the duration of the study. Participants who exit the study prior to completion of the study will receive a gift card amount that is prorated. 


\section{WHAT ARE MY RIGHTS AS A PARTICIPANT?}

Participation in this study is voluntary. You do not have to participate in this study.

You will also be informed of any new information discovered during the course of this study that might influence your health, welfare, or willingness to be in this study.

\section{WHO DO I CONTACT IF I HAVE QUESTIONS, CONCERNS, OR COMPLAINTS?}

Please contact Amy Frisz-Conlon at amyfrisz@gmail.com or Dr. Benyamin Schwarz at bschwarz@missouri.edu if you have questions about the research. Additionally, you may ask questions, voice concerns or complaints to the research team.

\section{WHOM DO I CALL IF I HAVE QUESTIONS OR PROBLEMS?}

If you have any questions regarding your rights as a participant in this research and/or concerns about the study, or if you feel under any pressure to enroll or to continue to participate in this study, you may contact the University of Missouri Campus Institutional Review Board (which is a group of people who review the research studies to protect participants' rights) at (573) 882-9585 or umcresearchcirb@missouri.edu.

You may ask more questions about the study at any time. For questions about the study or a research-related injury, contact Amy Frisz-Conlon at 919.623.8775.

A copy of this Informed Consent form will be given to you before you participate in the research.

\section{SIGNATURES}

I have read this consent form and my questions have been answered. My signature below means that I do want to be in the study. I know that I can remove myself from the study at any time without any problems. 


\section{APPENDIX 6. Child Assent Document}

Child Assent Form to Participate in a Research Study

Researcher's Name(s): Amy Frisz-Conlon

Project Number: 2009139C

Project Title: Stitching Cognition: An Investigation of Formal and Informal Learning Environments

\section{INTRODUCTION}

This consent may contain words that you do not understand. Please ask the investigator or the study staff to explain any words or information that you do not clearly understand. You are being asked to participate in a research study.

This is a study about understanding students' spatial preferences of learning environments across formal and informal environments. Further, it will address student perceptions of cognition, and the use of learning technologies across these formal and informal learning environments. When you are invited to participate in research, you have the right to be informed about the study procedures so that you can decide whether you want to consent to participation. This form may contain words that you do not know. Please ask the researcher to explain any words or information that you do not understand.

You have the right to know what you will be asked to do so that you can decide whether or not to be in the study. Your participation is voluntary. You do not have to be in the study if you do not want to. You may refuse to be in the study, and nothing will happen. If you do not want to continue to be in the study, you may stop at any time without penalty or loss of benefits to which you are otherwise entitled.

\section{WHY IS THIS STUDY BEING DONE?}

The purpose of this research is to understand students' spatial preferences of learning environments across formal and informal environments. Further, it will address student perceptions of cognition, and the use of learning technologies across these formal and informal learning environments. You are invited to be in this study because you are a student at Panther Creek High School. We have received permissions from Dr. Hedrick and Mathew Lenard at WCPSS Crossroads to conduct this research at Panther Creek High School. One of your teachers has also elected to participate in this research. As part of this research, you will have the opportunity to reflect on your spatial preferences of learning environments at school and home. Further, you will have the opportunity to reflect on your cognitive levels and use of technology in these formal and informal learning spaces. 


\section{HOW MANY PEOPLE WILL BE IN THE STUDY?}

About 25 people will take part in this study at Panther Creek High School.

\section{WHAT AM I BEING ASKED TO DO?}

You and other students will participate in a research study. A group interview process in the beginning of the study will foster greater understanding of your spatial preferences, perceptions of cognition and use of technology. A second, individual interview at the end of the study will shed light on individual photovoice projects. The photovoice project is explained next.

You will take photos and videos at school (formal learning environments) and outside of school (informal learning environments) with your phone. The photos and videos you take should feature places where you feel that you are learning best. You will also have the opportunity to reflect on your selfperception of your cognition (learning) in these spaces. Lastly, the photos and videos will feature the technology that you use in these learning spaces. You will have the opportunity to take photos and videos over two, tenday intervals. It is advised at the end of each school day, that each participant download photos and videos from their phones and add them to their password-protected website blogs. When uploading photos and videos to the blogs, it is advised that participants add a note or two in regard to their selfperception of cognition and technology use relevant to the photo of the learning space.

Complete a photovoice blog. This password-protected blog will offer an opportunity for students to upload their photos, voice recordings and videos about their formal and informal learning environments. The photos and videos may include images of other students and teachers. The blogs will be anonymous private, password-protected sites managed by the researcher. The purpose of the blogs is to show the variety of the learning environments and establish easy visual comparison across places and times. It is hoped that patterns will surface through examination of place, self-perception of cognition and use of technology.

The study will commence in February 2018 and should conclude by April 2018. Students will be asked to provide feedback for two two-week intervals. Each two-week interval consists of 10 school days. Students will be able to provide feedback at school and at home. The amount of time required should be no more than five minutes per day over the two ten-day intervals. The interviews at the beginning and end of the research should take no more than thirty minutes.

\section{HOW LONG WILL I BE IN THE STUDY?}

The study will commence in February 2018 and should conclude by April 2018. You can stop participating at any time without penalty. 
Can anything good happen to me?

Your participation will benefit the way in which you describe spatial preferences, perceptions of your cognition related to these spaces, and your understanding of your use of learning technologies in these spaces. You will be compensated with a $\$ 30$ gift card at the end of the data collection. Participants who do not complete the study will be awarded a pro-rated gift card amount.

Can anything bad happen to me?

The risks of the research are that you may become tired of participating. Students may come to understand that they prefer certain spatial configurations and learn best in these environments. The challenge might be to endure less ideal spatial preferences.

There will be the use of photography, audio or video recording by subjects in their learning environments. Risks will be minimized because identities will not be revealed in the study.

Another risk is possible invasion of privacy, as subjects will be documenting their learning environments inside and outside of school. Risks will be minimized because identities will not be revealed in the study.

What if I don't want to do this?

If you say you do not want to be in the study, you just have to tell us. No one will be mad at you. You can also say yes and later if you change your mind, you can quit the study. The choice is up to you [and your parent(s)].

Who will know my answers, see my information?

Your identity in the study will be kept confidential. We will do our best to make sure that your information is kept a secret. Your parents or guardian will get the information. Your name will not be included. Who can I talk to about the study?

You can ask questions any time. You can ask now. You can ask later. You can talk to me or you can talk to someone else, at any time during the study. Here is the telephone number to reach us 919-623-8775 (Amy Frisz-Conlon) or Dr. Benyamin Schwarz, advisor, Department of Architectural Studies (bschwarz@missouri.edu). You may contact the University of Missouri

Review Board (which is a group of people who review the research studies to protect participants' rights) if you have questions regarding your rights as a research participants, and/or concerns about the study, or if you feel under any pressure to enroll or to continue to participate in this study. The IRB can be reached directly by telephone at (573)8829585 and e- mail umcresearchcirb@missouri.edu.

A copy of this Informed Consent form will be given to you before you participate in the research. 


\section{SIGNATURES}

I have read this consent form and my questions have been answered. My signature and my parent signatures below means that I do want to be in the study. I know that I can remove myself from the study at any time without any problems. Please return the forms directly to the researcher, Amy FriszConlon in lab 3511, or through the Panther Creek main office.

Subject

Date

Parent Signature

Date

Do you want to be in the study?

YES NO

Signature of Child

Date

A copy of this form will be given to you and your parents.

IRB Approved Date 3/1/2018 Expiration Date 3/1/2019 Project \#2009139 


\section{APPENDIX 7. Consent Document - Parents}

Parental Consent Form to Participate in a Research Study

Researcher's Name(s): Amy Frisz-Conlon

Project Number: 2009139C

Project Title: Stitching Cognition: An Investigation of Formal and Informal Learning Environments

\section{INTRODUCTION}

We ask for permission that your child be allowed to participate in a research study. This research is being conducted in order to understand students' spatial preferences of learning environments across formal and informal environments. Further, it will address student perceptions of cognition, and their use of blended learning technologies across these formal and informal learning environments. You have the right to be informed about the study procedures so that you can decide whether you want to consent for your child to participate in this research study. This form may contain words that you do not know. Please ask the researcher to explain any words or information that you do not understand.

You have the right to know what your child will be asked to do so that you can decide whether or not to include your child in the study. Your child's participation is voluntary. They do not have to be in the study if they do not want to. You may refuse for your child to be in the study and nothing will happen. If your child does not want to continue to be in the study, they may stop at any time without penalty or loss of benefits to which they are otherwise entitled.

We ask that you read this form and ask any questions that you may have before allowing your child to participate in this study.

\section{DESCRIPTION OF THE RESEARCH}

Your child has been invited to be in this study because your child is a student at Panther Creek High School. We have received permissions from Dr. Hedrick and Mathew Lenard at WCPSS Crossroads to conduct this research at Panther Creek High School. One of your child's teachers has also elected to participate in this research. As part of this research, your child will have the opportunity to reflect on their spatial preferences of learning environments at school and home. Further, they will have the opportunity to reflect on their cognitive levels and use of learning technologies in these formal and informal learning spaces. 


\section{PROCEDURES OF THE STUDY}

If you agree to have your child be a part of the study, they will be asked to do the following things:

Your child will participate in a group interview process in the beginning of the study to allow for greater understanding of their spatial preferences, perceptions of cognition and use of learning technologies. A second individual interview at the end of the study will be conducted for the purpose of learning more about each photovoice entry. Photovoice will be explained next.

Complete a photovoice blog. This password-protected blog will offer an opportunity for your child to upload their photos, voice recordings and videos about their formal and informal learning environments. The photos and videos may include images of other students and teachers. The blogs will be anonymous private, password-protected sites managed by the researcher.

The study will commence in February 2018 and should conclude by April of 2018. Your child will be asked to provide feedback for two two-week intervals. Each two- week interval consists of 10 school days. Your child will be able to provide feedback at school and at home. The amount of time required should be no more than five minutes per day over the two ten-day intervals. The interviews at the beginning and end of the research should take no more than twenty minutes each.

How long will my child be in the study?

The study will take place during February 2018 and should conclude by April of 2018 . Your child can stop participating at any time without penalty.

How many people will be in this study?

Four or more teachers and twenty or more students from Panther Creek High School are expected to participate in the study.

What are the benefits of the research? Your child's participation will benefit the way in which they describe spatial preferences, perceptions of their cognition related to these spaces, and their understanding of their use of technology in these spaces.

What are the risks of the research?

The risks of the research are that your child may become tired of participating. Your child may come to understand that they prefer certain spatial configurations and learn best in these environments. The challenge might be to endure less ideal spatial preferences.

There will be the use of photography, audio or video recording by subjects in their learning environments. Risks will be minimized because identities will not be revealed in the study. Another risk is possible invasion of privacy, as subjects will be documenting their learning environments inside and outside of school. Risks will be minimized because identities will not be revealed in the study. 
Participation is voluntary.

Participation in this research study is voluntary. You may refuse to allow your child to participate or withdraw your child from the study at any time. Your child may also refuse to participate or withdraw themselves at any time. Your child will not be penalized in any way if you decide not to allow your child to participate or to withdraw your child from this study.

Your child's participation may be terminated by the investigator without regard to the subject's consent. Should a student decide to withdraw from the research, your child should notify the researcher in writing that they no longer wish to participate in the study.

Will my child be paid?

At the conclusion of the data collection, your child will receive a $\$ 30$ gift card. The gift card will be pro-rated if your child completes only part of the study.

What about Confidentiality?

We will do our best to make sure that your child's answers to these questions are kept private. Information produced by this study will be stored in the investigator's file and identified by a code number only. The code key connecting your child's name to specific information about you will be kept in a separate, secure location. Information contained in your child's records may not be given to anyone unaffiliated with the study in a form that could identify your child without your written consent, except as required by law. Your child will be audio recorded, videotaped, or photographed during this study. You will be given the opportunity to view or listen to the photographs, audiotapes or videotapes before you give your permission for their use if you so request.

Who can I talk to about the study?

If you have any questions about the study or if you would like additional information, please contact Amy Frisz-Conlon, principal investigator at 919.623.8775. You may also reach my doctoral advisor, Dr. Benyamin Schwarz at bschwarz@missouri.edu. You may contact the University of Missouri Institutional Review Board (which is a group of people who review the research studies to protect participants' rights) if you have questions regarding your child's rights as a research participants, and/or concerns about the study, or if you feel under any pressure to enroll your child or to continue to participate in this study. The IRB can be reached directly by telephone at (573) 882-9585 and e-mail umcresearchcirb@missouri.edu.

\section{CONSENT}

I have read this parental consent form and have been given the opportunity to ask questions. I give my permission for my child to participate in this study. I understand that, in order to for my child to participate, they will need to be able to give their consent also. I understand that participation is voluntary, and I can withdraw my child at any time without penalty or loss of benefits. You will be informed of any significant new findings 
discovered during the course of this study that might influence your child's health, welfare, or willingness to continue participation in this study.

Parent Name:

Date:

Child's Name:

You will be given a copy of this consent form to keep for your records.

IRB Approved Date 3/1/2018 Expiration Date 3/1/2019 Project \#2009139 


\section{APPENDIX 8. Photo Release Form for Subjects Not in the Study, But Who Will}

\section{Have Their Photo Taken}

\section{PHOTO/VIDEO RELEASE}

Please check the box that best describes you:

$\square$ Panther Creek HS student age 18 or older

$\square$ Non-Panther Creek HS student age 18 or older

$\square$ Panther Creek HS student under age 18

$\square$ Non- Panther Creek HS student under age 18

For valuable consideration received, I (print name) hereby give Amy Frisz-Conlon, Doctoral Candidate at the University of Missouri, the absolute and irrevocable right and permission, with respect to the videos, audio recordings and/or photographs that its employees, officers, agents or assigns have taken of me, and/or my child, on at
(date)
(list location)

a. To copyright the same in the name of Amy Frisz-Conlon, Doctoral Candidate at the University of Missouri.

b. To use, re-use, sublicense to other entities, publish and republish the same in whole or in part, individually or in conjunction with other photographs or images, in any medium including, but not limited to print, video, audio recordings or the Internet, for all purposes, including advertising, trade or any commercial purpose throughout the world and in perpetuity.

I hereby release and discharge Amy Frisz-Conlon, Doctoral Candidate at the University of Missouri, from any and all claims and demands arising out of or in connection with the use of such photographs, film or tape, including, but not limited to, any claims for defamation or invasion of privacy.

I understand Amy Frisz-Conlon, Doctoral Candidate at the University of Missouri, cannot warrant or guarantee that, on placement of such photograph or video image on the University's website or in other media, any further dissemination of my photograph or video image will be subject to University supervision or control. Accordingly, I release Amy Frisz-Conlon, Doctoral Candidate at the University of Missouri, from any and all liability related to further dissemination of my photograph or video image.

If I am a Panther Creek HS student, I hereby consent to the release of said videotape, audio recordings, film, photographs or any other medium for the above-stated purposes 
and in accordance with the terms stated above, pursuant to the consent provisions of the Family Educational Rights and Privacy Act, 20 U.S.C. 1232 et seq.

I am of legal age and have read the foregoing and fully understand the contents thereof.

Sign on appropriate line(s).

Signature

Print name

Parent/Guardian signature on behalf of

(for subjects under age 18) (child's full name) 


\section{APPENDIX 9. Student Photo Release Form}

Student Photo Release Form

Researcher's Name(s): Amy Frisz-Conlon

Project Number: 2009139C

Project Title: Stitching Cognition: An Investigation of Formal and Informal Learning

Environments

TO WHOM IT MAY CONCERN: I hereby grant full permission to Amy Frisz-Conlon, to use, reproduce, publish, distribute, or exhibit my photograph for official purposes, such as information, training, education, and communication. Without limitation as to time, I hereby waive all rights for compensation in connection with the use of my photograph or in connection with the material in which it will appear, in whole or edited form, so long as Amy Frisz-Conlon uses the material only for official purposes, such as information, training, education, and health communication. Note: If the person is under the age of 18 , a parent or guardian must sign this consent form.

Print name here

\section{Signature}

Name of parent or guardian (if necessary)

Signature of parent or guardian (if necessary)

Address

Date 


\section{APPENDIX 10. Photovoice Instructions}

Photovoice Instructions

Researcher's Name(s): Amy Frisz-Conlon

Project Number: 2009139C

Project Title: Stitching Cognition: An Investigation of Formal and Informal Learning

Environments

The interview and photovoice activities are designed to go hand in hand. Students and teachers will create a private, password protected website blog featuring photos and videos that document their experience and cognition related to learning environments over the course of one quarter. Interviews will be conducted with students and teachers before and after the Photovoice sessions. Introductory interviews will be in a group format and will include information such as how to take photos and how to add the images and comments to password-protected blogs. The interviews at the end will be individual and will be for the purpose of seeking additional information in regard to the blog.

Directions:

You are asked to take photographs or videos of the following things:

1. Your favorite learning spaces at school and outside of school. (Teachers take photos of your perceptions of students' favorite places.)

2. The places at school and outside of school where you feel that you are learning the best. (Teachers take photos of your perceptions of where you think students are learning best.)

3. Your use of technology in these learning places. (Teachers take photos of where and when students are using technology in learning spaces.)

You will be given password information for the creation of a private, password-protected blog that is managed by the researcher. You are asked to upload your photos and videos at the end of each day (two sessions that are ten school days in length) to this private blog and describe each photo in a sentence or two. The only people with access to this website will be the researcher and professionals at the University of Missouri. At the conclusion of the photography process, you will be asked for a short interview, in order to discuss your photos, videos and sentiments. Names and identifying information will remain confidential.

Resources: http://people.umass.edu/afeldman/Photovoice.htm http://ctb.ku.edu/en/tableof-contents/assessment/assessing-community-needsandresources/photovoice/main 


\section{APPENDIX 11. Teacher Interview Questions}

Researcher's Name(s): Amy Frisz-Conlon

Project Number: 2009139C

Project Title: Stitching Cognition: An Investigation of Formal and Informal Learning Environments

Describe yourself:

What are your perceptions of students' favorite learning spaces at school and outside of school?

What are your perceptions of the places at school and outside of school where you feel that students learn the best?

Describe your perceptions of students' use of technology in these learning places. 


\section{APPENDIX 12. Student Interview Questions}

Researcher's Name(s): Amy Frisz-Conlon

Project Number: 2009139C

Project Title: Stitching Cognition: An Investigation of Formal and Informal Learning Environments

Featured below are the questions that will be provided to students in an interview.

Describe yourself:

What are your favorite learning spaces at school and outside of school?

What are the places at school and outside of school where you feel that you learn the best?

Describe your use of technology in these learning places. 


\section{APPENDIX 13. Schedule of Data Collection}

March 2, 2018 - IRB Approval granted

March 5, 2018 - Teacher and student introductory interviews commence

March 19-29, 2018 Teacher and student photovoice documentation round one March 30-April 6, 2018 - spring break

April $10-20,2018$ - Teacher and student photovoice documentation round two April 19 - May 7, 2018 -Interviews with students and teachers

January - February 28, 2019 -Conclusion interviews with students and teachers 


\section{References}

Akyol, Z., \& Garrison, D. R. (2009). Community of inquiry in adult online learning: Collaborative-constructivist approaches. In T. T. Kidd (Ed.), Adult learning in the digital age: Perspectives on online technologies and outcomes (Ch.VI). IGI Global.

Akyol, Z., \& Garrison, D. R. (2011). Assessing metacognition in an online community of inquiry. Internet and Higher Education, 14(3), 183-190.

Barker, R. G. (1968). Ecological psychology: Concepts and methods for studying the environment of human behavior. Stanford University Press.

Barrett, M., Davidson, E., Prabhu, J., \& Vargo, S. (2015). Service innovation in the digital age: Key contributions and future directions. MIS Quarterly, 39(1), 135-154.

Retrieved April 10, 2021, from https://www.jstor.org/stable/26628344

Barrett, P., Zhang, Y., Moffat, J., \& Kobbacy, K. (2013). A holistic, multi-level analysis identifying the impact of classroom design on pupils' learning. Building and Environment, 59, 678-689. https://doi.org/10.1016/j.buildenv.2012.09.016

Barrett, P., \& Zhang, Y. (2009). SCRI research report 2: Optimal learning spaces, design implications for primary schools. University of Salford, Salford Centre for Research.

Beldarrain, Y. (2006). Distance education trends: Integrating new technologies to foster student interaction and collaboration. Distance Education, 27(2), 139-153. https://doi.org/10.1080/01587910600789498

Bernhard, E., Recker, J., \& Burton-Jones, A. (2013). Understanding the actualization of affordances: A study in the process modeling context. ICIS 2013 Proceedings. 
Bernstein, H. (2010). Class dynamics of agrarian change (Vol. 1). Kumarian Press.

Blackmore, J., Bateman, D., Loughlin, J., O'Mara, J., \& Aranda, G. (2011). Research into the connection between built learning spaces and student outcomes. Melbourne: Education, Policy and Research Division, Department of Education and Early Childhood Development. [Google Scholar]

Borkowski, J. G., Chan, L. K., \& Muthukrishna, N. (2000). 1. A process-oriented model of metacognition: Links between motivation and executive functioning. Issues in the Measurement of Metacognition, 2.

Bricker, K. S., \& Kerstetter, D. H. (2000). Level of specialization and place attachment: An exploratory study of whitewater recreationists. Leisure Sciences, 22, 233-257. Google Scholar

Brunken, R., Plass, J. L., \& Leutner, D. (2003). Direct measurement of cognitive load in multimedia learning. Educational Psychologist, 38(1), 53-61. https://doi.org/10.1207/S15326985EP3801_7

Brünken, R., Plass, J., \& Leutner, D. (2003). How instruction guides attention in multimedia learning. Instructional Design for Multimedia Learning, 113-126.

Byers, T., Imms, W., \& Hartnell-Young, E. (2014). Making the case for space: The effect of learning spaces on teaching and learning. Curriculum and Teaching, 29(1), 519. DOI: https://doi.org/10.7459/ct/29.1.02

Casey, E. S. (2009). Remembering: A phenomenological study. Indiana University Press. Catalani, C., \& Minkler, M. (2010). Photovoice: A review of the literature in health and public health. Health Education \& Behavior, 37(3), 424-451. DOI:

$10.1177 / 1090198109342084$ 
Cho, M., Demei, S., \& Laffey, J. (2010). Relationships between self-regulation and social experiences in asynchronous online learning environments. Journal of Interactive Learning Research, 21(3), 297-316.

Choi, H. H., van Merriënboer, J. J. G., \& Paas, F. (2014). Effects of the physical environment on cognitive load and learning: Towards a new model of cognitive load. Educational Psychology Review, 26, 225-244.

https://doi.org/10.1007/s10648-014-9262-6

Choi, I., Land, S. M., \& Turgeon, A. J. (2005). Scaffolding peer-questioning strategies to facilitate metacognition during online small group discussion. Instructional Science, 33, 483-511. Google Scholar

Cohen, S., Evans, G. W., Krantz, D. S., \& Stokols, D. (1980). Physiological, motivational, and cognitive effects of aircraft noise on children: Moving from the laboratory to the field. American Psychologist, 35, 231-243. doi:10.1037/0003066X.35.3.231

Collins, A. (1990, December). The role of computer technology in restructuring schools. Restructuring for Learning with Technology, 31-46.

Cornell, E. H., Hadley, D. C., Sterling, T. M., Chan, M. A, \& Boechler, P. (2001). Adventure as a stimulus for cognitive development. Journal of Environmental Psychology, 21, 219-231. https://doi.org/10.1006/jevp.2001.0207

Cornoldi, C. (2009). Metacognition, intelligence and academic performance. In H. S. Waters \& W. Scheneider (Eds.), Metacognition, strategy use, and instruction (pp. 257-276). The Guilford Press. Google Scholar

Cox, R. (2013). Environmental communication and the public sphere. Sage. 
Dabbagh, N., \& Kitsantas, A. (2012). Personal learning environments, social media, and self-regulated learning: A natural formula for connecting formal and informal learning. Internet and Higher Education, 15(1), 3-8.

https://doi.org/10.1016/j.iheduc.2011.06.002

Davern, M., Shaft, T., \& Te'eni, D. Cognition matters: Enduring questions in cognitive IS research. Journal of the Association for Information Systems, 13(4), 273-314. DOI:10.17705/1jais.00290

Dörnyei, Z. (2007). Creating a motivating classroom environment. In J. Cummins \& C Davison (Eds.), International handbook of English language teaching (pp. 719731). Springer.

Duphorne, P. L., \& Gunawardena, C. N. (2005). The effect of three computer conferencing designs on critical thinking skills of nursing students. The American Journal of Distance Education, 19(1), 37-50. https://doi.org/10.1207/s15389286ajde1901_4

Dziuban, C. D., Hartman, J. L., \& Mehaffy, G. L. (2014). Blending it all together. In A. G. Picciano, C. D. Dziuban, \& C. R. Graham (Eds.), Blended learning: Research perspectives (Vol. 2, pp. 325-337). Routledge. Google Scholar

Emerson, R. M., Fretz, R. I., \& Shaw, L. L. (2011). Writing ethnographic fieldnotes. University of Chicago Press.

Erez, A., \& Isen, A. M. (2002). The influence of positive affect on the components of expectancy motivation. Journal of Applied Psychology, 87, 1055-1067. doi:10.1037/0021-9010.87.6.1055 
Evans, G. W. (2006). Child development and the physical environment. Annual Review of Psychology, 57, 423-451. DOI: 10.1146/annurev.psych.57.102904.190057

Evans, G. W., \& Lepore, S. J. (1993). Nonauditory effects of noise on children: A critical review. Children's Environments, 10, 31-51. doi:10.2307/41515250

Evans, G. W., \& Stecker, R. (2004). Motivational consequences of environmental stress. Journal of Environmental Psychology, 24, 143-165. doi:10.1016/S02724944(03)00076-8

Flavell, J. H. (1979). Metacognitive and cognitive monitoring: A new area of cognitive developmental inquiry. American Psychologist, 34, 906-911. https://doi.org/10.1037/0003-066X.34.10.906

Flavell, J. H. (1987). Speculations about the nature and development of metacognition. In F. E. Weinert \& R. H. Kluwe (Eds.), Metacognition, motivation and understanding (pp. 21-29). Lawrence Erlbaum Associates.

Flavell, J. H. (1987). Speculations about the nature and development of metacognition. In F. Weinert \& R. Kluwe (Eds.), Metacognition, motivation and understanding (pp. 21-29). Erlbaum. Google Scholar

Fujita, D. (2011). The challenges of building a safe school environment. Japan Medical Association Journal, 54(3), 172-174. Google Scholar

Garrison D. R., \& Anderson, T. (2003). E-Learning in the 21st century: A framework for research and practice. Routledge/Falmer. Google Scholar

Garrison, D. R. (2003). Cognitive presence for effective asynchronous online learning: The role of reflective inquiry, self-direction and metacognition. In J. Bourne \& J. 
C. Moore (Eds.), Elements of quality online education: Practice and direction (Sloan C Series, Vol. 4, pp. 29-38). Google Scholar

Garrison, D. R. (2011). E-Learning in the 21st century: A framework for research and practice (2nd ed.). Routledge/Taylor and Francis.

Garrison, D. R., \& Akyol, Z. (2013). The community of inquiry theoretical framework. In M. G. Moore (Ed.), Handbook of distance education (Vol. 3, pp. 104-120). Routledge.

Garrison, D. R., \& Anderson, T. (2003). E-Learning in the 21st century: A framework for research and practice. Routledge/Falmer.

Garrison, D. R., \& Vaughan, N. (2008). Blended learning in higher education. JosseyBass.

Garrison, D. R., Anderson, T., \& Archer, W. (2001). Critical thinking, cognitive presence, and computer conferencing in distance education. American Journal of Distance Education, 15(1), 7-23. https://doi.org/10.1080/08923640109527071

Garrison, D. R., Anderson, T., \& Archer, W. (2001). Critical thinking, cognitive presence, and computer conferencing in distance education. American Journal of Distance Education, 15(1), 7-23.

Garrison, D. R., Anderson, T., \& Archer, W. (2010). The first decade of the community of inquiry framework: A retrospective. The Internet and Higher Education, 13(12), 5-9. https://doi.org/10.1016/j.iheduc.2009.10.003

Garrison, D. R., Cleveland-Innes, M., \& Fung, T. S. (2010). Exploring causal relationships among teaching, cognitive and social presence: Student perceptions 
of the community of inquiry framework. The Internet and Higher Education, 13(1-2), 31-36. https://doi.org/10.1016/j.iheduc.2009.10.002

Geertz, C. (1973). Thick description: Toward an interpretive theory of culture. In Y. S. Lincoln \& N. K. Denzin (Eds.), Turning points in qualitative research: Tying knots in a handkerchief (pp. 143-168). AltaMira Press.

Gibson, J. J. (1977). The theory of affordances. In R. E. Shaw \& J. Bransford (Eds.), Perceiving, acting, and knowing. Lawrence Erlbaum Associates.

Gibson, J. J. (1986). The ecological approach to visual perception. Lawrence Erlbaum Associates.

Gibson, J. J. (1979) 1986. The ecological approach to visual perception. Lawrence Erlbaum.

Godden, D., \& Baddeley, A. D. (1980). When does context influence recognition memory? British Journal of Psychology, 71, 99-104. doi:10.1111/j.20448295.1980.tb02735.x

Greene, S. (2015). Race, community, and urban schools: Partnering with African American families. Teachers College Press.

Greenhow, C., \& Lewin, C. (2016) Social media and education: reconceptualizing the boundaries of formal and informal learning. Learning, Media and Technology, 41(1), 6-30. DOI: 10.1080/17439884.2015.1064954

Greeno, J. G. (1994). Gibson's affordances. Psychological Review, 101(2), 336-342. https://doi.org/10.1037/0033-295X.101.2.336 
Hacker, D. J. (1998). Definitions and empirical foundations. In D. J. Hacker, J. Dunloky, \& A. C. Graesser (Eds.), Metacognition in educational theory and practice (pp. 123). Lawrence Erlbaum Associates.

Hartson, R. (2003). Cognitive, physical, sensory, and functional affordances in interaction design. Behaviour \& Information Technology, 22(5), 315338, DOI: 10.1080/01449290310001592587

Hattie, J., \& Watkins, D. (1988). Preferred classroom environment and approach to learning. British Journal of Educational Psychology, 58, 345-349. doi:10.1111/j.2044-8279.1988.tb00910.x

Heft, H. (2001). Ecological psychology in context: James Gibson, Roger Barker, and the legacy of William James' radical empiricism. Lawrence Erlbaum Associates. Google Scholar

Heft, H., Hoch, J., Edmunds, T., \& Weeks, J. (2014). Can the identity of a behavior setting be perceived through patterns of joint action? An investigation of place perception. Behavioral Sciences, 4, 371-393. https://doi.org/10.3390/bs4040371

Hiemstra, R. (2004). Self-directed learning lexicon. International Journal of Self-directed Learning, 1(2), 1-6.

Hiemstra, R. (2013). Self-directed learning: Why do most instructors still do it wrong. International Journal of Self-directed Learning, 10(1), 23-34.

Higgins, S., Hall, E., Wall, K., Woolner, P., \& McCaughey, C. (2005). The impact of school environments: A literature review. The Centre for Learning and Teaching, School of Education, Communication and Language Science. University of 
Newcastle. Retrieved on February 16, 2014

from http://www.ncl.ac.uk/cflat/news/DCReport.pdf

Hutchby, I. (2013). Conversation and technology: From the telephone to the Internet. Cambridge. Google Scholar

Hygge, S., \& Knez, I. (2001). Effects of noise, heat and indoor lighting on cognitive performance and self-reported affect. Journal of Environmental Psychology, 21, 291-299. doi:10.1006/jevp.2001.0222

Hygge, S., \& Knez, I. (2001). Effects of noise, heat and indoor lighting on cognitive performance and self-reported affect. Journal of Environmental Psychology, 21, 291-299. doi:10.1006/jevp.2001.0222

Jahnke, I. (2015). Digital didactical designs - Teaching and learning in CrossActionSpaces. Routledge.

Johnson, D. W., \& Johnson, R. T. (2004). Cooperation and the use of technology. The Association for Educational Communications and Technology. http://members.aect.org/edtech/ed1/35/index.html

Jongeneel, D., Withagen, R., \& Zaal, F. T. (2015). Do children create standardized playgrounds? A study on the gap-crossing affordances of jumping stones. Journal of Environmental Psychology, 44, 45-52. DOI:10.1016/j.jenvp.2015.09.003

Kanuka, H., \& Anderson, T. (1998). Online social interchange, discord, and knowledge construction. Journal of Distance Education, 13(1) 57-74.

Khaddage, F., Müller, W., \& Flintoff, K. (2016). Advancing mobile learning in formal and informal settings via mobile app technology: Where to from here, and how? Journal of Educational Technology \& Society, 19(3), 16-26. 
Kitsantas, A., \& Dabbagh, N. (2010). Learning to learn with Integrative Learning Technologies (ILT): A practical guide for academic success. Information Age Publishing.

Kiverstein, J., \& Miller, M. (2015). The embodied brain: Towards a radical embodied cognitive neuroscience. Frontiers in Human Neuroscience, 9, 237. https://doi.org/10.3389/fnhum.2015.00237

Knez, I., \& Enmarker, I. (1998). Effects of office lighting on mood and cognitive performance and a gender effect in work-related judgment. Environment and Behavior, 30, 553-567. doi:10.1177/001391659803000408

Knez, I., \& Hygge, S. (2002). Irrelevant speech and indoor lighting: Effects on cognitive performance and self-reported affect. Applied Cognitive Psychology, 16, 709718. doi:10.1002/acp.829

Knez, I., \& Kers, C. (2000). Effects of indoor lighting, gender, and age on mood and cognitive performance. Environment and Behavior, 32, 817-831. doi:10.1177/0013916500326005

Kramarski, B., \& Dudai, V. (2009). Group-metacognitive support for online inquiry in mathematics with differential self-questioning. Journal of Educational Computing Research, 40, 377-404. [Google Scholar]

Kutsyuruba, B., Klinger, D. A., \& Hussain, A. (2015). Relationships among school climate, school safety, and student achievement and well-being: A review of the literature. Review of Education, 3, 103-135. https://doi.org/10.1002/rev3.3043

Kyle, G. T., Mowen, A. J., \& Tarrant, M. (2004). Linking place preferences with place meaning: An examination of the relationship between place motivation and place 
attachment. Journal of Environmental Psychology, 24(4), 439-454.

https://doi.org/10.1016/j.jenvp.2004.11.001

Leonardi, P. M. (2011). When flexible routines meet flexible technologies: Affordance, constraint, and the imbrication of human and material agencies. MIS Quarterly, $35(1), 147-168$.

Leonardi, P. M. (2013). When does technology use enable network change in organizations? A comparative study of feature use and shared affordances. MIS Quarterly, 37(3). DOI:10.25300/MISQ/2013/37.3.04

Leonardi, P. M., \& Barley, S. R. (2010). What's under construction here? Social action, materiality, and power in constructivist studies of technology and organizing. Academy of Management Annals, 4(1), 1-51. https://doi.org/10.5465/19416521003654160

Lewicka, M. (2011). Place attachment: How far have we come in the last 40 years? Journal of Environmental Psychology, 31(3), 207-230. https://doi.org/10.1016/j.jenvp.2010.10.001

Lincoln, Y. S., \& Guba, E. G. (1985). Establishing trustworthiness. Naturalistic Inquiry, 289(331), 289-327.

Manuti, A., Pastore, S., Scardigno, A. F., Giancaspro, M. L., \& Morciano, D. (2015). Formal and informal learning in the workplace. International Journal of Training and Development, 19, 1-17. https://doi.org/10.1111/ijtd.12044

Markus, M. L., \& Silver, M. S. (2008). A foundation for the study of IT effects: A new look at DeSanctis and Poole's concepts of structural features and spirit. Journal of 
the Association for Information Systems, 9(10/11), 609-632.

DOI:10.17705/1jais.00176

Mayfield-Johnson, S., \& Butler III, J. (2017). Moving from pictures to social action: An introduction to photovoice as a participatory action tool. New Directions for Adult and Continuing Education, 2017(154), 49-59. https://doi.org/10.1002/ace.20230

McCoy, J. M., \& Evans, G. W. (2002). The potential role of the physical environment in fostering creativity. Creativity Research Journal, 14, 409-426. doi:10.1207/S15326934CRJ1434_11

McGrenere, J., \& Ho, W. (2000). Affordances: Clarifying and evolving a concept. Proceedings of Graphic Interface Conference, Montreal, Canada. pp. 1-8.

Mehta, R., \& Zhu, R. J. (2009). Blue or red? Exploring the effect of color on cognitive task performances. Science, 323, 1226-1229. doi:10.1126/science.1169144

Mehta, R., Zhu, R. J., \& Cheema, A. (2012). Is noise always bad? Exploring the effects of ambient noise on creative cognition. Journal of Consumer Research, 39, 784799. doi:10.1086/665048

Mehta, R., Zhu, R. J., \& Cheema, A. (2012). Is noise always bad? Exploring the effects of ambient noise on creative cognition. Journal of Consumer Research, 39, 784799. doi:10.1086/665048

Mendell, M. J., \& Heath, G. A. (2005). Do indoor pollutants and thermal conditions in schools influence student performance? A critical review of the literature. Indoor Air, 15(1), 27-52. https://doi.org/10.1111/j.1600-0668.2004.00320.x 
Meyers-Levy, J., \& Zhu, R. J. (2007). The influence of ceiling height: The effect of priming on the type of processing that people use. Journal of Consumer Research, 34, 174-186. DOI:10.1086/519146

Mills, L. A., Knezek, G., \& Khaddage, F. (2014). Information seeking, information sharing, and going mobile: Three bridges to informal learning. Computers in Human Behavior, 32, 324-334. https://doi.org/10.1016/j.chb.2013.08.008

Moore, J. L., \& Marra, R. M. (2005). A comparative analysis of online discussion participation protocols. Journal of Research on Technology in Education, 38(2), 191-212.

Ng, W., \& Nicholas, H. (2013). A framework for sustainable mobile learning in schools. British Journal of Educational Technology, 44(5), 695-715. https://doi.org/10.1111/j.1467-8535.2012.01359.x

Nielsen, H. D., \& Moos, R. H. (1978). Exploration and adjustment in high school classrooms: A study of person-environment fit. The Journal of Educational Research, 72, 52-57. doi:10.2307/27537177.

Norman, D. A. (1988). The psychology of everyday things. Basic Books.

Norman, D. A. (1990). The design of everyday things. Doubleday.

Norman, D. A. (1999). Affordance, conventions and design. Interactions, 38-42.

Oliver, M., \& Trigwell, K. (2005). Can 'blended learning' be redeemed? E-Learning and Digital Media, 2(1), 17-26. https://doi.org/10.2304/elea.2005.2.1.17

Paas, F. (1992). Training strategies for attaining transfer of problem-solving skill in statistics: A cognitive-load approach. Journal of Educational Psychology, 84, 429-434. doi:10.1037/0022-0663.84.4.429 
Paas, F., \& Van Merriënboer, J. J. G. (1994a). Instructional control of cognitive load in the training of complex cognitive tasks. Educational Psychology Review, 6, 351371. doi:10.1007/bf02213420

Paas, F., \& Van Merriënboer, J. J. G. (1994b). Variability of worked examples and transfer of geometrical problem-solving skills: A cognitive-load approach. Journal of Educational Psychology, 86, 122-133. doi:10.1037/00220663.86 .1 .122

Paas, F., Tuovinen, J. E., Tabbers, H., \& Van Gerven, P. W. M. (2003b). Cognitive load measurement as a means to advance cognitive load theory. Educational Psychologist, 38, 63-71. doi:10.1207/S15326985ep3801_8

Paas, F., Tuovinen, J. E., Van Merriënboer, J. J. G., \& Darabi, A. A. (2005). A motivational perspective on the relation between mental effort and performance: Optimizing learner involvement in instruction. Educational Technology Research and Development, 53, 25-34. doi:10.1007/Bf02504795

Paris, S. G., \& Winograd, P. (1990). How metacognition can promote academic learning and instruction. In B. F. Jones \& L. Idol (Eds.), Dimensions of thinking and cognitive instruction (pp. 15-51). Lawrence Erlbaum Associates, Inc.

Pasalar, C. (2004). The effects of spatial layouts on students' interactions in middle schools: Multiple case analysis. Computer Science. https://repository.lib.ncsu.edu/bitstream/handle/1840.16/5083/etd.pdf?isAllowed= y\&sequence $=1$ 
Pavlides, E., \& Cranz, G. (2012). Ethnographic methods in support of architectural practice. In S. Mallory-Hill, W. F. E. Preiser, \& C. Watson (Eds.), Enhanced building performance (pp. 299-311). Blackwell Publishing.

Pintrich, P. R., Wolters, C. A., \& Baxter, G. P. (2000). 2. Assessing metacognition and self-regulated learning. Issues in the Measurement of Metacognition.

Pintrich, P. R., Wolters, C. A., \& Baxter, G. P. (2000). Assessing metacognition and selfregulated learning. In G. Schraw \& J. C. Impara (Eds.), Issues in the measurement of metacognition. University of Nebraska-Lincoln. Google Scholar

Proshansky, H. M. (1978). The city and self-identity. Environment and Behavior, 10(2), 147-169. https://doi.org/10.1177/0013916578102002

Rasmussen, K. (2004). Places for children - Children's places. Childhood, 11(2), 155173. https://doi.org/10.1177/0907568204043053

Raymond, C. M., Brown, G., \& Weber, D. (2010). The measurement of place attachment: Personal, community, and environmental connections. Journal of Environmental Psychology, 30(4), 422-434. https://doi.org/10.1016/j.jenvp.2010.08.002

Renick, M. J., \& Harter, S. (1989). Impact of social comparisons on the developing selfperceptions of learning disabled students. Journal of Educational Psychology, 81(4), 631-638.

Rivlin, L. G., \& Weinstein, C. S. (1984). Educational issues, school settings, and environmental psychology. Journal of Environmental Psychology, 4, 347-364. doi:10.1016/S0272-4944(84)80005-5

Ryle, G. (1949). Meaning and necessity. Philosophy, 24(88), 69-76. 
Salamé, P., \& Baddeley, A. D. (1982). Disruption of short-term memory by unattended speech: Implications for the structure of working memory. Journal of Verbal Learning and Verbal Behavior, 21, 150-164. doi:10.1016/S0022-5371(82)905217

Salamé, P., \& Baddeley, A. D. (1986). Phonological factors in STM: Similarity and the unattended speech effect. Bulletin of the Psychonomic Society, 24, 263-265. doi:10.3758/BF03330135

Saldaña, J. (2014). Coding and analysis strategies. In P. Leavy (Ed.), The Oxford handbook of qualitative research. Oxford Library of Psychology.

Savoli, A., \& Barki, H. (2013). Functional affordance archetypes: A new perspective for examining the impact of IT use on desirable outcomes. In ICIS 2013 proceedings. Retrieved from http://aisel.aisnet.org/icis2013/proceedings/ResearchInProgress/110

Scholey, A. B., Harper, S., \& Kennedy, D. O. (2001). Cognitive demand and blood glucose. Physiology \& Behavior, 73, 585-592. doi:10.1016/S00319384(01)00476-0

Scholey, A. B., Moss, M. C., Neave, N., \& Wesnes, K. (1999). Cognitive performance, hyperoxia, and heart rate following oxygen administration in healthy young adults. Physiology \& Behavior, 67, 783-789. doi:10.1016/S0031-9384(99)001833

Schraw, G. (2001). Promoting general metacognitive awareness. In H. J. Hartman (Ed.), Metacognition in learning and instruction (pp. 3-16). Springer, Dordrecht. 
Seamon, D. (2017). Architecture, place and phenomenology: Buildings as lifeworlds, atmospheres, and environmental wholes. In J. Donohoe (Ed.), Place and phenomenology (pp. 247-263). Rowan \& Littlefield International. Google Scholar

Seamon, D. (2018). Life takes place: Phenomenology, lifeworlds, and place making. Taylor and Francis. Google Scholar

Seamon, D. (2015). Understanding place holistically: Cities, synergistic relationality, and space syntax. Journal of Space Syntax, 6(1), 19-33. [Google Scholar]

Seidel, S., Recker, J., \& Brocke, J. (2013). Sensemaking and sustainable practicing: Functional affordances of information systems in green transformations. MIS Quarterly, 37(4), 1275-A10. DOI:10.25300/MISQ/2013/37.4.13

Smith, E. E., \& Jonides, J. (1999). Storage and executive processes in the frontal lobes. Science, 283, 1657-1661. doi:10.1126/science.283.5408.1657

Smith, S. M., \& Vela, E. (2001). Environmental context-dependent memory: A review and meta-analysis. Psychonomic Bulletin \& Review, 8, 203-220. doi:10.3758/BF03196157

Staker, H., \& Horn, M. B. (2012). Classifying K-12 blended learning. Innosight Institute. https://www.christenseninstitute.org/wp-content/uploads/2013/04/Classifying-K12-blended-learning.pdf

Staker, H., \& Horn, M. (2014). Blended learning in the K-12 education sector. In A. Picciano, C. D. Dziuban, \& C. R. Graham (Eds.), Blended learning research perspectives (Vol. 2, pp. 287-303). Routledge. [Google Scholar]

Staker, H., \& Horn, M. (2012). Classifying K-12 blended learning. Innosight Institute. http://files.eric.ed.gov/fulltext/ED535180.pdf 
Stewart, P. W., Cooper, S. S., \& Moulding, L. R. (2007). Metacognitive development in professional educators. The Researcher, 21(1), 32-40.

Stewart, P. W., Cooper, S. S., \& Moulding, L. R. (2007). Metacognitive development in professional educators. The Researcher, 21(1), 32-40.

Stokols, D., \& Shumaker, S. A. (1981). People in places. A transactional view of settings. In J. Harvey (Ed.), Cognition, social behavior and the environment (pp. 441488). Lawrence Erlbaum Associates. Google Scholar

Stokols, D., \& Shumaker, S. A. (1982). The psychological context of residential mobility and well-being. Journal of Social Issues, 38, 149-171. Google Scholar

Strong, D. M., Johnson, S. A., Tulu, B., Trudel, J., Volkoff, O., Pelletier, L. R., Bar-On, I., \& Garber, L. (2014). A theory of organization-EHR affordance actualization. Journal of the Association for Information Systems, 15(2), 53-85. DOI: $10.17705 / 1$ jais.00353

Tanner, C. K. (2000). The influence of school architecture on academic achievement. Journal of Educational Administration, 38, 309-330. doi:10.1108/09578230010373598.

Tanner, C. K. (2008). Explaining relationships among student outcomes and the school's physical environment. Journal of Advanced Academics, 19, 444-471. doi:10.4219/jaa-2008-812.

Tobias, S., \& Everson, H. T. (2009). The importance of knowing what you know: A knowledge monitoring framework for studying metacognition in education. In D. J. Hacker, J. Dunlosky, \& A. C. Graesser (Eds.), Handbook of metacognition in 
education (Educational Psychology Series, p. 107-127). Routledge/Taylor \& Francis Group.

Turker, M. A., \& Zingel, S. (2008). Formative interfaces for scaffolding self-regulated learning in PLEs. eLearning Papers. https://www.semanticscholar.org/paper/Formative-Interfaces-for-ScaffoldingSelf-Regulated-Turker-Zingel/15cffaa5e270bc1b33ab0bf9acc6bd413db66f29

Turner, J. R., \& Carroll, D. (1985). Heart rate and oxygen consumption during mental arithmetic, a video game, and graded exercise: Further evidence of metabolicallyexaggerated cardiac adjustments? Psychophysiology, 22, 261-267. doi:10.1111/j.1469-8986.1985.tb01597.x

Uline, C., \& Tschannen-Moran, M. (2008). The walls speak: The interplay of quality facilities, school climate, and student achievement. Journal of Educational Administration, 46, 55-73. doi:10.1108/09578230810849817

Van Note Chism, N. (2006). Teaching awards: What do they award? The Journal of Higher Education, 77(4), 589-617. DOI: 10.1080/00221546.2006.11772308

Vaughan, N., \& Garrison, D. R. (2005). Creating cognitive presence in a blended faculty development community. The Internet and Higher Education, 8(1), 1-12. https://doi.org/10.1016/j.iheduc.2004.11.001

Vavoula, G., Sharples, M., Scanlon, E., Lonsdale, P., \& Jones, A. (2005). Report on literature on mobile learning, science and collaborative activity. HAL ArchivesOuvertes, 〈hal-00190175〉 
Volkoff, O., \& Strong, D. (2013). Critical realism and affordances: Theorizing it-associated organizational change processes. MIS Quarterly, 37(3), 819-834. Retrieved April 11, 2021, from http://www.jstor.org/stable/43826002

Volkoff, O., \& Strong, D. M. (2013). Critical realism and affordances: Theorizing itassociated organizational change processes. MIS Quarterly, 37(3), 819-834.

Vygotsky, L. (2005). Readings on the development of children. Worth Publishers.

Wang, C. (2003). Using photovoice as a participatory assessment and issue selection tool: A case study with the homeless in Ann Arbor. In M. Minkler \& N. Wallerstein (Eds.), Community based participatory research for health (pp. 179-196). JosseyBass/Wiley.

Wang, C. C. (2006). Youth participation in photovoice as a strategy for community change. Journal of Community Practice, 14(1-2), 147-161. DOI: $10.1300 / J 125 v 14$ n01_09

Wang, C., \& Burris, M. A. (1997). Photovoice: Concept, methodology, and use for participatory needs assessment. Health Education \& Behavior, 24(3), 369-387. DOI: $10.1177 / 109019819702400309$

Weinstein, C. S. (1979). The physical environment of the school: A review of the research. Review of Educational Research, 49, 577-610. doi:10.3102/00346543049004577

White, B. Y., Frederiksen, J. R., \& Collins, A. (2009). The interplay of scientific inquiry and metacognition: More than a marriage of convenience. In D. Hacker, J. Dunlosky, \& A. Graesser (Eds.), Handbook of metacognition in education (pp. 175-205). Routledge. 
Williams, D. R., \& Roggenbuck, J. W. (1989, October). Measuring place attachment: Some preliminary results. In NRPA Symposium on Leisure Research, San Antonio, TX (Vol. 9).

Williams, S., \& Lew, A. A. (2014). Tourism geography: Critical understandings of place, space and experience. Routledge.

Wong, N., \& Watkins, D. (1996). Self-monitoring as a mediator of person-environment fit: An investigation of Hong Kong mathematics classroom environments. British Journal of Educational Psychology, 66, 223-229. doi:10.1111/j.20448279.1996.tb01191.x

Yin, R. K. (2011). Applications of case study research. Sage.

Yin, R. K. (2012). Case study methods. In H. Cooper, P. M. Camic, D. L. Long, A. T. Panter, D. Rindskopf, \& K. J. Sher (Eds.), APA handbooks in psychology ${ }^{\circledR} . A P A$ handbook of research methods in psychology, Vol. 2. Research designs: Quantitative, qualitative, neuropsychological, and biological (pp. 141-155). American Psychological Association. https://doi.org/10.1037/13620-009

Young, A., \& Fry, J. D. (2008). Metacognitive awareness and academic achievement in college students. Journal of the Scholarship of Teaching and Learning, 8(2), 1-10. Google Scholar

Zammuto, R. F., Griffith, T. L., Majchrzak, A., Dougherty, D. J., \& Faraj, S. (2007). Information technology and the changing fabric of organization. Organization Science, 18(5), 749-762. https://doi.org/10.1287/orsc.1070.0307

Zeiher, H. (2001). Children's islands in space and time: The impact of spatial differentiation on children's ways of shaping social life. In H. H. Krüger, M. 
S. Bois-Reymond, \& H. Sünker (Eds.), Childhood in Europe, approaches - trends -findings (pp. 139-159). Peter Lang. [Google Scholar]

Zepeda, S. J., \& Ponticell, J. A. (Eds.). (2018). The Wiley handbook of educational supervision. John Wiley \& Sons.

Zimmerman, B. J. (2000). Attainment of self-regulation: A social cognitive perspective. In M. Boekaerts, P. Pintrich, \& M. Zeidner (Eds.), Self-regulation: Theory, research, and applications (pp. 13-39). Academic Press. 


\section{VITA}

Amy Frisz-Conlon was born in Cincinnati, Ohio and has thrived in the fields of research, education and design for the majority of her career. Her undergraduate degrees include a BFA in interior design and textile surface design, as well as a BA in education and general arts. Her Master of Science in Architecture degree was earned at the University of Cincinnati and involved primary research in Europe on the temples of Asklepios. A second master of design degree, also from the University of Cincinnati, focused on the structural and surface relationships between fashion and architecture. To support this masters work, primary research was conducted in Europe and Asia. After completion of these dual masters degrees, Amy pursued a $\mathrm{PhD}$ at the University of Missouri, researching spatial affordances and technology in learning environments. In conjunction with this $\mathrm{PhD}$, Amy earned a graduate certificate in Usability and User Experience from the School of Information Science and Learning Technologies. Amy's years of professional experience include work designing museum, civic, educational, retail and commercial properties. For years, she has served as an instructor at K-12 and higher education institutions. Amy has conducted research at a variety of institutions including the Bay Area Discovery Museum, the Museum of Life and Science, the NC Museum of Natural Science and the North Carolina Museum of Art. Amy's most recent research focuses on the convergence of environments, affordance perception and technology. 